\title{
Untersuchung exogener Einflüsse auf den Reproduktionserfolg des Rindes unter Anwendung von In-vitro-Verfahren
}

\author{
Dissertation \\ zur Erlangung des Doktorgrades \\ der Fakultät für Agrarwissenschaften \\ der Georg-August-Universität Göttingen

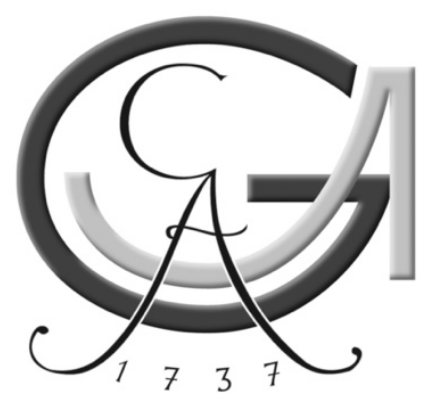

vorgelegt von

Sophie Diers

geboren am 17.04.1991 in Goslar

Göttingen, im März 2020 
D7

1. Gutachter: Prof. Dr. Jens Tetens

2. Gutachter: Prof. Dr. Detlef Rath

Tag der mündlichen Prüfung: 28. Mai 2020 
Wege entstehen dadurch, dass man sie geht.

Franz Kafka 
Diese Arbeit wurde durch die H. Wilhelm Schaumann Stiftung gefördert. 


\section{Inhaltsverzeichnis}

Inhaltsverzeichnis .....................................................................................................................

Veröffentlichungen ................................................................................................................. III

Abbildungsverzeichnis.................................................................................................................. V

Abkürzungsverzeichnis ..................................................................................................VI

$1 \quad$ Allgemeine Einleitung ................................................................................................ 8

2 Einfluss von gesextem Sperma auf Produktionsmerkmale und funktionale Merkmale bei deutschen Holstein Friesian.............................................................9

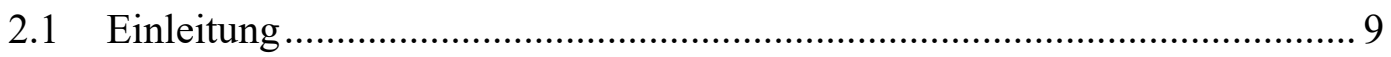

2.2 Effect of sexed semen on different production and functional traits in

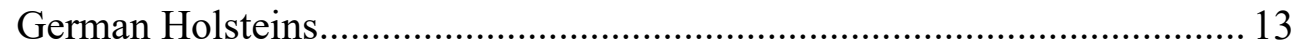

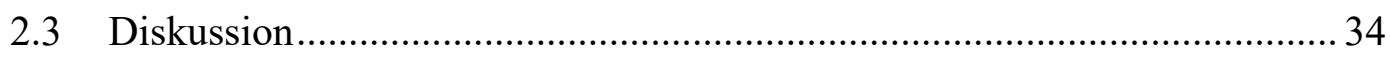

3 Einfluss eines ölfreien Kultursystems auf in vitro produzierte bovine Oozyten und Embryonen ........................................................................................................... 38

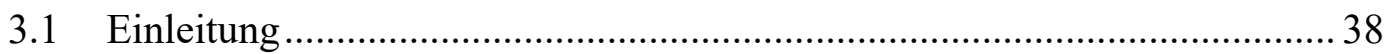

3.2 The effect of an oil covered culture system on bovine in vitro produced

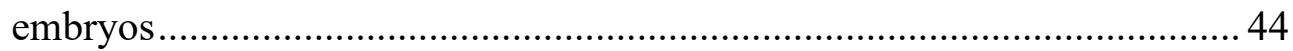

3.3 Evaluation of a small volume oil-free in vitro production system for bovine

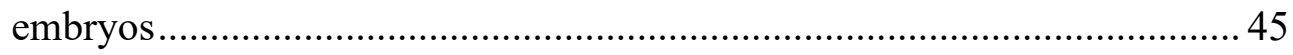

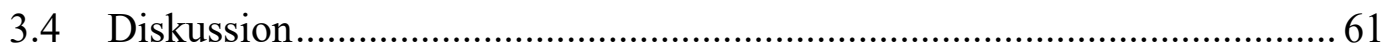

4 Einfluss des Wirkstoffes Glyphosat auf die In-vitro-Maturation und weitere Entwicklung boviner Oozyten ...................................................................................... 64

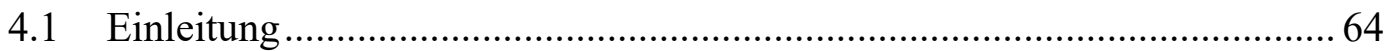

4.2 Effect of glyphosate on bovine oocyte development during in vitro maturation

4.3 Does glyphosate affect the expression of developmental genes in bovine oocytes?

4.4 Beeinflusst Glyphosat die In-vitro-Maturation und weitere Entwicklung boviner Oozyten? .70 


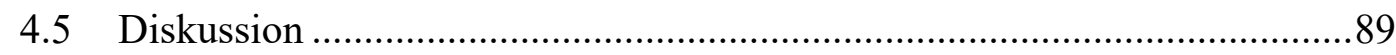

$5 \quad$ Allgemeine Diskussion ...........................................................................................95

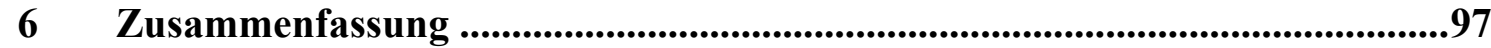

$7 \quad$ Summary

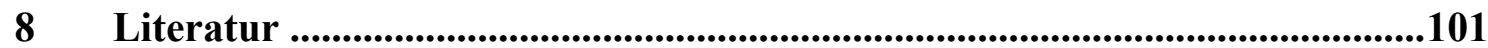

Erklärung über den geleisteten Eigenanteil an der Arbeit...................................... VIII

Danksagung........................................................................................................................... IX

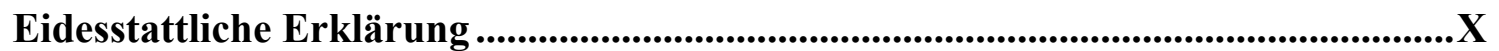




\section{Veröffentlichungen}

Diese Arbeit basiert auf folgenden Beiträgen:

\section{Veröffentlichungen in referierten Fachzeitschriften:}

S. Diers, C. Blaschka, I. Kilic, A. Rathgeb, A. Silbersdorff, P. Karlovsky, J. Tetens (2020): Beeinflusst Glyphosat die In-vitro-Maturation und weitere Entwicklung boviner Oozyten? Züchtungskunde, 92(4). ISSN: 0044-5401.

S. Diers, J. Heise, T. Krebs, J. Groenewold, J. Tetens (2020): Effect of sexed semen on different production and functional traits in German Holsteins. Veterinary and Animal Science, 9. DOI: 10.1016/j.vas.2020.100101.

S. Diers, C. Blaschka, I. Kilic, A. Silbersdorff, J. Tetens (2020): Does glyphosate affect the expression of developmental genes in bovine oocytes? Reproduction in Domestic Animals, 55(S1): 8. DOI: 10.1111/rda.13591.

S. Diers, C. Blaschka, A. Silbersdorff, C. Knorr, J. Tetens (2019): Effect of glyphosate on bovine oocyte development during in vitro maturation. Reproduction in Domestic Animals, 54(S1): 3. DOI: 10.1111/rda.13387.

M. Aravina, S. Diers, J. Tetens, C. Blaschka (2019): The effect of an oil covered culture system on bovine in vitro produced embryos. Reproduction in Domestic Animals, 54(S1): 4. DOI: 10.1111/rda.13387.

Zur Veröffentlichung vorgesehene Beiträge:

C. Blaschka, S. Diers, M. Aravina, S. Geisler, G. Schuler, J. Tetens: Evaluation of a small volume oil-free in vitro production system for bovine embryos. Vorgesehen zur Einreichung in: Reproduction in Domestic Animals. 


\section{Tagungsbeiträge:}

S. Diers, C. Blaschka, I. Kilic, A. Silbersdorff, J. Tetens (2020): Beeinflusst Glyphosat die Expression entwicklungsrelevanter Gene in bovinen Oozyten? Poster 16, Jahrestagung Physiologie und Pathologie der Fortpflanzung, Rostock.

S. Diers, I. Kilic, C. Blaschka, J. Tetens (2019): Beeinflusst Glyphosat die Expression entwicklungsrelevanter Gene? Vortragstagung der DGfZ/GfT in Gießen.

M. Aravina, S. Diers, C. Knorr, J. Tetens, C. Blaschka (2019): Effects of an oil covered culture system on bovine in vitro produced embryos. Poster A068E, Annual Meeting of the AETE, Murcia, Spain.

S. Diers, C. Blaschka, A. Silbersdorff, C. Knorr, J. Tetens (2019): Einfluss des Wirkstoffes Glyphosat auf die Entwicklungskompetenz boviner Oozyten während der Invitro-Maturation. Vortrag, Jahrestagung Physiologie und Pathologie der Fortpflanzung, Göttingen.

S. Diers, C. Blaschka, A. Silbersdorff, J. Tetens, C. Knorr (2018): Einfluss des Wirkstoffes Glyphosat auf die Entwicklungskompetenz boviner Oozyten während der Invitro-Maturation. Vortragstagung der DGfZ/GfT in Bonn.

S. Diers, J. Heise, K. Stock, J. Groenewold, C. Knorr (2017): Totgeburtenrate beim Einsatz gesexten Spermas bei Deutschen Holsteins in Niedersachsen. Vortragstagung der DGfZ/GfT in Stuttgart. 


\section{Abbildungsverzeichnis}

Abbildung 1: Prinzip der flowzytometrischen Spermatrennung (Rath, 2020).

Abbildung 2: Schematische Darstellung der IVP boviner Embryonen.

Abbildung 3: Darstellung der Kultursysteme.

61 

Abkürzungsverzeichnis
AMPA
BfR
BMP15
BSA
BSA-FAF
C_F
C_M
CI
$\mathrm{COC}$
CON-1
$\mathrm{CON}-10$
CYP19A1
DAPI
E2
EC
eCG
EDSP
EDTA
EFSA
EPA
EPSP
ESR1
Fert.-TALP
FSH
G1
G10
GBH1
GBH10
GDF9
GnRH
hCG
aminomethylphosphonic acid
Bundesinstitut für Risikobewertung
bone morphogenetic protein 15
bovine serum albumin, bovines Serumalbumin
bovine serum albumin, fatty acid free
conventional semen $\times$ female calves
conventional semen $\times$ male calves
confidence interval
cumulus-oocyte-complex
control-corresponding to the $1 \mu \mathrm{g} / \mathrm{ml}$ treatments
control-corresponding to the $10 \mu \mathrm{g} / \mathrm{ml}$ treatments
aromatase
4'-6-diamidino-2-phenylindole
$17 \beta$-oestradiol, Östradiol
European Commission
equine chorionic gonadotropin, equines Choriongonadotropin
Endocrine Disruptor Screening Program
ethylenediaminetetraacetate
European Food Safety Authority
Environmental Protection Agency
5-enolpyruvylshikimat-3-phosphate
estrogen receptor 1
Fertilisation-Tyrode's albumin, lactate and pyruvate
follicle stimulating hormone, follikelstimulierendes Hormon
glyphosate- $1 \mu \mathrm{g} / \mathrm{ml}$
glyphosate- $10 \mu \mathrm{g} / \mathrm{ml}$
glyphosate-based herbicide- $1 \mu \mathrm{g} / \mathrm{ml}$
glyphosate-based herbicide- $10 \mu \mathrm{g} / \mathrm{ml}$
growth differentiation factor 9
gonadotropin releasing hormone, Gonadotropin Releasing Hor- mon
human chorionic gonadotropin, humanes Choriongonadotropin 


$\begin{array}{ll}\text { HPLC-MS/MS } & \text { liquid chromatography-tandem mass spectrometry } \\ \text { HSD3B1 } & \text { hydroxy-delta-5-steroid dehydrogenase } \\ \text { IARC } & \text { International Agency for Research on Cancer } \\ \text { IVC } & \text { in vitro culture, In-vitro-Kultur } \\ \text { IVF } & \text { in vitro fertilisation, In-vitro-Fertilisation } \\ \text { IVM } & \text { in vitro maturation, In-vitro-Maturation } \\ \text { IVP } & \text { in vitro production, In-vitro-Produktion } \\ \text { KOK } & \text { Kumulus-Oozyten-Komplexe } \\ \text { LH } & \text { luteinizing hormone, luteinisierendes Hormon } \\ \text { M } & \text { mean } \\ \text { MED } & \text { median } \\ \text { n } & \text { number of observations } \\ \text { OPU } & \text { Ovum Pick-Up } \\ \text { P4 } & \text { progesterone, Progesteron } \\ \text { PGR } & \text { nuclear progesterone receptor } \\ \text { POEA } & \text { polyoxyethylene tallow amine } \\ \text { PPIA } & \text { peptidylprolyl isomerase A } \\ \text { PTSCl } & \text { para-toluene sulfonyl chloride } \\ \text { qPCR } & \text { real-time quantitative PCR } \\ \text { RUSITEC } & \text { rumen simulation technic, Pansensimulationstechnik } \\ \text { S_F } & \text { sexed semen } \times \text { female calves } \\ \text { S_M } & \text { sexed semen } \times \text { male calves } \\ \text { SD } & \text { standard deviation } \\ \text { SE } & \text { standard error } \\ \text { SOF } & \text { synthetic oviduct fluid } \\ \text { STAR } & \text { steroidogenic acute regulatory protein } \\ \text { TCM-199 } & \text { tissue culture medium 199 } \\ \text { vit } & \text { IT Solutions for Animal Production } \\ \text { VOST } & \text { Verein Ostfriesischer Stammviehzüchter } \\ \text { YWHAZ } & \text { tyrosine 3-monooxygenase/tryptophan 5-monooxygenase activa- } \\ \text { ZAR1 } & \text { tion } \\ & \end{array}$




\section{$1 \quad$ Allgemeine Einleitung}

Der Reproduktionserfolg des Rindes ist die Grundvoraussetzung für die Milchproduktion, die Remontierung und damit für die wirtschaftliche Effizienz eines Betriebes (Gröhn \& Rajala-Schultz 2000; Vishwanath \& Moreno 2018).

Zur Erfassung der Reproduktionsleistung werden verschiedene funktionale Merkmale herangezogen. $\mathrm{Zu}$ diesen gehören beispielsweise der Besamungsindex, die Non-ReturnRate, die Zwischenkalbezeit, aber auch der Kalbeverlauf, die Schwer- und die Totgeburtenraten (ADR 2017).

Eine Steuerung der Reproduktionsleistung kann beim Rind sowohl auf der männlichen als auch auf der weiblichen Seite über den Einsatz von Biotechniken erfolgen, wobei hier neben der künstlichen Besamung und dem Embryotransfer besonders das Spermasexing und die In-vitro-Produktion (IVP) von Embryonen als bedeutende Technologien hervorzuheben sind. Mit dem Einsatz von weiblich gesextem Sperma wird auf weibliche Nachkommen selektiert und der Anteil unerwünschter männlicher Kälber reduziert. Mittels IVP wird das Potenzial genetisch wertvoller Tiere genutzt, um daraus eine hochwertige Nachzucht bei gleichzeitiger Verkürzung des Generationsintervalls zu erzeugen. Die erfolgreiche Anwendung dieser Biotechniken unterliegt verschiedenen exogenen Einflüssen.

Die vorliegende Dissertationsschrift geht deshalb auf den Einsatz dieser beiden Biotechniken ein und verfolgt dabei drei verschiedene Zielsetzungen.

Im ersten Teil der Arbeit wird untersucht, ob die Art des eingesetzten Spermas und das Kalbgeschlecht einen Einfluss auf funktionale Merkmale und Produktionsmerkmale von Färsen haben.

Der zweite Teil der Arbeit beschäftigt sich mit einer methodischen Fragestellung der IVP. Hier werden zwei Kultursysteme und deren Auswirkungen auf die Entwicklung boviner Embryonen vergleichend dargestellt.

Für die dritte Fragestellung der Arbeit wird die IVP als Modell herangezogen, um die Wirkung von Glyphosat auf die Reproduktion landwirtschaftlicher Nutztiere in vitro nachzustellen und daraus gegebenenfalls auch Erkenntnisse für den Humanbereich ableiten zu können.

In den Untersuchungen zur IVP boviner Embryonen wird der Reproduktionserfolg dabei als erfolgreiche Befruchtung und Kultivierung der Embryonen verstanden. 


\section{Einfluss von gesextem Sperma auf Produktionsmerkmale und funktionale Merkmale bei deutschen Holstein Friesian}

\subsection{Einleitung}

Die unterschiedliche Länge der Geschlechtschromosomen bei Säugetieren führt zu differierenden DNA-Gehalten in X- und Y-Chromosom-tragenden Spermien (Moruzzi 1979). Versuche, diese Differenz genau zu messen, gelangen in den 1980er Jahren und ergaben beim Rind einen um 3,8 \% höheren relativen DNA-Gehalt des X- chromosomalen Spermiums (Gledhill et al. 1982; Pinkel et al. 1982). Dies ermöglichte die gezielte Sortierung von X- und Y-Chromosom-tragenden Spermien mittels quantitativer Durchflusszytometrie (Garner et al. 1983).

In den frühen Ansätzen der Durchflusszytometrie mussten die Zellmembranen der Spermien für den membranundurchlässigen Fluoreszenzfarbstoff DAPI (4'-6Diamidino-2-phenylindol) entfernt werden, wodurch die Spermien abgetötet wurden (Garner et al. 1983). Die Verwendung des membrandurchlässigen Fluoreszenzfarbstoffes Hoechst 33342 ermöglichte schließlich die Sortierung von intakten Spermien (Johnson et al. 1987) und die Geburt der ersten lebenden Nachkommen aus geschlechtssortiertem Bullen- und Kaninchensperma im Jahr 1989 (Johnson et al. 1989).

Mit der Einführung der Hochgeschwindigkeits-Durchflusszytometrie begann 1996 die kommerzielle Nutzung von gesextem Rindersperma (Seidel et al. 1999).

Das Prinzip der flowzytometrischen Spermatrennung ist in Abbildung 1 dargestellt. Hierbei wird die sich im Spermienkopf befindliche DNA durch Hoechst 33342 angefärbt. Nach der Färbung werden die Spermien in einem Tröpfchenstrom angeordnet und passieren einen UV-Laserstrahl, der die Fluoreszenz anregt. Eine Photozelle (PhotoMultiplier PMT 90 ) stellt fest, ob der Spermienkopf mit der flachen Seite senkrecht zum Laser ausgerichtet ist, und eine zweite Photozelle (PMT $0^{\circ}$ ) misst die Fluoreszenz der korrekt ausgerichteten Spermien. Die Tröpfchen, die X- oder Y-Chromosomtragende Spermien enthalten, werden elektrisch entgegengesetzt geladen und dann in einem elektrostatischen Feld abgelenkt. In membrangeschädigten Spermien kommt es zur Überlagerung des Fluoreszenzfarbstoffes durch einen Lebensmittelfarbstoff (FD40), so dass diese Spermien nicht elektrisch geladen, und damit nicht sortiert werden (Seidel 
et al. 1999; Garner \& Seidel 2003). So erfolgt die Geschlechtsbestimmung mit einer Genauigkeit von 85 \% bis $95 \%$ (Johnson et al. 1999).

\section{Prinzip der flowzytometrischen Spermatrennung}

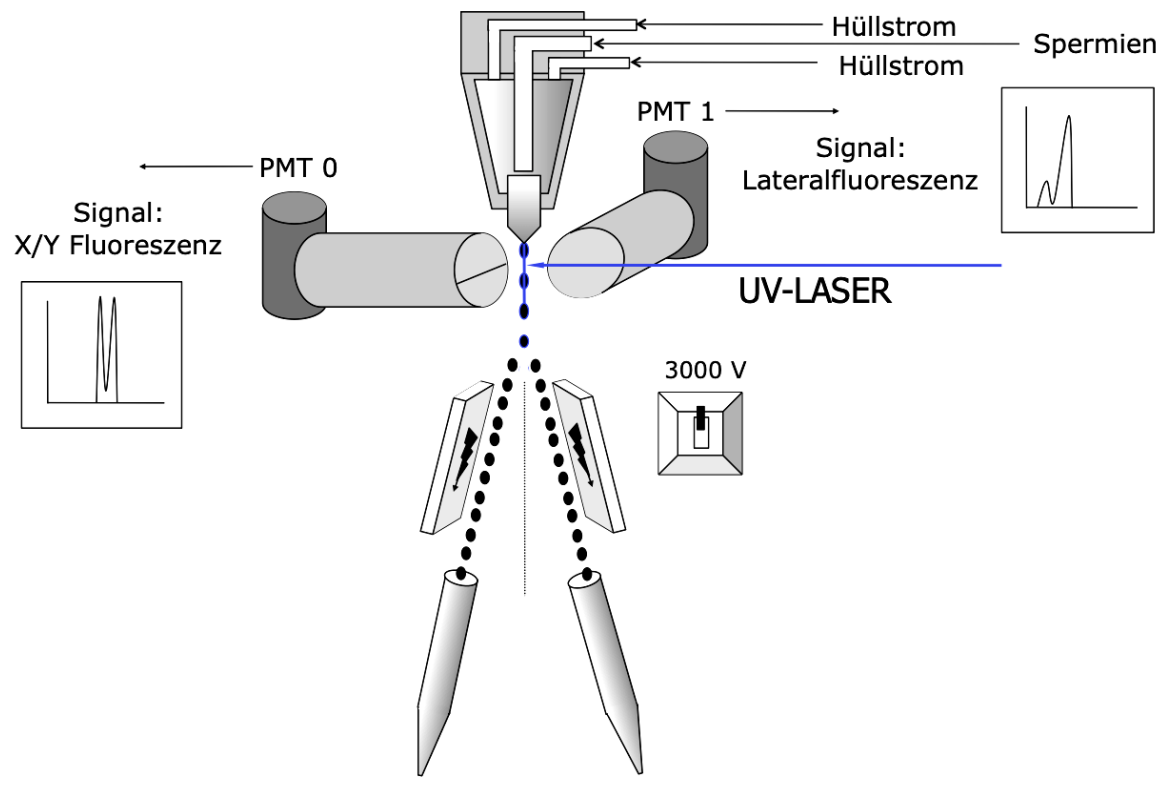

Freigabe, D. Rath, Repro-GamTec, 3/2020

Abbildung 1: Prinzip der flowzytometrischen Spermatrennung (Rath, 2020).

Obwohl in den vergangenen Jahren alternative Methoden getestet wurden, ist die Durchflusszytometrie, nach einigen Modifikationen, immer noch die Methode der Wahl für das Spermasexing. Fluoreszierende In-situ-Hybridisierungstechniken (Kawarasaki et al. 1998), Goldnanopartikel, die an Y-Chromosom-spezifische Sequenzen binden (Rath et al. 2013) oder die Spermaseparation durch die Swim-up-Methode mit Validierung durch die qPCR (Asma-ul-Husna et al. 2017) ermöglichen ebenfalls die Geschlechtsbestimmung von Spermien, sind aber nicht von kommerzieller Bedeutung.

Gesextes Sperma wird züchterisch gezielt eingesetzt, um eine hochwertige weibliche Nachzucht zu erhalten. Gleichzeitig wird der Anteil von unerwünschten männlichen Milchkälbern, die von geringem Nutzen für die Rindfleischproduktion sind, verringert und die mit männlichen Kälbern verbundenen höheren Schwergeburtenraten können stark reduziert werden (Hohenboken 1999; Seidel 2002). Andererseits ist der Sortier- 
prozess aufwendig und mit höheren Produktionskosten verbunden. Die reduzierte Spermienmenge in den gesexten Spermaportionen kann außerdem die Reproduktionsleistung beeinträchtigen und erfordert ein strenges Besamungsmanagement. Eine gesexte Spermaportion enthält etwa 2 Millionen Spermien und damit nur ein Zehntel der herkömmlichen Spermamenge (20 Millionen Spermien/Dosis) (Mallory et al. 2013; Seidel 2014). Durch die Manipulation der Spermien während des Sortierprozesses, können Schäden an diesen entstehen (Garner \& Seidel 2003; Mallory et al. 2013). Nachteilig sind außerdem die schlechteren Eigenschaften von gesextem Sperma nach Kryokonservierung im Vergleich zu konventionellem Sperma (Schenk et al. 1999).

Verschiedene Leistungsmerkmale von Milchkühen nach Besamung mit gesextem Sperma wurden bereits in mehreren Studien untersucht und dabei insbesondere niedrigere Konzeptionsraten ermittelt (DeJarnette et al. 2008; Schenk et al. 2009; Norman et al. 2010; Healy et al. 2013). Spermasexing in Verbindung mit der hohen Verdünnung scheint die Befruchtungsfähigkeit auf $60 \%$ bis $90 \%$ im Vergleich zu konventionellem Sperma zu reduzieren (Seidel et al. 1999; Borchersen \& Peacock 2009; DeJarnette et al. 2009). Die geringeren Konzeptionsraten und die höheren Kosten für gesextes Sperma führen dazu, dass dieses vor allem für Färsen und erste Besamungen verwendet wird, da bei diesen die Fruchtbarkeit am höchsten ist (Seidel 2007; DeJarnette et al. 2008, 2009). Die Fruchtbarkeitsleistung kann allerdings auch in Abhängigkeit von betrieblichen Faktoren, wie der Östruserkennung sowie kuhbezogener Faktoren wie Alter, Körperzustand und Parität, stark unterschiedlich ausfallen (Seidel \& Schenk 2008).

Stressbelastungen während des Spermasexings und insbesondere die mögliche Anreicherung Y-chromosomaler Spermien mit erhöhtem DNA-Gehalt in der X-chromosomal sortierten Spermienpopulation beeinflussen nicht nur die Empfängnisrate, sondern auch die Totgeburtenrate der männlichen Kälber. DeJarnette et al. (2009) und Norman et al. (2010) berichteten bei Holstein-Färsen über deutlich höhere Totgeburtenraten männlicher Kälber aus weiblich gesextem Sperma.

Neueste Entwicklungen zur Minimierung der negativen Einflüsse des Sortierprozesses basieren insbesondere auf einer Überarbeitung der verwendeten Medien (GonzalezMarin et al. 2016; Lenz et al. 2016). Neue Sortiermaschinen ermöglichen zusätzlich eine schnellere, genauere und weniger schädliche Produktion (Thomas et al. 2017). Darüber hinaus können höhere Dosen von z.B. 4 Millionen weiblich gesexten Spermien 
pro Portion die Lücke zwischen den Empfängnisraten von gesextem und konventionellem Sperma minimieren (Lenz et al. 2016). Erste Analysen nach Einsatz dieser Spermienmengen ergaben höhere Empfängnisraten im Vergleich zur üblichen Spermamenge nach der Sortierung und Non-Return-Raten, die sich denen des konventionellen Spermas annähern (Lenz et al. 2016).

Ziel der vorliegenden Studie war es, mögliche Auswirkungen der Spermaart (konventionell vs. weiblich gesext) und des Kalbgeschlechts auf funktionale Merkmale und Produktionsmerkmale von Holstein-Färsen in Niedersachsen zu analysieren. 
2.2 Effect of sexed semen on different production and functional traits in German Holsteins

S. Diers ${ }^{\mathrm{a}, 1, *}$, J. Heise ${ }^{\mathrm{b}, 1}$, T. Krebs ${ }^{\mathrm{a}}$, J. Groenewold ${ }^{\mathrm{c}}$, J. Tetens ${ }^{\mathrm{a}}$

a'Department of Animal Science, Georg-August-University, Burckhardtweg 2, 37077 Göttingen, Germany

${ }^{b}$ IT Solutions for Animal Production (vit), Heinrich-Schröder-Weg 1, 27283 Verden, Germany, ${ }^{\mathrm{c} C h a m b e r}$ of Agriculture Lower Saxony, Mars-la-Tour-Straße 6, 26121 Oldenburg, Germany

${ }^{1}$ These authors contributed equally.

*Corresponding author

Erscheint in:

Veterinary and Animal Science 2020, 9

doi.org/10.1016/j.vas.2020.100101

DOI: 10.1016/j.vas.2020.100101

\begin{abstract}
The aim of this study was to analyze possible effects of semen type (conventional vs. female sexed) and calf sex on fertility and production traits. For this purpose, field data of German Holstein heifers in Lower Saxony were evaluated.

Sexed semen was mainly used for first insemination. $87.0 \%$ female calves were born from sexed semen, while 52.7\% female calves were born from conventional semen. Heifers inseminated with sexed semen were on average 43 to 48 days younger at their first calving than heifers inseminated with conventional semen.

Calf sex had an influence on the average calving ease and the dystocia rates. Male calves showed higher calving ease scores and caused a higher risk for dystocia than female calves. The semen type had no influence on these characteristics.

Within the same calf sex, sexed semen had only minor effects on most traits, except for stillbirth rates: the stillbirth rate for male calves from female sexed semen was $30.6 \%$, which was 2.86 times the stillbirth rate of male calves from conventional semen, possibly due to trisomies.

Sexed semen played only a minor role for production traits in first lactations.

The extrapolated 305-day milk yield was $200 \mathrm{~kg}$ lower for first calf heifers, which were inseminated with sexed semen compared to heifers inseminated with conventional semen. Fat and protein yield were $6 \mathrm{~kg}$ to $8 \mathrm{~kg}$ lower after use of sexed semen. Animals
\end{abstract}


with female offspring from sexed semen showed higher survival rates than the other groups.

Keywords: sexed semen, calf sex, heifer, stillbirth

\begin{abstract}
Abbreviations:
conventional semen $\times$ male calves $\left(\mathbf{C}_{-} \mathbf{M}\right)$, conventional semen $\times$ female calves $\left(\mathbf{C}_{-} \mathbf{F}\right)$, sexed semen $\times$ male calves $\left(\mathbf{S} \_\mathbf{M}\right)$, sexed semen $\times$ female calves $\left(\mathbf{S} \_\mathbf{F}\right)$
\end{abstract}

\title{
1. Introduction
}

Different total lengths of sex chromosomes in mammals lead to different DNA contents in X-and Y-chromosome bearing spermatozoa (Moruzzi, 1979). Attempts to precisely measure this difference succeeded in the 1980s (Gledhill, Pinkel, Garner, \& Van Della, 1982; Pinkel et al., 1982) and revealed a 4\% higher DNA amount of the Xchromosome, which made it possible to sort X- and Y-sperm using flow cytometry (Garner et al., 1983).

In early flow cytometric approaches, the cell membranes had to be removed to use the membrane impermeant fluorescent dye DAPI (4'-6-diamindino-2-phenylindole), thus killing the sperm (Garner et al., 1983). The transition to the membrane permeant fluorescent dye Hoechst 33342 enabled sorting with intact sperm (Johnson, Flook, \& Look, 1987).

The first live offspring were born after use of sex-sorted bull and rabbit semen in 1988 (Morrell, Keeler, Noakes, Mackenzie, \& Dresser, 1988).

With the implementation of the high-speed flow cytometry in 1996, the commercialized use of bovine sexed semen finally became feasible (Seidel et al., 1999).

Subsequent to staining, the sperm are arranged in a droplet stream and pass a laser beam. Two detectors are used, one to determine if the sperm head is oriented with the flat surface perpendicular to the laser and the other to measure fluorescence of those sperm oriented correctly. The relative fluorescence is measured by a photomultiplier tube and analyzed by a computer. The droplets containing X- and Y-chromosome bearing spermatozoa are electrically oppositely charged and then sorted in an electrostatic 
field (Garner \& Seidel, 2003). With that procedure, sex can be predetermined with $85 \%$ to $95 \%$ accuracy (Johnson, Welch, \& Rens, 1999).

Although alternative methods were tested in past years, the flow-cytometric technology is with some modifications still the method of choice for semen sex sorting. Fluorescent in situ hybridization techniques (Kawarasaki, Welch, Long, Yoshida, \& Johnson, 1998), gold nanoparticles binding to Y-chromosome-specific sequences (Rath et al., 2013) or semen separation by swim-up method with validation by real-time PCR (Asma-ulHusna et al., 2017) do also provide opportunities for sperm sexing but are not of commercial interest.

Sex preselection of females is the most common treatment to achieve an adequate number of replacement heifers. Simultaneously, dystocia rates and the number of unwanted male dairy calves inferior for beef production are decreased (Hohenboken, 1999; Seidel, 2002). On the other hand, the time-consuming and costly sorting process makes semen more expensive. At the same time, the doses are sold with a reduced concentration, which may impair fertility and requires stringent insemination management. A sexed semen dose contains approximately 2 million spermatozoa, which is only a tenth of the conventional semen (20 million sperm/dose) (Mallory, Lock, Woods, Poock, \& Patterson, 2013; Seidel, 2014).

Furthermore, the sexing process encompasses different manipulations of the sperm which can cause damage (Garner \& Seidel, 2003; Mallory et al., 2013). Moreover, conventional semen can cope better with cryopreservation (Schenk, Suh, Cran, \& Seidel, 1999).

Several studies examined different performance characteristics of dairy cattle after insemination with sexed semen and found some effects, especially lower conception rates (DeJarnette et al., 2008; Healy, House, \& Thomson, 2013; Norman, Hutchison, \& Miller, 2010; Schenk, Cran, Everett, \& Seidel, 2009).

The sperm sorting process seems to reduce the fertilization capability to $60 \%$ to $90 \%$ as compared to conventional sperm (Borchersen \& Peacock, 2009; DeJarnette, Nebel, \& Marshall, 2009; Seidel et al., 1999). Lower conception rates in addition to the higher costs for sexed semen lead to the fact that sexed semen is primarily used for nulliparous heifers and first services, for which fertility is expected to be the highest (DeJarnette et al., 2009, 2008; Seidel, 2007). The reported conception rates widely differed which emphasizes the influence of farm-related factors such as estrus detection as well as cowrelated factors such as age, body condition and parity (Seidel \& Schenk, 2008). 
The multitude of manipulations of spermatozoa during sex sorting might not only affect conception rate, but also the stillbirth rate or even calf viability. Several studies have already investigated this and DeJarnette et al. (2009) and Norman et al. (2010) e.g. reported strikingly higher stillbirth rates for male calves among Holstein heifers inseminated with female sexed semen.

Latest developments to minimize the negative influences of sorting steps resulted in the new SexedULTRA technology (STgenetics, USA) which is especially based on revised conditions of the media used during the various stages of the sexing process (GonzalezMarin et al., 2016; Lenz et al., 2016). Additionally, the new Genesis III sorting machine (STgenetics, USA) enables more rapid, accurate, and less damaging production (Thomas et al., 2017). Furthermore, a higher dose rate of 4 million sex-sorted sperm per straw was introduced to the market in 2017 (SexedULTRA-4M, STgenetics, USA) in order to lessen the gap between conception rates of sexed and conventional semen (Lenz et al., 2016). First analyses showed greater conception rates compared to the usual sexing routine and non-return rates approaching conventional semen (Lenz et al., 2016).

The aim of the current study was thus to analyze possible effects of semen type (conventional vs. female sexed) and calf sex on fertility and production traits using field data of German Holstein heifers in Lower Saxony.

\section{Materials and methods}

Data of first lactation Holstein Friesian cows from the breeding value estimation of December 2015 were assessed (data cut-off: July 10, 2015). These data were provided by the breeding associations Masterrind and Verein Ostfriesischer Stammviehzüchter (VOST) via the data center vit (IT Solutions for Animal Production).

Different criteria had to be fulfilled for data selection:

a) Only herd-years with at least 20 inseminations on heifers with sexed and unsexed semen were considered. The performance data of the first lactation were selected for these heifers.

b) The interval from last insemination to calving was required to be between 265 and 295 days to assign the calves to the last insemination. If other inseminations were conducted within a range of $\leq 10$ days around the last insemination, data were used only if the bull and the type of semen were the same both times. 
c) Selected herds had to show at least 10 such verified calvings from each, sexed and unsexed semen.

As the amount of male calves out of female sexed semen is relatively low and the effects therefore hard to find, the interaction levels semen type $\times$ calf sex were created. These levels were: conventional semen $\times$ male calves $\left(\mathbf{C}_{-} \mathbf{M}\right)$, conventional semen $\times$ female calves $\left(\mathbf{C}_{-} \mathbf{F}\right)$, sexed semen $\times$ male calves $\left(\mathbf{S} \_\mathbf{M}\right)$, sexed semen $\times$ female calves $\left(\mathbf{S} \_\mathbf{F}\right)($ Table 1$)$.

Table 1. Description of the interaction levels semen type $\times$ calf sex (number of samples $(\mathrm{n})=55,554)$

\begin{tabular}{lccrr}
\hline Abbreviation & Semen type & Calf sex & $\mathrm{n}$ & $\begin{array}{r}\text { Proportion } \\
(\%)\end{array}$ \\
\hline C_M & Conventional & male & 15,585 & 28.0 \\
C_F & Conventional & female & 17,389 & 31.3 \\
S_M & Sexed & male & 2,930 & 5.3 \\
S_F & Sexed & female & 19,650 & 35.4 \\
\hline
\end{tabular}

conventional semen $\times$ male calves $\left(C_{-} M\right)$, conventional semen $\times$ female calves $\left(C_{-} F\right)$, sexed semen $\times$ male calves $\left(S_{-} M\right)$, sexed semen $\times$ female calves $\left(S_{-}\right.$F $)$.

Initially, 105,565 heifers were included into the analysis to get an overview of the use of sexed semen. The ratio between the use of sexed semen and conventional semen for first and following services of nulliparous heifers was calculated based on these data.

The number of animals was higher for this partial analysis than for the following evaluations because exits till calving and the criterium c) mentioned above were not considered.

55,554 calves were examined in total. 22,580 of them were born from sexed semen and 32,974 were born from conventional semen.

Calving ease: Only calvings with observed calving ease, categories 1 to 4 (ADR, 2017), were considered $(\mathrm{n}=52,710)$.

Dystocia: Calving ease categories 3 and 4 were considered as dystocia, coded as ' 1 ', $(\mathrm{n}=52,710)$.

Stillbirth: Stillbirths included all stillborn calves and those which died within 48 hours after birth $(A D R, 2017)(n=55,554)$. 
Calving to first service interval: Only heifers with less than 200 days from calving to first service were evaluated. Moreover, the time range between calving and cut-off date had to be more than 200 days to give the animals an equal chance for showing calving to first service interval $(\mathrm{n}=37,629)$.

Non-return rate: For this evaluation, only heifers which had not exited the herd before day $56(\mathrm{n}=37,173)$ or day $90(\mathrm{n}=36,086)$ after first service were analyzed.

Number of services in first lactation: In addition to the mentioned selection criteria above, only heifers first inseminated with deep-frozen semen were considered $(\mathrm{n}=35,727)$.

Lactation performance - milk, fat and protein yield: The lactation performance for milk, fat and protein yield was analyzed for all cows with at least eight test days in first lactation $(\mathrm{n}=32,718)$.

Survival rates within first lactation: Heifers with calvings at least 100 days before data cut-off were included in the analysis $(n=51,436)$.

\subsection{Statistical analyses}

Statistical analyses were performed with $R$ (version 3.1.2; $R$ Development Core Team, 2014).

Nominal variables are presented descriptively in cross tables.

The description of continuous variables against nominal variables are shown in mean value tables.

Logit models were used for binary dependent variables according to the general equation:

$y_{i j}^{*}=$ sexed semen $\times$ calf $\operatorname{sex}_{i j}$

$y_{i j}^{*}$ is a latent variable for individual $i$ with interaction effect level $j$ of the effect sexed sperm $\times$ calf sex, linked to observation $y_{i j}^{*}(0 / 1)$ via the logit link function.

Odds ratios show the proportion between the probabilities of different effect levels in relation to a reference level with a given odds ratio of 1 .

Survival rates for the interval first calving to 450 days were estimated using KaplanMeier estimators (Kaplan \& Meier, 1958). The risk of an animal to be culled at a given timepoint $R(t)$ is estimated using the following equation: 
- $\quad R(t)=\frac{n_{\text {animals culled at timepoint } t}}{\begin{array}{c}n_{\text {animals being at risk for timepoint } t} \\ \text { i.e.having survived } t-1\end{array}}$

The probability of an animal to survive from $t=0$ up to timepoint $t$ is then:

$S(t)=\prod_{i=0}^{t} 1-R(t)$

$S(t)$ can also be considered as an estimator of the amount of all animals with a first calving which survived up to timepoint $t$.

The interval first calving to 450 days was also assumed as survived if the cow had a second calving.

In the following, the simplified term sexed semen is exploited instead of female sexed semen.

\section{Results and discussion}

The proportion of sexed semen was decreasing with the number of services. While $59.7 \%$ of nulliparous heifers were inseminated with sexed semen for first service, this proportion dropped to $6.6 \%$ for fourth service. Sexed semen is mainly used for first (and second) insemination of heifers. If the first and second insemination are not successful, the following inseminations will most likely be performed with conventional semen due to lower costs and higher conception rates (Schenk et al., 2009). Here, the percentage of first services with sexed semen is very high compared to older studies (DeJarnette et al., 2009; Norman et al., 2010). Although the studies were performed with data of another population, decreasing costs for sexed semen during the last years certainly contribute to this observation (McCullock et al., 2013).

$87.0 \%$ female calves were born from sexed semen. In comparison to that, the percentage of female calves from unsexed semen was $52.7 \%$. This distribution of calf sex after use of sorted semen correspond with literature: Tubman et al. (2004) and Healy et al. (2013) found rates of $87.8 \%$ and $86.0 \%$, respectively. DeJarnette et al. (2009) and Norman et al. (2010) reported rates closer to the aimed 90.0\%. These deviations might occur because of different accuracies of sorting or because of an incomplete or erroneous data recording (Healy et al., 2013; Seidel, 2003). 
The sex ratio for conventional semen differed from expectations. Most studies achieved approximately $50.0 \%$ to $52.0 \%$ male offspring (DeJarnette et al., 2009; Tubman et al., 2004). In the present study, the ratio behaved in reverse proportion. $52.7 \%$ female calves were born after use of conventional semen. Norman et al. (2010) reported 51.5\% female calves as well.

These various rates may be due to a data reporting bias. Female calves are of a higher value for the farmer and are therefore much more likely to be reported correctly.

The statistical models were kept simple, because many factors which affect the response variables might also be correlated to the effect of sexed semen $\times$ calf sex. For example, the different traits are heritable, but including a bull effect might lead to collinearity between the bull effect and the effect of sexed semen $\times$ calf sex.

\subsection{Age at first calving}

Heifers inseminated with sexed semen were on average 43 to 48 days younger at their first calving than heifers inseminated with conventional semen $(\mathrm{P}<0.001)$ (Table 2).

Table 2. Age at first calving (days) for the interaction levels

\begin{tabular}{lrrrrr}
\hline & $\mathrm{n}$ & $\mathrm{M}$ & SD & SE & MED \\
\hline C_M & 15,585 & $845.8^{\mathrm{a}}$ & 103.1 & 0.8 & 824 \\
C_F & 17,389 & $840.1^{\mathrm{b}}$ & 99.7 & 0.8 & 820 \\
S_M & 2,930 & $798.2^{\mathrm{c}}$ & 78.6 & 1.5 & 781 \\
S_F & 19,650 & $797.0^{\mathrm{c}}$ & 77.5 & 0.6 & 780 \\
\hline
\end{tabular}

conventional semen $\times$ male calves $\left(\mathrm{C}_{-} \mathrm{M}\right)$, conventional semen $\times$ female calves $\left(\mathrm{C}_{-} \mathrm{F}\right)$,

sexed semen $\times$ male calves $\left(S_{-}\right.$M), sexed semen $\times$female calves $\left(S_{-}\right.$F); Mean $(M)$, standard deviation (SD), standard error (SE), median (MED).

${ }^{\mathrm{a}-\mathrm{c}}$ Means with different superscripts differ $(\mathrm{P}<0.001)$.

The decreased age at first calving of heifers inseminated with sexed semen is in contrast to the results of other studies. Chebel et al. (2010) reported a longer interval from first insemination to calving after use of sexed semen but no differences in age at calving compared to heifers inseminated with conventional semen. Joezy-Shekalgorabi et al. (2014) even observed an increased age at first calving after an insemination with sexed semen while comparing different breeding strategies. The authors acknowledged a great 
influence of management strategies such as estrus detection rate or the percentage of sexed semen utilized in the herd.

The results of the current study coincide with the fact that sex-sorted semen is mainly used for first and second services (Schenk et al., 2009). Therefore, these heifers showed a lower age at first calving. The average age at first calving in the current data set (26 to 28 months) is relatively high compared to literature (Chebel et al., 2010; Ettema \& Santos, 2004).

\subsection{Calving ease and dystocia}

The average calving ease showed differences between calf sexes $(\mathrm{P}<0.001)$, but there was no significant differentiation of semen type used within calf sex (Table 3 ).

Table 3. Calving ease for the interaction levels

\begin{tabular}{lrrrr}
\hline & $\mathrm{n}$ & $\mathrm{M}$ & $\mathrm{SD}$ & $\mathrm{SE}$ \\
\hline C_M & 14,680 & $1.41^{\mathrm{a}}$ & 0.61 & 0.005 \\
C_F & 16,535 & $1.26^{\mathrm{b}}$ & 0.50 & 0.004 \\
S_M & 2,671 & $1.42^{\mathrm{a}}$ & 0.61 & 0.012 \\
S_F & 18,824 & $1.25^{\mathrm{b}}$ & 0.48 & 0.004 \\
\hline
\end{tabular}

conventional semen $\times$ male calves $\left(C_{-} M\right)$, conventional semen $\times$ female calves $\left(C_{-}\right.$F), sexed semen $\times$ male calves $\left(S_{-} M\right)$, sexed semen $\times$ female calves $\left(S_{-}\right.$F $)$.

${ }^{a-b}$ Means with different superscripts $\operatorname{differ}(\mathrm{P}<0.001)$.

The same observation applies to dystocia rates (Table 4 and 5). Male calves caused a higher risk for dystocia than female calves $(\mathrm{P}<0.001)$. The semen type again had no influence on this characteristic. 
Table 4. Incidence of dystocia for the interaction levels

\begin{tabular}{lrcr}
\hline & \multicolumn{3}{c}{ Dystocia } \\
\cline { 2 - 4 } & $0^{1}$ & $1^{1}$ & Rate \\
\hline C_M & 13,786 & 894 & $0.061^{\mathrm{a}}$ \\
C_F & 16,125 & 410 & $0.025^{\mathrm{b}}$ \\
S_M & 2,521 & 150 & $0.056^{\mathrm{a}}$ \\
S_F & 18,419 & 405 & $0.022^{\mathrm{bc}}$ \\
\hline
\end{tabular}

conventional semen $\times$ male calves $\left(C_{-}\right.$M), conventional semen $\times$female calves (C_F), sexed semen $\times$ male calves $\left(\mathrm{S} \_\mathrm{M}\right)$, sexed semen $\times$ female calves $\left(\mathrm{S} \_\mathrm{F}\right)$.

${ }^{1} 0$ : calving ease score 1 and 2 (no dystocia); 1 : calving ease score 3 and 4 (dystocia).

${ }^{\mathrm{a}-\mathrm{c}}$ Rates with different superscripts $\operatorname{differ}(\mathrm{P}<0.001)$.

Table 5. Logit model of the dystocia rates

\begin{tabular}{lccr}
\hline & Odds Ratio & $\begin{array}{r}\text { Lower bound } \\
95 \% \text { CI }\end{array}$ & $\begin{array}{r}\text { Upper bound } \\
95 \% \text { CI }\end{array}$ \\
\hline C_M & 1.00 & 0.93 & 1.07 \\
C_F & 0.39 & 0.35 & 0.44 \\
S_M & 0.92 & 0.77 & 1.09 \\
S_F & 0.34 & 0.30 & 0.38 \\
\hline conventional semen $\times$ male calves (C_M), conventional semen $\times$ female calves (C_F), \\
sexed semen $\times$ male calves (S_M), sexed semen $\times$ female calves (S_F). \\
Confidence interval (CI).
\end{tabular}

Due to the larger size of bull calves at birth, they showed higher calving ease scores compared with female calves and had a larger incidence of difficult births (Gregory, Cundiff, \& Koch, 1991). The detected scores are in agreement with other studies for both traits. Tubman et al. (2004) reported least squares means of 1.15 for female calves and 1.30 for males regarding the calving ease.

Norman et al. (2010) showed dystocia rates of $8.0 \%$ to $9.0 \%$ for males in comparison to $4.0 \%$ for female calves.

\subsection{Stillbirth rate}

The stillbirth rates for female calves were 5.0\%, independent of the semen preparation. $13.4 \%$ male calves out of conventional semen were born dead or died within 48 hours 
after birth. However, the stillbirth rate for male calves from sexed semen was $30.6 \%$, which is higher than for the other interaction levels $(\mathrm{P}<0.001)$ (Table 6).

Table 6. Incidence of stillbirths for the interaction levels

\begin{tabular}{lrrr}
\hline & \multicolumn{3}{c}{ Stillbirth } \\
\cline { 2 - 4 } & $0^{1}$ & $1^{1}$ & Rate \\
\hline C_M & 13,502 & 2,083 & $0.134^{\mathrm{b}}$ \\
C_F & 16,521 & 868 & $0.050^{\mathrm{c}}$ \\
S_M & 2,033 & 897 & $0.306^{\mathrm{a}}$ \\
S_F & 18,675 & 975 & $0.050^{\mathrm{c}}$ \\
\hline
\end{tabular}

conventional semen $\times$ male calves $\left(C_{-}\right.$M), conventional semen $\times$female calves $\left(C_{-}\right.$F), sexed semen $\times$ male calves $\left(S_{-} M\right)$, sexed semen $\times$ female calves $\left(S_{-}\right.$F $)$.

${ }^{1} 0$ : born alive; 1 : born dead or died within the first $48 \mathrm{~h}$.

${ }^{\mathrm{a}-\mathrm{c}}$ Rates with different superscripts differ $(\mathrm{P}<0.001)$.

The respective logit model (Table 7) showed an odds ratio of 2.86 for the probability of a stillbirth of male calves from sexed semen in comparison to male calves from conventional semen.

Table 7. Logit model of the stillbirth rates

\begin{tabular}{lcrr}
\hline & Odds ratio & $\begin{array}{r}\text { Lower bound } \\
95 \% \text { CI }\end{array}$ & $\begin{array}{r}\text { Upper bound } \\
95 \% \text { CI }\end{array}$ \\
\hline C_M & 1.00 & 0.96 & 1.05 \\
C_F & 0.34 & 0.31 & 0.37 \\
S_M & 2.86 & 2.61 & 3.13 \\
S_F & 0.34 & 0.31 & 0.37 \\
\hline
\end{tabular}

conventional semen $\times$ male calves $\left(\mathrm{C}_{-} \mathrm{M}\right)$, conventional semen $\times$ female calves $\left(\mathrm{C}_{-} \mathrm{F}\right)$, sexed semen $\times$ male calves $\left(S_{-} M\right)$, sexed semen $\times$ female calves $\left(S_{-}\right.$F).

The incidence of female stillborn calves was relatively low for both semen types, namely only half the average described in other studies (Borchersen \& Peacock, 2009; DeJarnette et al., 2009; Norman et al., 2010). DeJarnette et al. (2009) found an influence of herd, season of calving and sire within semen type on female stillbirth rate. 
For male calves from conventional semen, the rate was comparable to literature (DeJarnette et al., 2009; Norman et al., 2010). However, the frequency of stillborn male calves from sexed semen was strikingly high. DeJarnette et al. (2009) and Norman et al. (2010) had already shown an obvious tendency for greater stillbirth rates of male calves born from sexed semen. They found rates of 15.6\% (Norman et al., 2010) and 20.0\% (DeJarnette et al., 2009) stillborn male calves, respectively. The current study presents an even higher incidence. The cause for this phenomenon was not identified so far. In 2009, DeJarnette et al. speculated about an aneuploidy among Y-bearing chromosomes. Non-disjunctions lead to a triple set of chromosomes. Because of these numerical chromosome aberrations, Y-bearing aneuploidic sperm will show a higher DNA content and therefore may be wrongly assigned during the sorting process. The XYY-trisomy and the Klinefelter's syndrome (XXY-trisomy) are the most known human gonosomal trisomies, but human individuals with these diseases are usually viable (Jacobs \& Strong, 1959; Ross et al., 2012), whereas individuals with autosomal trisomies are not. These autosomal chromosomal disorders increase the risk of human neonatal mortality (Alberman \& Creasy, 1977; Cereda \& Carey, 2012). Consequently, autosomal trisomies are likely the cause of greater stillbirth rates of male calves born from sexed semen.

For cattle, there are not enough data available to prove this hypothesis.

Furthermore, the number of male calves from sexed semen is relatively low in general. With more than 2,900 male calves born out of sexed semen, the current study achieved an adequate size of data set to demonstrate that this is a true effect.

Norman et al. (2010) did not only evaluate stillbirth rates among calves born from Holstein heifers, but also stillbirth incidences of calves born from cows. This analysis led to an opposite result. The male calves born from sexed semen were less frequently stillborn $(2.6 \%)$ than the male calves from conventional semen $(3.6 \%)$. The field study of Borchersen and Peacock (2009) showed a significantly increased incidence of stillbirths for male calves born from conventional semen $(20.0 \%)$ in comparison to male calves from sexed semen (14.0\%). Tubman et al. (2004) reported nonsignificant differences of male and female stillbirth rates.

Thus, differences in management and data recording should be considered to evaluate these partly divergent results. The monetary value of male dairy calves may also play a role for the reporting of stillbirths. 
In future studies, attention should be paid to autopsies and cytogenetic investigations of stillborn male calves to examine the biological source of this phenomenon. Furthermore, a pedigree analysis of the sires used may be of interest.

\subsection{Interval from calving to first service}

The length of the interval from calving to first service differed slightly between the sexes of the calves: the interval was longer after birth of male calves (Table 8).

Table 8. Interval from calving to first service (days) for the interaction levels

\begin{tabular}{lrrrrr}
\hline & $\mathrm{n}$ & $\mathrm{M}$ & SD & SE & MED \\
\hline C_M & 10,607 & $82.9^{\mathrm{a}}$ & 32.7 & 0.3 & 76 \\
C_F & 11,828 & $81.0^{\mathrm{b}}$ & 31.3 & 0.3 & 74 \\
S_M & 1,907 & $82.1^{\mathrm{ab}}$ & 31.1 & 0.7 & 76 \\
S_F & 13,287 & $80.6^{\mathrm{b}}$ & 31.2 & 0.3 & 74 \\
\hline
\end{tabular}

conventional semen $\times$ male calves $\left(C_{-} M\right)$, conventional semen $\times$ female calves $\left(C_{-}\right.$F), sexed semen $\times$ male calves $\left(S_{-} M\right)$, sexed semen $\times$ female calves $\left(S_{-}\right.$F) .

${ }^{a-b}$ Means with different superscripts differ $(\mathrm{P}<0.001)$.

A correlation between higher dystocia and stillbirth rates of male calves and lower reproductivity of the dam in first lactation might be possible. Again, there was no difference between semen types.

\subsection{Non-return rate}

The results for this characteristic were not distinct enough and applied for 56- and 90day non-return rates. Heifers with calvings from sexed semen showed slightly increased non-return rates in first lactation, but differences did exist for the interaction levels c_m and s_f only $(\mathrm{P}<0.001)$. Differences between calf sexes were found, if conventional semen was used $(\mathrm{P}<0.01)$ (Table 9). 
Table 9. Incidence of non-return for the interaction levels within first lactation

\begin{tabular}{lrrrrrrr}
\hline & \multicolumn{2}{c}{ Non-return 56 days } & & \multicolumn{3}{c}{ Non-return 90 days } \\
\cline { 2 - 4 } \cline { 5 - 7 } & $0^{1}$ & $1^{1}$ & Rate & & $0^{1}$ & $1^{1}$ & Rate \\
\hline C_M & 4,232 & 6,297 & $0.598^{\mathrm{b}}$ & & 4,882 & 5,326 & $0.522^{\mathrm{b}}$ \\
C_F & 4,422 & 7,263 & $0.622^{\mathrm{ac}}$ & & 5,167 & 6,170 & $0.544^{\mathrm{ac}}$ \\
S_M & 706 & 1,184 & $0.626^{\mathrm{ab}}$ & & 836 & 989 & $0.542^{\mathrm{ab}}$ \\
S_F & 4,812 & 8,157 & $0.624^{\mathrm{a}}$ & & 5,715 & 7,001 & $0.551^{\mathrm{a}}$ \\
\hline
\end{tabular}

conventional semen $\times$ male calves $\left(C_{-}\right.$M), conventional semen $\times$female calves (C_F),

sexed semen $\times$ male calves $($ S_M $)$, sexed semen $\times$ female calves $($ S_F $)$.

${ }^{1} 0$ : Return; 1: Non-return.

${ }^{\mathrm{a}-\mathrm{c}}$ Rates with different superscripts $\operatorname{differ}(\mathrm{P}<0.01)$.

\subsection{Number of services in first lactation}

Same as for calving to first service interval applies for the number of services in first lactation. The higher averaged numbers of insemination after birth of male calves could be caused by problems during parturition. However, the differences between the numbers of services are negligible (Table 10).

Table 10. Number of services for the interaction levels in first lactation

\begin{tabular}{lrrrr}
\hline & $\mathrm{n}$ & $\mathrm{M}$ & $\mathrm{SD}$ & $\mathrm{SE}$ \\
\hline C_M & 10,094 & $2.04^{\mathrm{a}}$ & 1.45 & 0.01 \\
C_F & 11,217 & $1.95^{\mathrm{b}}$ & 1.38 & 0.01 \\
S_M & 1,797 & $1.98^{\mathrm{ab}}$ & 1.47 & 0.04 \\
S_F & 12,619 & $1.91^{\mathrm{c}}$ & 1.32 & 0.01 \\
\hline
\end{tabular}

conventional semen $\times$ male calves $\left(C_{-} M\right)$, conventional semen $\times$ female calves $\left(C_{-} F\right)$, sexed semen $\times$ male calves $\left(S_{-}\right.$M $)$, sexed semen $\times$female calves $\left(S_{-}\right.$F $)$.

${ }^{\mathrm{a}-\mathrm{c}}$ Means with different superscripts $\operatorname{differ}(\mathrm{P}<0.05)$.

\subsection{Lactation performance, milk, fat and protein yield}

There were no differences between calf sex within semen type. However, the lactation performance between semen types differed. The extrapolated 305-day milk yield was $200 \mathrm{~kg}$ lower for first calf heifers which were inseminated with sexed semen compared to heifers inseminated with conventional semen (Table 11). 
Table 11. Milk yield (kg) for the interaction levels in first lactation

\begin{tabular}{lrrrrr}
\hline & $\mathrm{n}$ & $\mathrm{M}$ & $\mathrm{SD}$ & $\mathrm{SE}$ & $\mathrm{MED}$ \\
\hline C_M & 9,184 & $8,658^{\mathrm{a}}$ & 1,408 & 15 & 8,618 \\
C_F & 10,286 & $8,656^{\mathrm{a}}$ & 1,382 & 14 & 8,625 \\
S_M & 1,685 & $8,456^{\mathrm{b}}$ & 1,421 & 35 & 8,418 \\
S_F & 11,563 & $8,487^{\mathrm{b}}$ & 1,362 & 13 & 8,434 \\
\hline
\end{tabular}

conventional semen $\times$ male calves $\left(C_{-} M\right)$, conventional semen $\times$ female calves $\left(C_{-} F\right)$,

sexed semen $\times$ male calves $\left(S_{-} M\right)$, sexed semen $\times$ female calves $\left(S \_F\right)$.

${ }^{\mathrm{a}-\mathrm{b}}$ Means with different superscripts differ $(\mathrm{P}<0.001)$.

Fat and protein yield were $6 \mathrm{~kg}$ to $8 \mathrm{~kg}$ lower after use of sexed semen (Table 12 and 13).

Table 12. Fat yield $(\mathrm{kg})$ for the interaction levels in first lactation

\begin{tabular}{lrrrrr}
\hline & $\mathrm{n}$ & $\mathrm{M}$ & $\mathrm{SD}$ & SE & MED \\
\hline C_M & 9,184 & $338.2^{\mathrm{a}}$ & 50.5 & 0.5 & 337.3 \\
C_F & 10,286 & $339.1^{\mathrm{a}}$ & 50.6 & 0.5 & 338.1 \\
S_M & 1,685 & $331.1^{\mathrm{b}}$ & 51.9 & 1.2 & 329.5 \\
S_F & 11,563 & $331.6^{\mathrm{b}}$ & 49.2 & 0.5 & 330.9 \\
\hline
\end{tabular}

conventional semen $\times$ male calves $\left(C_{-} M\right)$, conventional semen $\times$ female calves (C_F),

sexed semen $\times$ male calves $\left(\mathrm{S} \_\mathrm{M}\right)$, sexed semen $\times$ female calves $\left(\mathrm{S} \_\mathrm{F}\right)$.

${ }^{a-b}$ Means with different superscripts $\operatorname{differ}(\mathrm{P}<0.001)$.

Table 13. Protein yield $(\mathrm{kg})$ for the interaction levels in first lactation

\begin{tabular}{lrrrrr}
\hline & $\mathrm{n}$ & $\mathrm{M}$ & SD & SE & MED \\
\hline C_M & 9,184 & $289.6^{\mathrm{a}}$ & 45.0 & 0.5 & 289.4 \\
C_F & 10,286 & $289.9^{\mathrm{a}}$ & 44.2 & 0.4 & 289.4 \\
S_M & 1,685 & $282.5^{\mathrm{b}}$ & 45.6 & 1.1 & 280.3 \\
S_F & 11,563 & $283.7^{\mathrm{b}}$ & 43.4 & 0.4 & 283.3 \\
\hline
\end{tabular}

conventional semen $\times$ male calves $\left(C_{-} M\right)$, conventional semen $\times$ female calves $\left(C_{-} F\right)$,

sexed semen $\times$ male calves $\left(S_{-} M\right)$, sexed semen $\times$ female calves $\left(S_{-}\right.$F $)$.

${ }^{\mathrm{a}-\mathrm{b}}$ Means with different superscripts differ $(\mathrm{P}<0.001)$.

As mentioned above, the age at first calving was lower after insemination with sexed semen, which may affect lactation performance. It should be mentioned that the records 
were not adjusted for age. Environmental and management influences should also be considered as possible effects on milk, fat and protein yield.

\subsection{Survival rates within first lactation}

The animals with female offspring from sexed semen showed higher survival rates than the other groups $(\mathrm{P}<0.001) .88 .0 \%$ of these heifers were still in production 400 days after calving (in comparison to c_m: 85.4\%; c_f: 86.5\%; s_m: 86.0\%) (Figure 1).

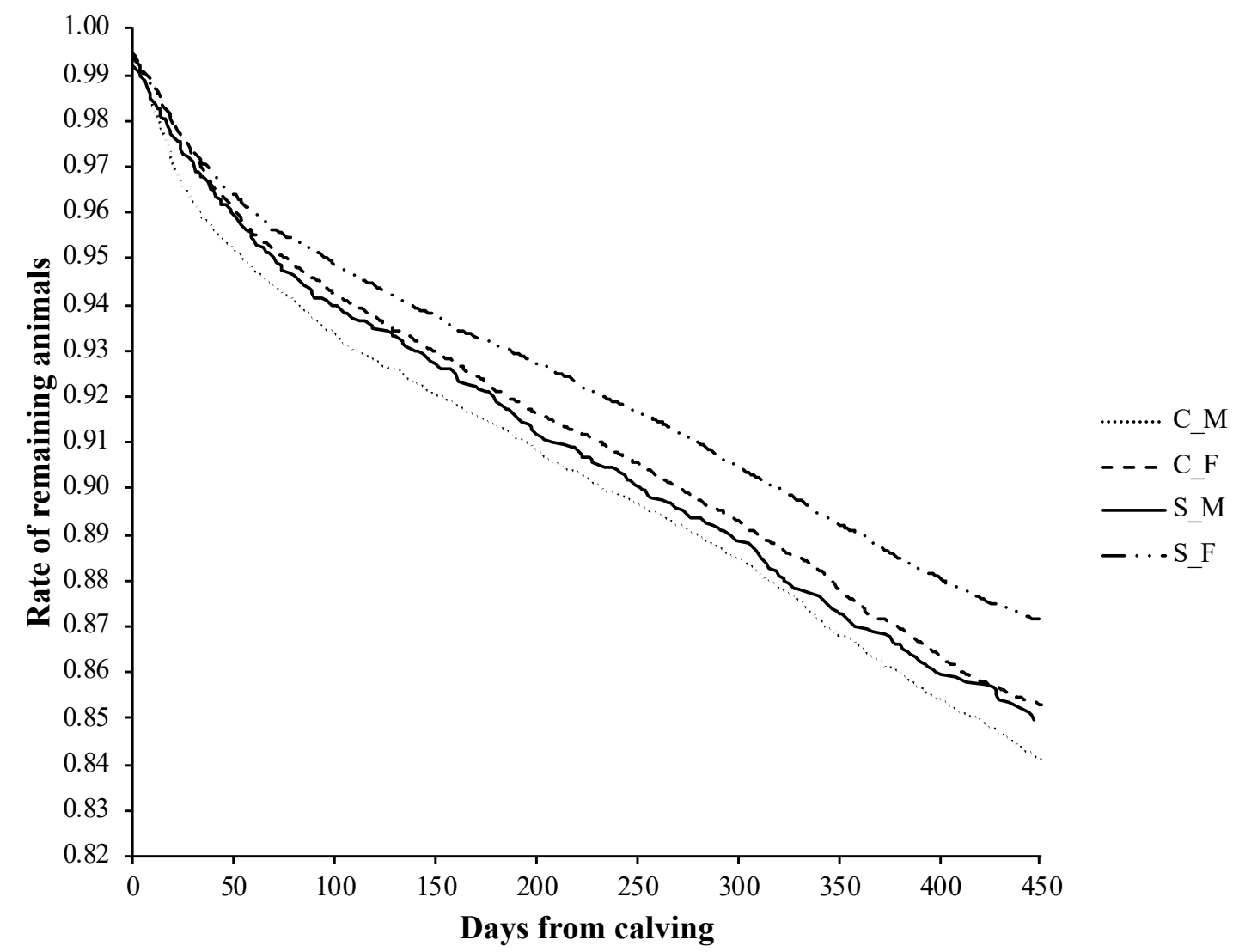

Figure 1. Kaplan-Meier estimators of survival rates within first lactation.

conventional semen $\times$ male calves $\left(C_{-} M\right)$, conventional semen $\times$ female calves $\left(C_{-} F\right)$, sexed semen $\times$ male calves $\left(S_{-}\right.$M) , sexed semen $\times$female calves $\left(S_{-}\right.$F) .

The higher survival rates of heifers with female calves from sexed semen can probably be attributed to better health characteristics and breeding values of these animals wherefore they had already been selected for sexed semen insemination. 


\section{Conclusions}

Sexed semen within the same calf sex had only minor effects on most traits, except for stillbirth rates: the stillbirth rate for male calves from sexed semen was 2.86 times the stillbirth rate of male calves from conventional semen. Further research is required to disclose the reasons for this finding. As mentioned above, autopsies and cytogenetic investigations should follow.

For all other traits analyzed, we showed that the type of semen plays a minor role for performances in first lactation. In future studies, possible interactions with the calving season or the sires used should be taken into account.

\section{Conflict of interest}

The authors declare that there is no conflict of interest.

\section{Acknowledgments}

The authors kindly acknowledge Masterrind and VOST for the provision of data.

\section{Funding}

The authors would like to thank the H. Wilhelm Schaumann Foundation and the Open Access Publication Funds of the Göttingen University for financial support.

\section{References}

ADR. (2017). ADR - Empfehlung 3.1; Leistungsprüfung für funktionale Merkmale bei Bullen und Kühen. Arbeitsgemeinschaft deutscher Rinderzüchter e.V., 1-10.

Alberman, E. D., \& Creasy, M. R. (1977). Frequency of chromosomal abnormalities in miscarriages and perinatal deaths. Journal of Medical Genetics, 14(5), 313-315. https://doi.org/10.1136/jmg.14.5.313

Asma-ul-Husna, Awan, M. A., Mehmood, A., Sultana, T., Shahzad, Q., Ansari, M. S., Akhter, S. (2017). Sperm sexing in Nili-Ravi buffalo through modified swim up: Validation using SYBR ® green real-time PCR. Animal Reproduction Science, 182, 69-76. https://doi.org/10.1016/j.anireprosci.2017.04.011

Borchersen, S., \& Peacock, M. (2009). Danish A.I. field data with sexed semen. Theriogenology, 71(1), 59-63. 
https://doi.org/10.1016/j.theriogenology.2008.09.026

Cereda, A., \& Carey, J. C. (2012). The trisomy 18 syndrome. Orphanet Journal of Rare Diseases, 7(1), 81. https://doi.org/10.1186/1750-1172-7-81

Chebel, R. C., Guagnini, F. S., Santos, J. E. P., Fetrow, J. P., \& Lima, J. R. (2010). Sexsorted semen for dairy heifers: Effects on reproductive and lactational performances. Journal of Dairy Science, 93(6), 2496-2507. https://doi.org/10.3168/jds.2009-2858

DeJarnette, J. M., Nebel, R. L., \& Marshall, C. E. (2009). Evaluating the success of sexsorted semen in US dairy herds from on farm records. Theriogenology, 71(1), 4958. https://doi.org/10.1016/j.theriogenology.2008.09.042

DeJarnette, J. M., Nebel, R. L., Marshall, C. E., Moreno, J. F., McCleary, C. R., \& Lenz, R. W. (2008). Effect of sex-sorted sperm dosage on conception rates in holstein heifers and lactating cows. Journal of Dairy Science, 91(5), 1778-1785. https://doi.org/10.3168/jds.2007-0964

Ettema, J. F., \& Santos, J. E. P. (2004). Impact of age at calving on lactation, reproduction, health, and income in first-parity Holsteins on commercial farms. Journal of Dairy Science, 87(8), 2730-2742. https://doi.org/10.3168/jds.S00220302(04)73400-1

Garner, D. L., Gledhill, B. L., Pinkel, D., Lake, S., Stephenson, D., Van Dilla, M. A., \& Johnson, L. A. (1983). Quantification of the X-and Y-Chromosome-Bearing Spermatozoa of Domestic Animals by Flow Cytometry. Biology of Reproduction, 28(2), 312-321. https://doi.org/10.1095/biolreprod28.2.312

Garner, D. L., \& Seidel, G. E. (2003). Past, present and future perspectives on sexing sperm. Canadian Journal of Animal Science, 83(3), 375-384. https://doi.org/10.4141/A03-022

Gledhill, B. L., Pinkel, D., Garner, D. L., \& Van Della, M. A. (1982). Identifying Xand Y-chromosome-bearing sperm by DNA content: retrospective perspectives and prospective opinions. In Prospects for Sexing Mammalian Sperm. Colorado Associated University Press, 177-191.

Gonzalez-Marin, C., Lenz, R. W., Gilligan, T. B., Evans, K. M., Gongora, C. E., Moreno, J. F., \& Vishwanath, R. (2016). SexedULTRA ${ }^{\mathrm{TM}}$, a new method of processing sex-sorted bovine sperm improves post-thaw sperm quality and in vitro fertility. Reproduction, Fertility and Development, 29, 204-205. https://doi.org/10.1071/rdv29n1ab191 
Gregory, K. E., Cundiff, L. V., \& Koch, R. M. (1991). Breed effects and heterosis in advanced generations of composite populations for birth weight, birth date, dystocia, and survival as traits of dam in beef cattle. Journal of Animal Science, 69(9), 3574-3589. https://doi.org/10.2527/1991.6993574x

Healy, A. A., House, J. K., \& Thomson, P. C. (2013). Artificial insemination field data on the use of sexed and conventional semen in nulliparous Holstein heifers. Journal of Dairy Science, 96(3), 1905-1914. https://doi.org/10.3168/jds.2012-5465

Hohenboken, W. D. (1999). Applications of sexed semen in cattle production. Theriogenology, 52(8), 1421-1433. https://doi.org/10.1016/s0093-691x(99)002277

Jacobs, P. A., \& Strong, J. A. (1959). A case of human intersexuality having a possible XXY sex-determining mechanism. Nature, 183(4657), 302-303. https://doi.org/10.1038/183302a0

Joezy-Shekalgorabi, S., Shadparvar, A. A., de Vries, A., \& Gay, K. D. (2014). The extent of increase in first calving age as a result of implementing various sexed semen breeding strategies. Spanish Journal of Agricultural Research, 12(1), 106116. https://doi.org/10.5424/sjar/2014121-4516

Johnson, L. A., Flook, J. P., \& Look, M. V. (1987). Flow cytometry of X and Y chromosome-bearing sperm for DNA using an improved preparation method and staining with Hoechst 33342. Gamete Research, 17(3), 203-212. https://doi.org/10.1002/mrd.1120170303

Johnson, L. A., Welch, G. R., \& Rens, W. (1999). The Beltsville sperm sexing technology: high-speed sperm sorting gives improved sperm output for in vitro fertilization and AI. Journal of Animal Science, 77 Suppl 2, 213-220.

Kaplan, E. L., \& Meier, P. (1958). Nonparametric estimation from incomplete samples. $J$. of the ASA, 53(282), 457-481. Retrieved from https://web.stanford.edu/ lutian/coursepdf/KMpaper.pdf

Kawarasaki, T., Welch, G. ., Long, C. ., Yoshida, M., \& Johnson, L. (1998). Verification of flow cytometorically-sorted X-and Y-bearing porcine spermatozoa and reanalysis of spermatozoa for DNA content using the fluorescence in situ hybridization (FISH) technique. Theriogenology, 50(4), 625-635. https://doi.org/10.1016/S0093-691X(98)00167-8

Lenz, R. W., Gonzalez-Marin, C., Gilligan, T. B., DeJarnette, J. M., Utt, M. D., Helser, L. A., Vishwanath, R. (2016). SexedULTRA ${ }^{\mathrm{TM}}$, a new method of processing sex- 
sorted bovine sperm improves conception rates. Reproduction, Fertility and Development, 29(1), 203-204. https://doi.org/10.1071/RDv29n1Ab190

Mallory, D. A., Lock, S. L., Woods, D. C., Poock, S. E., \& Patterson, D. J. (2013). Hot topic: Comparison of sex-sorted and conventional semen within a fixed-time artificial insemination protocol designed for dairy heifers. Journal of Dairy Science, 96(2), 854-856. https://doi.org/10.3168/jds.2012-5850

McCullock, K., Hoag, D. L. K., Parsons, J., Lacy, M., Seidel, G. E., \& Wailes, W. (2013). Factors affecting economics of using sexed semen in dairy cattle. Journal of Dairy Science, 96(10), 6366-6377. https://doi.org/10.3168/jds.2013-6672

Morrell, J., Keeler, K., Noakes, D., Mackenzie, N., \& Dresser, D. (1988). Sexing of sperm by flow cytometry. Veterinary Record, 122(14), 322-324. https://doi.org/10.1136/vr.122.14.322

Moruzzi, J. F. (1979). Selecting a mammalian species for the separation of X- and Ychromosome-bearing spermatozoa. Journal of Reproduction and Fertility, 57(2), 319-323. https://doi.org/10.1530/jrf.0.0570319

Norman, H. D., Hutchison, J. L., \& Miller, R. H. (2010). Use of sexed semen and its effect on conception rate, calf sex, dystocia, and stillbirth of Holsteins in the United States. Journal of Dairy Science, 93(8), 3880-3890. https://doi.org/10.3168/jds.2009-2781

Pinkel, D., Lake, S., Gledhill, B. L., Van Dilla, M. A., Stephenson, D., \& Watchmaker, G. (1982). High resolution DNA content measurements of mammalian sperm. Cytometry, 3(1), 1-9. https://doi.org/10.1002/cyto.990030103

Rath, D., Barcikowski, S., Graaf, S. De, Garrels, W., Grossfeld, R., Klein, S., Washausen, S. (2013). Sex selection of sperm in farm animals: Status report and developmental prospects. Reproduction, 145(1), 15-30. https://doi.org/10.1530/REP-12-0151

Ross, J. L., Roeltgen, D. P., Kushner, H., Zinn, A. R., Reiss, A., Bardsley, M. Z., Tartaglia, N. (2012). Behavioral and Social Phenotypes in Boys With 47,XYY Syndrome or 47,XXY Klinefelter Syndrome. Pediatrics, 129(4), 769-778. https://doi.org/10.1542/peds.2011-0719

Schenk, J. L., Cran, D. G., Everett, R. W., \& Seidel, G. E. (2009). Pregnancy rates in heifers and cows with cryopreserved sexed sperm: Effects of sperm numbers per inseminate, sorting pressure and sperm storage before sorting. Theriogenology, 71(5), 717-728. https://doi.org/10.1016/j.theriogenology.2008.08.016 
Schenk, J. L., Suh, T. K., Cran, D. G., \& Seidel, G. E. (1999). Cryopreservation of flow-sorted bovine spermatozoa. Theriogenology, 52(8), 1375-1391. https://doi.org/10.1016/S0093-691X(99)00224-1

Seidel, G. E. (2002). Sexing sperm for beef and dairy cattle breeding. Factors Affecting Calf Crop: Biotechnology of Reproduction. CRC Press Inc. Boca Raton, FL, 281287.

Seidel, G. E. (2003). Sexing mammalian sperm—intertwining of commerce, technology, and biology. Animal Reproduction Science, 79(3-4), 145-156. https://doi.org/10.1016/S0378-4320(03)00162-3

Seidel, G. E. (2007). Overview of sexing sperm. Theriogenology, 68(3), 443-446. https://doi.org/10.1016/j.theriogenology.2007.04.005

Seidel, G. E. (2014). Update on sexed semen technology in cattle. Animal, 8(SUPPL. 1), 160-164. https://doi.org/10.1017/S1751731114000202

Seidel, G. E., \& Schenk, J. L. (2008). Pregnancy rates in cattle with cryopreserved sexed sperm: Effects of sperm numbers per inseminate and site of sperm deposition. Animal Reproduction Science, 105(1-2), 129-138. https://doi.org/10.1016/j.anireprosci.2007.11.015

Seidel, G. E., Schenk, J. L., Herickhoff, L. A., Doyle, S. P., Brink, Z., Green, R. D., \& Cran, D. G. (1999). Insemination of heifers with sexed sperm. Theriogenology, 52(8), 1407-1420. https://doi.org/10.1016/s0093-691x(99)00226-5

Thomas, J. M., Locke, J. W. C., Vishwanath, R., Hall, J. B., Ellersieck, M. R., Smith, M. F., \& Patterson, D. J. (2017). Effective use of SexedULTRA ${ }^{\mathrm{TM}}$ sex-sorted semen for timed artificial insemination of beef heifers. Theriogenology, 98, 88-93. https://doi.org/10.1016/j.theriogenology.2017.03.018

Tubman, L. M., Brink, Z., Suh, T. K., \& Seidel, G. E. (2004). Characteristics of calves produced with sperm sexed by flow cytometry/cell sorting. Journal of Animal Science, 82(4), 1029-1036. 


\subsection{Diskussion}

In der vorliegenden Studie wurde der Einsatz von gesextem Sperma unter Berücksichtigung des Kalbgeschlechts bei Holstein-Färsen in Niedersachsen untersucht.

Gesextes Sperma wird auf den Betrieben überwiegend für die erste und zweite Besamung eingesetzt, das spiegelten auch unsere Ergebnisse wider. Waren diese ersten Besamungen nicht erfolgreich, wurden die Folgebesamungen aufgrund geringerer Kosten und höherer Konzeptionsraten mit konventionellem Sperma durchgeführt (Schenk et al. 2009). Der Anteil weiblicher Kälber aus gesextem Sperma lag mit 87,0 \% im erwartenden Rahmen. Mit 52,7 \% wurden mehr weibliche als männliche Kälber aus konventionellem Sperma geboren. Andere Studien berichteten von einem umgekehrten Verhältnis mit einem höheren Anteil der Geburten männlicher Kälber (Tubman et al. 2004; DeJarnette et al. 2009; Norman et al. 2010). Hier könnte in unserer Studie eine leichte Datenverzerrung vorliegen. Weibliche Kälber sind von höherem Wert für den Landwirt und werden deshalb bei der korrekten Meldung der Kalbedaten stärker berücksichtigt.

Das Kalbgeschlecht wirkte sich in unserer Untersuchung auf einige funktionale Merkmale aus. So zeigten sich bei der Geburt männlicher Kälber, wie auch schon in anderen Studien berichtet (Tubman et al. 2004; Norman et al. 2010), schwierigere Kalbeverläufe und damit verbunden auch höhere Schwergeburtenraten. Männliche Kälber sind bei der Geburt oft größer als weibliche Kälber, dies kann sich negativ auf den Geburtsverlauf auswirken (Gregory et al. 1991). Es zeigte sich nach Geburten männlicher Kälber ein längeres Intervall von der Kalbung bis zur ersten Besamung, was wiederum in Verbindung zu den schwierigeren Geburten steht.

Die Art des eingesetzten Spermas wirkte sich ebenfalls auf einige Merkmale aus. Färsen, die mit gesextem Sperma besamt wurden, zeigten ein um 43 bis 48 Tage geringeres Erstkalbealter als Färsen, die mit konventionellem Sperma besamt wurden. Dieses Ergebnis passt zu dem Fakt, das gesextes Sperma hauptsächlich für die ersten Besamungen eingesetzt wird und die Färsen dann bei erfolgreicher Aufnahme aus der ersten oder zweiten Besamung zum Zeitpunkt der Kalbung jünger sind, als Färsen, die aus der dritten oder vierten Besamung kalben.

Das geringere Erstkalbealter kann ebenfalls einen Effekt auf die Leistungen in der ersten Laktation haben. Die Färsen mit Kalbungen aus gesextem Sperma zeigten etwas geringere Leistungen. Die hochgerechnete 305-Tage-Leistung ergab eine um $200 \mathrm{~kg}$ 
geringere Milchleistung der Färsen, die aus gesextem Sperma gekalbt haben im Vergleich zu den Färsen mit Kalbungen aus konventionellem Sperma. Die Fett- und Proteinleistungen fielen 6 bzw. $8 \mathrm{~kg}$ geringer aus. Es ist hier aber zu beachten, dass die durchgeführten Untersuchungen nicht altersbereinigt sind. Außerdem müssen auch Umwelt- und Managementeffekte bei der Beurteilung der Laktationsleistung berücksichtigt werden.

Ein besonderes Augenmerk muss in der vorliegenden Studie allerdings auf die Ergebnisse der Totgeburtenraten gelegt werden. Als Totgeburt wurden, nach der Empfehlung der Arbeitsgemeinschaft Deutscher Rinderzüchter (ADR), alle tot geborenen und innerhalb von 48 Stunden nach der Geburt verendeten Kälber erfasst (ADR 2017). Bei den weiblichen Kälbern lagen die Totgeburtenraten für beide Spermaarten bei $5 \%$ und fielen damit im Vergleich zu anderen Studien relativ gering aus (Borchersen \& Peacock 2009; DeJarnette et al. 2009; Norman et al. 2010). Die Raten der männlichen Kälber lagen insgesamt höher. Männliche Kälber aus konventionellem Sperma zeigten eine Rate von 13,4 \%, wohingegen auffallend viele, nämlich 30,6 \%, der männlichen Kälber aus Sperma, das für X-chromosomale Spermien sortiert wurde, tot geboren wurden. Aus dem dazugehörigen Logit-Modell ergab sich eine 2,86-fach erhöhte geschätzte Wahrscheinlichkeit für eine Totgeburt von männlichen Kälbern aus gesextem Sperma gegenüber männlichen Kälbern aus konventionellem Sperma. Die Totgeburtenrate der männlichen Kälber aus konventionellem Sperma ist vergleichbar mit den Angaben in der Literatur (DeJarnette et al. 2009; Norman et al. 2010). Dahingegen ist der Anteil der totgeborenen Bullenkälber aus X-chromosomal gesextem Sperma sehr viel höher, als bisher in der Literatur beschrieben. DeJarnette et al. (2009) und Norman et al. (2010) haben in ihren Feldversuchen mit Färsen Raten von 20,0 \% bzw. 15,6 \% ermittelt und damit aber ebenfalls schon die gleiche Tendenz für gesteigerte Totgeburtenraten männlicher Kälber aus X-chromosomal gesextem Sperma aufgezeigt. Schon DeJarnette et al. (2009) vermuteten aneuploide Y-Chromosom-tragende Spermien als Ursache.

Eine Aneuploidie ist eine Genommutation, bei der einzelne Chromosomen zusätzlich zum üblichen Chromosomensatz vorhanden sind oder fehlen (Hassold 1986; Hassold \& Hunt 2001). Sie tritt auf, wenn sich während der Meiose die homologen Chromosomen nicht voneinander trennen. Diese sogenannten Non-Disjunctions können sowohl während der ersten als auch während der zweiten meiotischen Teilung auftreten. So kann dann eine Keimzelle zu viele oder zu wenige Chromosomen enthalten und es kommt bei 
der Befruchtung zu einer numerischen Chromosomenaberration, entweder in Form einer Trisomie oder einer Monosomie. Im vorliegenden Fall könnte es während der Durchflusszytometrie zu einer fehlerhaften Selektion durch einen fälschlich höheren DNAGehalt der Y-Chromosom-tragenden Spermien kommen. Die Monosomie kann somit als Ursache ausgeschlossen werden, zumal Monosomien auch meist im Embryonaloder Fetalstadium letal sind (Hassold 1986).

Es bleiben also Trisomien als mögliche Ursache. Zu den gonosomalen Trisomien gehören z.B. die XYY-Trisomie oder das Klinefelter-Syndrom (XXY). Individuen mit so einer Erbkrankheit sind aber in der Regel lebensfähig (Jacobs \& Strong 1959; Ross et al. 2012). Bei autosomalen Trisomien ist hingegen die neonatale Sterblichkeit deutlich erhöht (Alberman \& Creasy 1977; Cereda \& Carey 2012). Folglich können autosomale Trisomien als Ursache für die erhöhten Totgeburtenraten der männlichen Kälber aus gesextem Sperma in Frage kommen. Trisomien sind bisher aber überwiegend im Humanbereich untersucht, für Rinder liegen hier nicht genügend Daten vor, um diese Hypothese tatsächlich bestätigen zu können. Weitere Studien sollten sich folglich auf Sektionen der männlichen Kälber und zytogenetische Untersuchungen konzentrieren, um so genetische Defekte oder sonstige Auffälligkeiten festzustellen. Unsere Studie hat die Felddaten von insgesamt 55554 Färsen analysiert, dabei sind 2930 männliche Kälber aus gesextem Sperma in die Untersuchung eingegangen, womit der Datensatz für die Ermittlung von Effekten eine adäquate Größenordnung besitzt. Trotzdem ist zu berücksichtigen, dass der Anteil der männlichen Kälber aus X-chromosomal gesextem Sperma insgesamt natürlich sehr gering ist, und somit die Gewährleistung für eine ausreichende Probenanzahl in Folgestudien erschwert.

Um chromosomale Auffälligkeiten festzustellen, könnte beispielsweise auch die Invitro-Produktion von Rinderembryonen Anwendung finden. Rinderoozyten könnten mit gesextem Sperma befruchtet werden, um nach der Kultivierung der Embryonen mittels Karyogrammen Aussagen über die Chromosomenausstattung zu treffen. Hier muss aber zunächst ebenfalls eine Vielzahl an Embryonen generiert werden, um männliche Embryonen aus weiblich gesextem Sperma zu erhalten und Effekte detektieren zu können.

Norman et al. (2010) haben nicht nur die Felddaten von Holstein-Färsen, sondern auch funktionale Merkmale von Kühen untersucht. Diese zeigten ein umgekehrtes Ergebnis für die Totgeburtenraten von Bullenkälbern. Die Raten der männlichen Kälber aus gesextem Sperma fielen im Vergleich zum konventionellem Sperma geringer aus (Norman 
et al. 2010), was auch mit den Ergebnissen von Borchersen \& Peacock (2009) übereinstimmt. Tubman et al. (2004) konnten in ihrer Untersuchung keine Unterschiede zwischen weiblichen und männlichen Totgeburtenraten feststellen. Deshalb sollten bei der Beurteilung der Daten ebenso Managementeffekte und mögliche Aufzeichnungsfehler berücksichtigt werden. Weibliche Kälber besitzen einen sehr viel höheren monetären Wert für den Landwirt und haben so eine höhere Priorität bei der Erstversorgung nach der Geburt. Auch eine verfälschte Meldung der Kalbedaten kann nicht ausgeschlossen werden.

Die eingesetzten Bullen wurden in unserer Analyse nicht berücksichtigt, in zukünftigen Studien sollte der Bulleneffekt aber mit in die Auswertung eingehen, dann wäre außerdem eine Pedigreeanalyse von Interesse. Seit 2011 wird zudem auch gesextes Sperma von genomisch selektierten Jungbullen in den Zuchtgebieten der Masterrind und des VOST eingesetzt. Ob sich deren schlechtere Fruchtbarkeitsleistungen möglicherweise ebenfalls auf die in unserer Studie untersuchten Merkmale ausgewirkt haben könnten, muss gesondert überprüft werden.

Der Datensatz stammt aus der Zuchtwertschätzung von 2015. Um Modifikationen der letzten Jahre, wie z.B. verbesserte Medienbedingungen durch die SexedULTRA ${ }^{\mathrm{TM}}$ Technologie, mit einzubeziehen, müssen aktuelle Daten der Zuchtwertschätzung analysiert werden. Falls die gesteigerten Totgeburtenraten, wie von uns vermutet, auf Fehler im Sortierprozess zurückzuführen sind, sind hier allerdings, zumindest für dieses Merkmal, keine Änderungen zu erwarten.

Die vorliegende Studie zeigte Effekte des Kalbgeschlechts auf den Kalbeverlauf und die Schwergeburtenrate. Die Art des eingesetzten Spermas war für die meisten funktionalen Merkmale und Produktionsmerkmale von untergeordneter Bedeutung. Allerdings waren die Totgeburtenraten der männlichen Kälber aus gesextem Sperma deutlich erhöht. Auch wenn der Anteil dieser totgeborenen männlichen Kälber bezogen auf die insgesamt geborenen Kälber aus gesextem Sperma sehr gering und damit ökonomisch nicht unbedingt von Bedeutung ist, berichteten auch schon andere Studien von den erhöhten Raten und es bedarf deshalb weiterer Forschung. 


\section{Einfluss eines ölfreien Kultursystems auf in vitro produzierte bo- vine Oozyten und Embryonen}

\subsection{Einleitung}

Erste Erkenntnisse zur IVP von Embryonen wurden bereits zum Ende des 19. Jahrhunderts bzw. zu Beginn des 20. Jahrhunderts gewonnen, als Untersuchungen zur Teilung von Zygoten und zu Unterschieden zwischen der In-vivo- und In-vitro-Befruchtung bei Säugetieren durchgeführt wurden (Schenk 1878; Pincus 1930; Pincus \& Enzmann 1932, 1935; Pincus \& Shapiro 1940). Diese bildeten die Grundlage für weitere Entwicklungsschritte, so dass im Jahr 1959 erstmalig lebende Nachkommen nach extrakorporaler Befruchtung erzeugt wurden (Chang 1959). Chang (1959) entnahm dafür ovulierte Oozyten und bereits kapazitierte Spermien aus Kaninchen und übertrug nach In-vitroFertilisation (IVF) die Embryonen in Empfängertiere. Die Spermienkapazitation wurde zu diesem Zeitpunkt schon als wichtige Voraussetzung für eine erfolgreiche Befruchtung beschrieben (Austin 1951; Chang 1951), konnte in vitro aber noch nicht durchgeführt werden. Dies gelang 1975 mit der Geburt von Kaninchen nach Fertilisation mit in vitro kapazitierten Spermien (Brackett \& Oliphant 1975). Die IVF von in vitro maturierten Rinderoozyten gelang zum ersten Mal 1977 (Iritani \& Niwa 1977). Das erste Kind wurde 1978 nach erfolgreicher IVF geboren (Steptoe \& Edwards 1978), das erste IVFKalb folgte im Jahr 1981 (Brackett et al. 1982).

Die IVP von Rinderembryonen wird heute sowohl in der Zucht, als auch in der Forschung angewendet. Die IVP ermöglicht beispielsweise in Kombination mit dem Ovum Pick-Up (OPU) eine erhöhte Effizienz bei der Erzeugung wertvoller Nachkommen, da von diesen eine größere Anzahl generiert werden kann. Auch das genetische Potenzial von präpuberalen Rindern kann durch die IVP genutzt und damit das Generationsintervall verkürzt und der Zuchtfortschritt erhöht werden (Hasler 1998; Faber et al. 2003; Geldermann 2005).

Für die Forschung ist die Gewinnung boviner Oozyten aus Schlachttierovarien und die sich anschließende IVP von Embryonen interessant, da somit günstiges Probenmaterial für vielfältige Fragestellungen bereitsteht (Thibier 2005). Darüber hinaus gilt der bovine Embryo auch als Modellorganismus für die Anwendung assistierter Reproduktionsbiotechnologien beim Menschen (Anderiesz et al. 2000; Wrenzycki et al. 2005). 
Allerdings ist es, trotz zahlreicher Modifikationen, noch nicht gelungen, die IVPBedingungen weiter an die Voraussetzungen in vivo anzupassen, so dass die Entwicklungsraten der in vitro produzierten Embryonen weit hinter den in vivo generierten Raten zurückbleiben (Wrenzycki \& Stinshoff 2013).

Die heutige IVP lässt sich in die drei methodischen Schritte In-vitro-Maturation (IVM), IVF und die In-vitro-Kultur (IVC) der Embryonen unterteilen (Bavister 1995). Die Teilschritte sind in Abbildung 1 schematisch dargestellt.

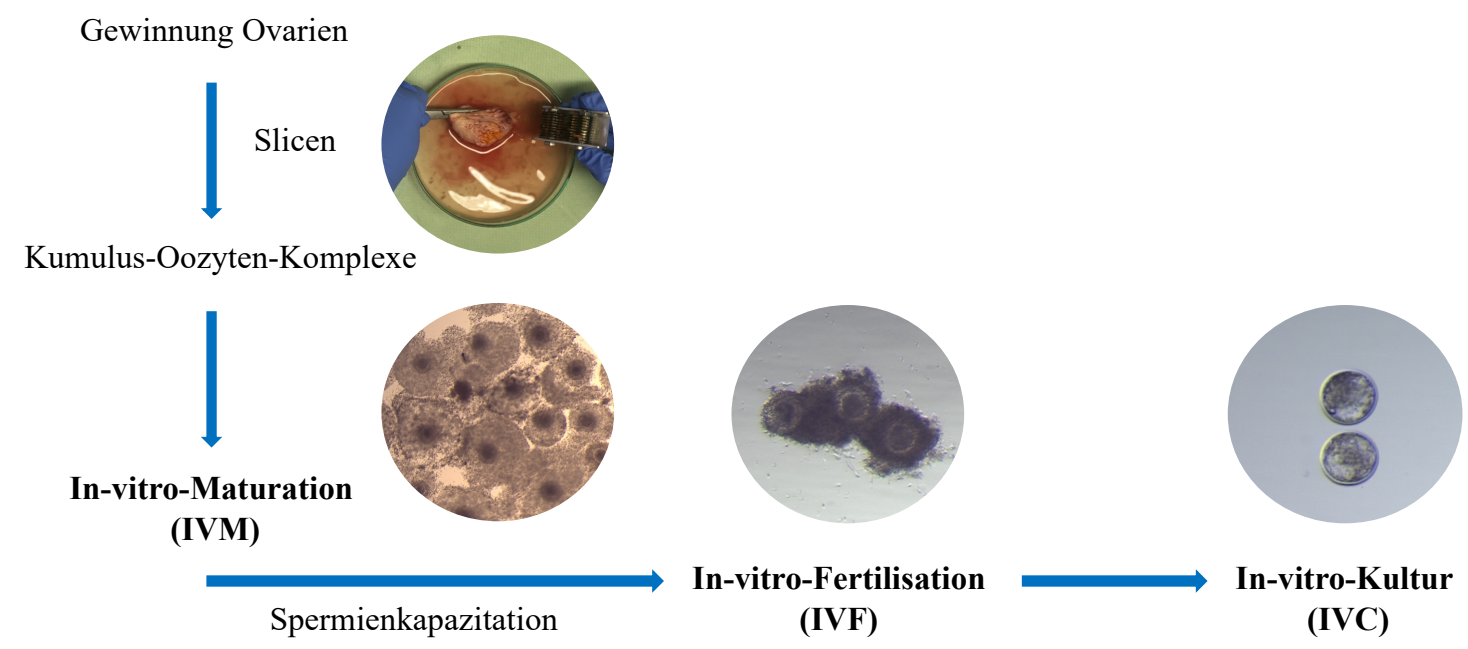

Abbildung 2: Schematische Darstellung der IVP boviner Embryonen aus Schlachthofovarien.

Die Kumulus-Oozyten-Komplexe (KOK) werden entweder über das OPU-Verfahren oder aus Schlachthofovarien mittels Aspiration oder durch die sogenannte SlicingMethode (Eckert \& Niemann 1995) gewonnen. Der KOK setzt sich aus der Oozyte und den sie umgebenen Kumuluszellen zusammen. Kumuluszellen und Oozyte stehen in engem metabolischen Kontakt zueinander. Der Stoffaustausch, welcher für die Entwicklung der Eizelle essentiell ist (Anderson \& Albertini 1976; Gilula et al. 1978; Simon et al. 1997), erfolgt über gap junctions und parakrine Wirkmechanismen (Anderson \& Albertini 1976; Gilula et al. 1978).

Für den Einsatz in der IVP werden die KOK morphologisch beurteilt und qualitativ selektiert (Pavlok et al. 1992).

In der IVM werden die KOK in ein Maturationsmedium überführt und reifen in der Regel für 24 Stunden im Inkubator (Abele et al. 2012). Über die Maturation erfolgt die Entwicklung der befruchtungsfähigen Oozyte, die IVM ist somit die Grundvorausset- 
zung für eine erfolgreiche IVP und wird im Folgenden genauer beschrieben, da auch in unseren Untersuchungen ein besonderes Augenmerk auf die durch die Maturation erworbene Entwicklungskompetenz der Oozyte gelegt wurde.

Die aus Antralfollikeln gewonnenen primären Oozyten sind in der 1. Reifeteilung arretiert. Während der Maturation erfolgt die Wiederaufnahme der 1. Reifeteilung durch den präovulatorischen LH-Anstieg (Edwards 1965; Sutton et al. 2003).

In vivo stellt der Hypothalamus den Ausgangspunkt für die Ausschüttung des Gonadotropin Releasing Hormons (GnRH) während der Follikelphase dar. Über die Adenohypophyse induziert GnRH die Sekretion des luteinisierenden Hormons (LH) und des follikelstimulierenden Hormons (FSH) (Clark et al. 1992; Kleine \& Rossmanith 2010). LH kann zwar sowohl von Theka- als auch von Granulosazellen gebunden werden, synthetisiert aber hauptsächlich über die Aktivierung von Enzymen Androgene in den Thekazellen, die dann in die Granulosazellen diffundieren und dort weiter zu Östrogenen synthetisiert werden. FSH wirkt hingegen direkt auf die Granulosazellen, welche die Östrogenproduktion vorantreiben (Moon et al. 1978). Während der Follikelphase werden durch den Anstieg der Östrogenproduktion und unter Einfluss von FSH vermehrt LH-Rezeptoren auf den Granulosazellen gebildet (Erickson et al. 1979). Die erhöhte Östrogenproduktion in der späten Follikelphase führt zu einer positiven Rückkopplung auf die Adenohypophyse und damit verbunden $\mathrm{zu}$ einer verstärkten GnRHAusschüttung aus der schließlich der präovulatorische LH-Peak resultiert (Moenter et al. 1990). Bis zur Ovulation findet in der Follikelflüssigkeit ein Wechsel von der Östrogen- zur Progesterondominanz statt (Dieleman et al. 1983).

Unter Abschnürung des 1. Polkörperchens entsteht die sekundäre Oozyte. Während der Ovulation tritt die Oozyte in die 2. Reifeteilung ein und wird im Stadium der Metaphase II erneut arretiert (Schnorr \& Kressin 2001; Sutton et al. 2003).

In der Reifeperiode der Oozyte findet sowohl die nukleäre Reifung mit der Reduktion des diploiden Chromosomensatzes als auch die damit verbundene zytoplasmatische Reifung mit molekularen und strukturellen Veränderungen der Oozyte statt (Gosden \& Lee 2010). Die Fähigkeit zur Maturation korreliert mit der Größe der Antralfollikel bzw. der Größe der Oozyte (Wickramasinghe \& Albertini 1993).

Parallel zur Oozytenreifung findet die Kumlusexpansion statt. Die Kumuluszellen bilden eine viskoelastische Matrix, die hauptsächlich aus Hyaluron besteht (Salustri et al. 1989), was zu einer abnehmenden Kommunikation zwischen Kumulus und Oozyte führt (Larsen et al. 1986). 
In vitro ist es bisher nicht gelungen, mit der Zusammensetzung des Maturationsmediums die In-vivo-Bedingungen der Follikelflüssigkeit vollständig nachzustellen. Dies wird noch dadurch erschwert, dass die physiologischen Prozesse in vivo und in vitro wahrscheinlich nicht identisch ablaufen (Blaschka et al. 2019).

TCM-199 wird meist als Grundlage für das Medium verwendet, dem außerdem Gonadotropine und beispielsweise bovines Serumalbumin zugesetzt werden (McGaughey 1977; Meinecke \& Meinecke-Tillmann 1979; Nagai et al. 1988; Yoshida et al. 1989; Wang et al. 1992).

Die 19-stündige IVF schließt sich an (Stinshoff et al. 2011). Wie oben bereits erwähnt, sind die Kapazitation, aber auch die Akrosomenreaktion, die physiologischen Voraussetzungen für eine erfolgreiche Befruchtung (Chang 1951, 1984; Brackett \& Zuelke 1993). Die Kapazitation wird im weiblichen Genitaltrakt durch Glukosaminoglykane, wie zum Beispiel Heparin, induziert (Parrish et al. 1988). In vitro wird dem Kulturmedium für die Koinkubation von Spermien und Oozyten aus diesem Grund Heparin zugesetzt (Parrish et al. 1988). Durch die Dichtegradientenzentrifugation werden außerdem nicht motile Spermien von den motilen Spermien getrennt (Parrish et al. 1995). Die zweite Reifeteilung der Oozyte wird durch den Befruchtungsvorgang abgeschlossen (Schnorr \& Kressin 2001).

Nach der IVF werden die Zygoten für 8 Tage in ein Kulturmedium überführt. Als IVCMedium hat sich inzwischen das synthetic oviduct fluid (SOF) bewährt (Tervit et al. 1972; Suthar \& Shah 2009). Die Embryonen reifen in vitro bis zum Blastozystenstadium (Corrêa et al. 2008; Stinshoff et al. 2011).

Die IVP kann sowohl mit als auch ohne Ölüberschichtung des jeweiligen Mediums stattfinden. Dabei sind Systeme mit Ölüberschichtung in der IVP boviner, aber auch porziner und muriner Oozyten am weitesten verbreitet. Hier werden überwiegend mit Öl überschichtete Medientropfen eingesetzt (Gwatkin 1963; Van Soom et al. 2001; Martinez et al. 2018). Es können verschiedene Arten von Ölen, wie Mineral-, Paraffinoder Silikonöl genutzt werden (Miller \& Pursel 1987; Martinez et al. 2017). Die Überschichtung bietet verschiedene Vorteile, so z.B. den Schutz vor Evaporation von Wasser aus dem Medium in die Umgebung (Gasperin et al. 2010). Bei Verdunstung von Wasser aus dem Medium, kann die Osmolalität des Kulturmediums signifikant ansteigen (Gasperin et al. 2010) und so zu osmotischem Stress der Oozyte bzw. des Embryos füh- 
ren, der sich wiederum auf die mRNA-Translation und die DNA-Replikation auswirken kann (Burg et al. 2007).

Die Ölüberschichtung führt nicht nur zur Stabilisierung der Osmolalität, sondern auch zur Aufrechterhaltung eines konstanten $\mathrm{pH}-$ Wertes sowie zu beständigen Temperaturund Gasbedingungen (Miller \& Pursel 1987).

Die Überschichtung mit Öl kann sich jedoch auch negativ auf die Oozytenentwicklung auswirken. Die Öle können für die IVP toxische Substanzen enthalten, die dann in das Medium gelangen (Miller \& Pursel 1987; Erbach et al. 1995; Lee et al. 2004). So konnte beispielsweise Zink nach Überschichtung mit Silikonöl im Medium nachgewiesen werden (Erbach et al. 1995). Freie Radikale, die im Mineralöl durch Peroxidation entstanden sind, können sich ebenfalls negativ auf das Wachstum der Oozyte bzw. des Embryos auswirken (Otsuki et al. 2009). Besonders zu berücksichtigen ist aber die Absorption von Steroidhormonen durch das Öl (Miller \& Pursel 1987; Funahashi et al. 1994; Shimada et al. 2002). Die lipophilen Steroidhormone Östradiol und Progesteron werden während der IVM von den KOK selbst synthetisiert und besitzen, wie oben beschrieben, eine große Bedeutung für die physiologische Entwicklung dieser (Moor et al. 1980; Armstrong et al. 1996).

Die Beurteilung der möglichen Absorption von Steroiden durch das Öl fällt in der Literatur allerdings nicht einheitlich aus. Xu et al. (1988) beobachteten zwar eine deutlich erhöhte Absorption von Östradiol, jedoch keine Auswirkungen auf die Maturationsraten boviner Oozyten. Shimada et al. (2002) berichteten hingegen von höheren Steroidkonzentrationen im Medium ohne Ölüberschichtung und damit verbundenen positiven Effekten auf die Entwicklungsraten beim Schwein.

Gasperin et al. (2010) zeigten, dass die Osmolalität auch in einem ölfreien System konstant gehalten werden kann. Sie nutzten dafür 4-Well-Platten, $400 \mu \mathrm{L}$ Medium, füllten den Raum zwischen den Wells mit Wasser und erreichten so gleiche Osmolalitäten und Entwicklungsraten der bovinen Embryonen (Gasperin et al. 2010).

In der Literatur werden Effekte der Embryonendichte und des Medienvolumens auf die Entwicklung von Oozyten bzw. Embryonen beschrieben. Bei gemeinsamer Kultur mehrerer Oozyten bzw. Embryonen stimulieren diese sich gegenseitig durch die Sekretion von Wachstumsfaktoren (Canseco et al. 1992; Lane \& Gardner 1992). Durch Verringerung des Medienvolumens oder Erhöhung der Embryonendichte konnten steigende Wachstumsraten beobachtet werden (Lane \& Gardner 1992; Gil et al. 2003). Bei zu 
hohen Medienvolumina kann dieser Effekt beeinträchtigt werden (Canseco et al. 1992; Lane \& Gardner 1992).

Ziel der vorliegenden Studie war es daher, die Verwendung eines kleineren Medienvolumens in einem ölfreien und einem ölüberschichteten Kultursystem zu testen und die Entwicklung boviner Embryonen in diesen Systemen vergleichend darzustellen. 


\subsection{The effect of an oil covered culture system on bovine in vitro produced em- bryos}

\section{Aravina, S. Diers, J. Tetens, C. Blaschka}

Department of Animal Science, Georg-August-University, Burckhardtweg 2, 37077 Göttingen, Germany

\section{Erschienen in:}

Reproduction in Domestic Animals 2019, 54(S1):4

onlinelibrary.wiley.com/doi/10.1111/rda.13387

DOI: $10.1111 /$ rda.13387

Embryos are usually produced in culture systems with an oil overlay, which conveys protection against the evaporation of water and microbial contamination. The oil can also release toxic substances and absorb essential components, such as hormones, which adversely affect the quality of the oocytes, and the resulting development of embryos in vitro. This study compares bovine in vitro production (IVP) with and without an oil overlay. Cumulus-oocyte-complexes (COC) were collected from abattoir-derived ovaries. Groups of 20 COCs were matured in Tissue Culture Medium 199 supplemented with BSA, eCG, hCG, fertilized in Fert.-TALP medium and cultured in SOF-culture medium with BSA-FAF employed as the standard protocol. The quantity of medium in both groups (with and without an oil overlay) and throughout all stages of IVP was maintained $(100 \mu \mathrm{L})$. The second group was covered with $75 \mu \mathrm{L}$ paraffin oil. The maturation stage of oocytes was assessed using a fluorescence staining (Hoechst 33342) after 24 hours of incubation and developmental stages were evaluated on day 8 postfertilization. So far, our results indicate that oocytes matured in the absence of an oil overlay had significantly $(\mathrm{P}<0.05)$ higher maturation rates $(71.56 \pm 6.82 \%)$ when compared against medium with an oil overlay $(61.74 \pm 7.84 \%)$. The developmental rate was significantly $(\mathrm{P}<0.05)$ higher in IVP systems without oil $(38.19 \pm 17.81 \%)$ than in oil overlaid systems $(22.75 \pm 9.83 \%)$. Based on the higher maturation and embryo development rates by bovine oil-free culture systems, we suggest this method as an alternative to oil covered culture medium. However, further work is still needed to confirm these results at the molecular level (We gratefully acknowledge our colleagues $\mathrm{H}$. Hellmold and D. Teuteberg.). 


\title{
3.3 Evaluation of a small volume oil-free in vitro production system for bovine embryos
}

\section{Blaschka ${ }^{a *}$, S. Diers ${ }^{a}$, M. Aravina ${ }^{a}$, S. Geisler ${ }^{a}$, G. Schuler ${ }^{b}$, J. Tetens ${ }^{a}$}

aDivision of Biotechnology and Livestock Reproduction, Department of Animal Sciences, Georg-August-University Goettingen, Germany

${ }^{\mathrm{b}}$ Clinic for Veterinary Obstetrics, Gynecology and Andrology, Molecular Reproductive Medicine, Justus-Liebig-University, Giessen, Germany

*Corresponding author

\section{Zur Veröffentlichung vorgesehen.}

\begin{abstract}
Embryos are usually produced in culture systems with an oil overlay, which conveys protection against the evaporation of water and microbial contamination. The oil can also release toxic substances and absorb essential components, such as hormones, which adversely affect the quality of the oocytes and the development of embryos in vitro. The aim of this study was to validate an oil-free bovine IVP system. Cumulus-oocytecomplexes collected from abattoir-derived ovaries were matured, fertilized and cultured employing a standard system. The quantity of medium in both groups (with and without an oil overlay) and throughout all stages of IVP was maintained at a volume of $100 \mu$. The oil group was covered with paraffin oil. The maturation stage of oocytes was assessed using fluorescence staining after $24 \mathrm{~h}$ and developmental stages were evaluated on day 8 . The morphological quality of expanded day 8 blastocysts was determined by live-dead-staining (total cell number as well as ratio of live and dead cells). Oocytes matured in the absence of an oil overlay had significantly higher maturation rates when compared against matured oocytes in medium with an oil overlay. Steroid concentration was higher in medium after maturation without oil cover. The developmental rate was significantly higher after culture without oil overlay. The total cell number and the livedead-ratio was not significantly different. The osmolality did not differ between both groups during maturation and slightly decreased during culture without oil. Based on the current study, bovine oil-free IVP-systems can be suggested as an alternative to oilcovered medium.
\end{abstract}

Keywords: Bovine; in vitro production; oil overlay 


\section{List of Abbreviations:}

BSA (bovine serum albumin); COC (cumulus-oocyte-complex); EDTA (ethylenediaminetetraacetate); E2 (17 $\beta$-oestradiol); IVC (in vitro culture); IVF (in vitro fertilisation); IVM (in vitro maturation), IVP (in vitro production); P4 (progesterone)

\section{Introduction}

Currently, in cattle breeding, in vitro production (IVP) of embryos is one of the most important biotechnologies. According to the data provided by the International Embryo Technology Society, the number of transferred bovine embryos produced worldwide rose from around 139,000 in 2000 to over 740,000 in 2018. Beside the significance of cattle as a source of high quality food, it is a relevant animal model in research, including its similar reproduction physiology to humans. The embryos of both species (human and cattle) are similar with respect to the microtubule organisation during fertilisation, metabolic requirements and interaction with used culture conditions as well. Moreover, the use of the bovine model is important in the light of the ethical and legal restrictions in human embryo work (Navara et al. 1995, Anderiesz et al. 2000, Neuber and Powers 2000, Menezo and Herubel 2002, Wrenzycki et al. 2005).

Since the first reported live bovine offspring was produced totally in vitro (Fukuda et al. 1990), this method has been further refined into a routine procedure. It does, however, still not fully mimic the in vivo process, resulting in reduced quality of gametes and embryos, as well as a limited output with only 30-40 \% developing blastocysts (Rizos et al. 2002, Sutton et al. 2003). Changes of the environment in which the oocytes and embryos are cultured can have a significant effect on this (Lonergan et al. 2003, Wrenzycki 2016). The most commonly used system is a micro drop culture method, where drops of medium are covered with an oil overlay, because of the simple assessment of the cells (Tae et al. 2006). Furthermore, protection from bacterial contamination, absorption of lipophilic toxic compounds, avoidance from evaporation of the medium, maintenance of osmotic pressure and $\mathrm{pH}$ value (Martinez et al. 2018) are usually quoted as beneficial impacts of the drop system. Three different types of oil are used for covering the drops, silicone oil, mineral oil and paraffin oil. Silicone oil is an anorganic polymerized siloxane, usually polydimethylsiloxane, compared to mineral oil which is a heavy hydrocarbon. Mineral and paraffin oil are basically the same product, even paraffin oil is higher 
purified and contains more saturated hydrocarbons as reviewed by Morbeck (2012). However, it is known that an overlay of oil is also able to negatively influence IVP (Van Soom et al. 2001, Otsuki et al. 2009). If gametes and embryos are cultured without oil overlay to avoid these undesirable effects, large amounts of media have to be used in order to elude an increase of osmolality (Gasperin et al. 2010). Thus, particular compounds derived from gametes or embryos can be diluted (Canseco et al. 1992, Hoelker et al. 2009). Depending on the individual background it has to be decided which are the more acceptable effects on the gametes or embryos.

In cases where only limited samples are available, such as from individual animals, cloned or gene edited embryos or from primates, and the negative effects of oil overlay should be avoided, special attention needs to be taken to ensure that the media remains present.

Therefore, the aim of the study was to evaluate an oil-free IVP system with small volumes of medium for cattle.

\section{Material and Methods}

\subsection{Experimental design}

Groups of 20 cumulus-oocytes-complexes (COC's; abattoir-derived ovaries) were matured (IVM), fertilized (IVF) and cultured (IVC) in vitro as explained in paragraph 2.2. The quantity of medium in both groups (total IVP with and without an oil overlay) and throughout all stages of IVP was maintained at a volume of $100 \mu 1$. The oil group was covered with $75 \mu$ paraffin oil (IVF Bioscience, Falmouth, UK). As a complement, medium was covered with oil in single parts of IVP (A: IVM without oil + IVF / IVC with oil; B: IVM / IVF without oil + IVC with oil; C: IVM / IVF with oil + IVC without oil; D: IVM with oil + IVF / IVC without oil). Each run was performed in duplicate. Microtiter strips (Thermo Fisher Scientific, Germany) with flat bottom were placed in a petri dish surrounded with approximately $3 \mathrm{ml}$ distilled water. The maturation stage of oocytes was assessed using fluorescence staining (Hoechst bisbenzimide 33342, SigmaAldrich, Germany) after $24 \mathrm{~h}$ of maturation. In addition, IVM medium was analysed via radioimmunoassay after $0 \mathrm{~h}$ (control) and $24 \mathrm{~h}$ (with and without COC's) to detect the $17 \beta$-oestradiol (E2) and progesterone (P4) concentration. Pools of each media type were generated from each duplicate. The developmental stage was assessed on day 8 (total IVP with and without an oil overlay / single steps of IVP covered with oil). The morphological quality of expanded day 8 blastocysts (total IVP with and without an oil 
overlay) was determined by live-dead-staining (total cell number as well as ratio of live and dead cells).

\subsection{Collection of cumulus-oocyte-complexes and in vitro production}

Abattoir-derived ovaries were transported to the laboratory in thermal tanks filled with $30{ }^{\circ} \mathrm{C}$ phosphate buffered saline (Abele et al. 2014). The ovaries were washed, COCs were isolated from the follicles, categorized and then selected as previously described (Blaschka et al. 2019). The in vitro production of embryos was performed using the procedure outlined by Abele et al. (2014).

The development rates of the embryos were determined morphologically on day 8 of cultivation and the percentage of oocytes, which had developed to at least morulae, or blastocysts was recorded.

\subsection{Maturation rate of oocytes}

The evaluation of nuclear maturation success was realized using Hoechst bisbenzimide 33342 (Sigma-Aldrich, Germany) staining with slight modification as previously described (Blaschka et al. 2019). Oocytes were classified as matured, when they had reached the metaphase II stage as characterized by the metaphase plate and the occurrence of the first polar body. Oocytes in metaphase I stage presenting single chromosomes were considered as immature.

\subsection{Live-dead-staining}

In addition, a live/dead-staining was performed with expanded blastocysts on day 8 according to Stinshoff et al. (2011). Ethidium homodimer (Invitrogen, USA) and Hoechst bisbenzimide 33342 were used at concentrations of $0.01 \%$ and $0.004 \%$, respectively, to differentiate between live and dead cells. Two to three expanded blastocysts $(n=2-$ 3/group) were stained per pass. The assessment of the stained blastocysts was achieved using a fluorescence microscope Eclipse Ci (Nikon, Düsseldorf, Germany). Image software NIS-Elements D version 5.02. (Nikon, Düsseldorf, Germany) was used to accomplish the cell counting. 


\subsection{Analysis of Medium}

Concentrations of P4 and E2 in IVM medium were determined in duplicates using established radioimmunological methods after extraction of the samples with organic solvents. The measurement of P4 followed the procedure outlined by Hoffmann et al. (1973) as previously described (Klein et al. 2003). Samples (200 $\mu 1)$ were extracted twice with $2 \mathrm{ml}$ hexane. The antiserum applied was generated against 4-pregnene-11aol-3,20-dione-hemisucciate-BSA. Intra- and inter-assay coefficients of variation were 8.8 and $8.9 \%$ respectively. The limit of quantification was $0.5 \mathrm{ng} / \mathrm{ml}$.

Measurements of E2 were performed as previously described (Klein et al. 2003). Medium samples $(200 \mu \mathrm{l})$ were extracted twice with $2.5 \mathrm{ml}$ toluene. The antiserum was directed against oestradiol-17b-6-carboxymethyloxim-BSA. The limit of quantification was $12.5 \mathrm{pg} / \mathrm{ml}$. Intra- and inter-assay coefficients were 7.1 and $17.6 \%$ respectively. At least, ten replicates were analysed.

In addition, the osmolality of IVM and IVC medium was analysed in $50 \mu 1$ of medium using a cryoscopic osmometer (Osmomat 3000basic, gonotec, Berlin, Germany). For each measurement technical repeats (three times) were performed.

\subsection{Statistical analyses}

Statistical analyses were performed with R (version 3.5.1; R Development Core Team, 2018). All data were tested for normal distribution using a Shapiro-Wilk-Test. Maturation and development rates were analysed using a binomial test. Data obtained from the live-dead-staining were analysed using a t-test. For assessment of the hormone concentration the non-parametric Wilcoxon-test was used. To determine significant difference of the osmolality a one-way-ANOVA followed by a tukey test was done. A pvalue $\leq 0.05$ was considered statistically relevant.

\section{Results}

3.1. Maturation rate of oocytes and development assessment of embryos

Total IVP with and without an oil overlay:

Oocytes matured in the absence of an oil overlay had significantly $(\mathrm{p} \leq 0.05)$ higher maturation rates $(n=200)$ when compared against matured oocytes in medium with an oil overlay $(\mathrm{n}=207)$.

The developmental rate on day 8 was significantly higher $(\mathrm{p} \leq 0.05)$ after culture without oil overlay (without oil: $\mathrm{n}=581$; with oil: 586). Both are depicted in figure 1 . 


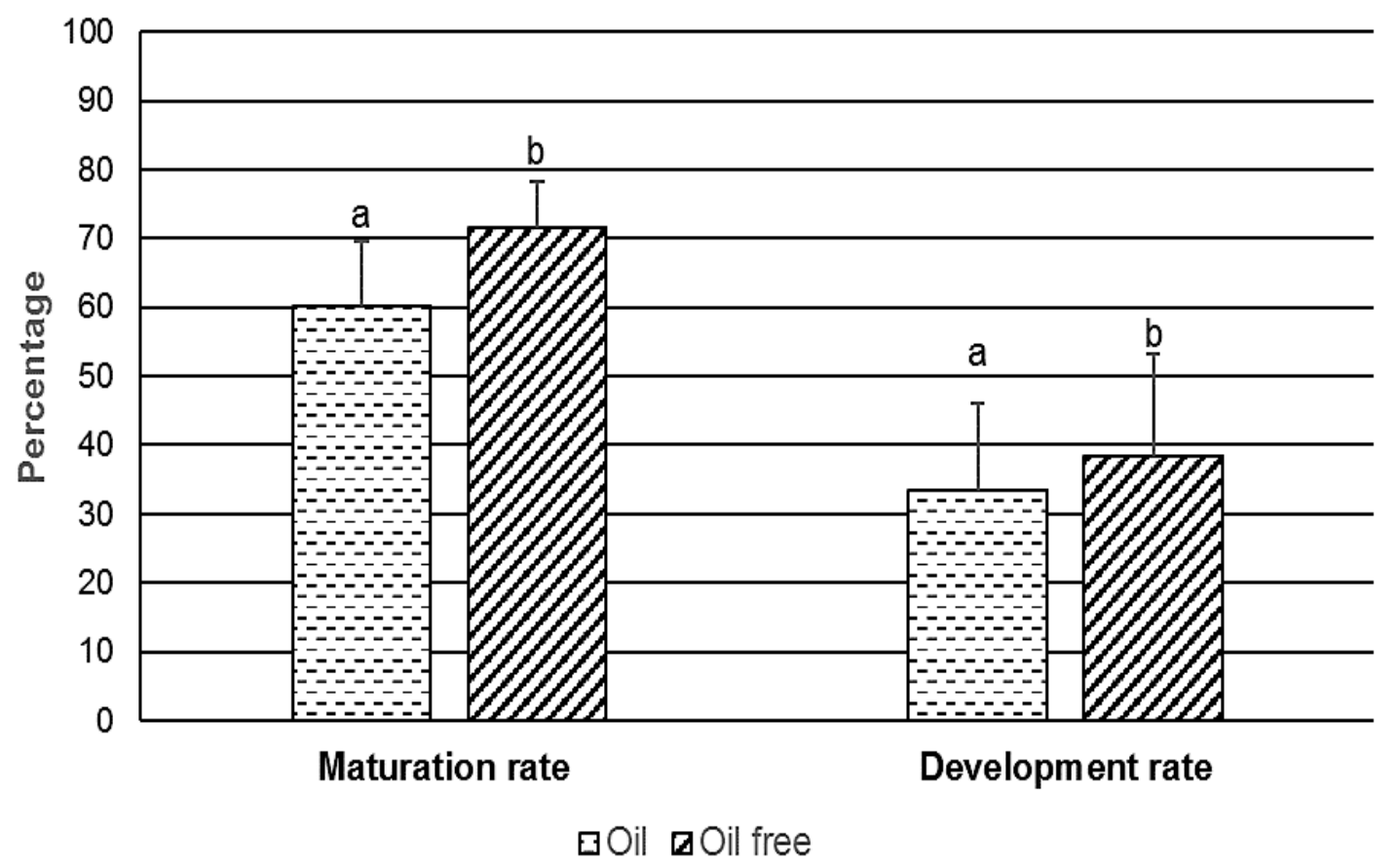

Figure 1: Maturation rate of COCs after $24 \mathrm{~h}$ and development rate on day 8 with and without an oil overlay (mean $\pm \mathrm{SD}$; $\mathrm{a}: \mathrm{b} \mathrm{p} \leq 0.05$ ).

Single steps of IVP covered with oil:

On day 8 the development rate was not significantly changed for embryos developed in IVP medium covered with oil in single parts of the procedure (A: $28.0 \pm 8.9 \%, \mathrm{n}=279$, B: $27.8 \pm 10.3 \%, \mathrm{n}=295, \mathrm{C}: 23.0 \pm 12.3 \%, \mathrm{n}=276, \mathrm{D}: 26.6 \pm 13.6 \%, \mathrm{n}=300)$.

\subsection{Steroid pattern in IVM medium}

After the maturation period the E2 concentration was found to be slightly lower in medium with an oil overlay $(\mathrm{p} \leq 0.1)$. The mean concentrations were $76.0 \pm 35.4 \mathrm{pg} / \mathrm{ml}$ and $109.0 \pm 46.4 \mathrm{pg} / \mathrm{ml}$ in media with or without oil covering, respectively. The median was $65.6 \mathrm{pg} / \mathrm{ml}$ (with oil) and $106.2 \mathrm{pg} / \mathrm{ml}$ (without oil). Ten biological replicates were assessed.

The P4 concentration was significantly lower in medium covered with oil compared to medium without overlay $(\mathrm{p} \leq 0.05 ; \mathrm{n}=11)$. The results are shown in figure 2 .

In medium analysed before incubation $(0 \mathrm{~h})$ and after $24 \mathrm{~h}$ of maturation without COCs, $\mathrm{E} 2$ and P4 concentrations were under the limit of quantification (E2: $12.5 \mathrm{pg} / \mathrm{ml}$; P4: $0.5 \mathrm{ng} / \mathrm{ml})$. 


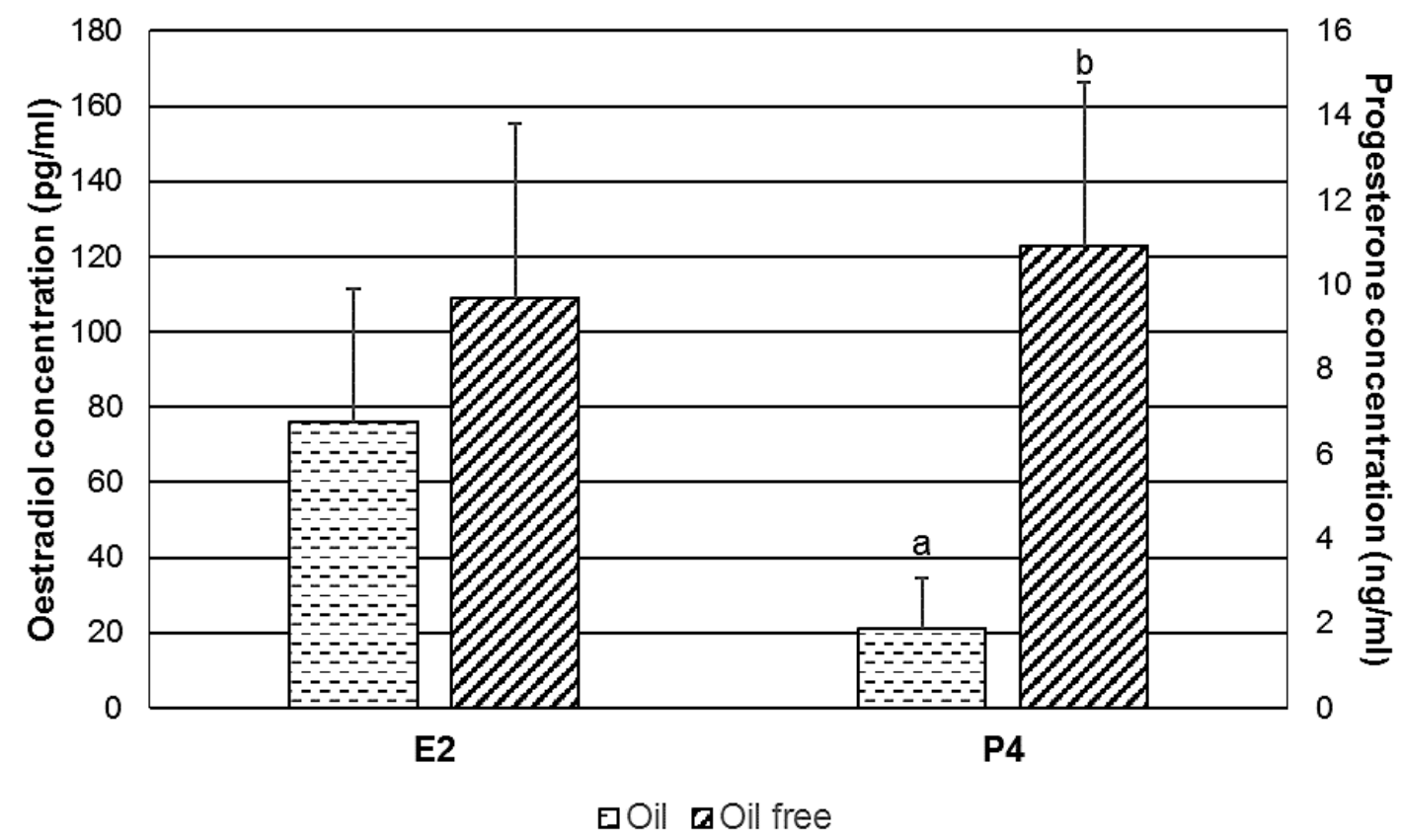

Figure 2: Steroid concentration in IVM medium after $24 \mathrm{~h}$ of maturation (E2: oestradiol; P4: progesterone; mean $\pm \mathrm{SD} ; * \mathrm{p} \leq 0.1$; $\mathrm{a}: \mathrm{b} \mathrm{p} \leq 0.05)$.

\subsection{Live-dead-staining}

The total cell number and the live-dead-ratio were not significantly different (total cell number: without oil: $129.0 \pm 30.1$, with oil: $119.0 \pm 30.0$; live-dead-ratio: without oil: $22.6 \pm 19.7$, with oil: $18.0 \pm 8.0$ ) as depicted in figure 3 . 


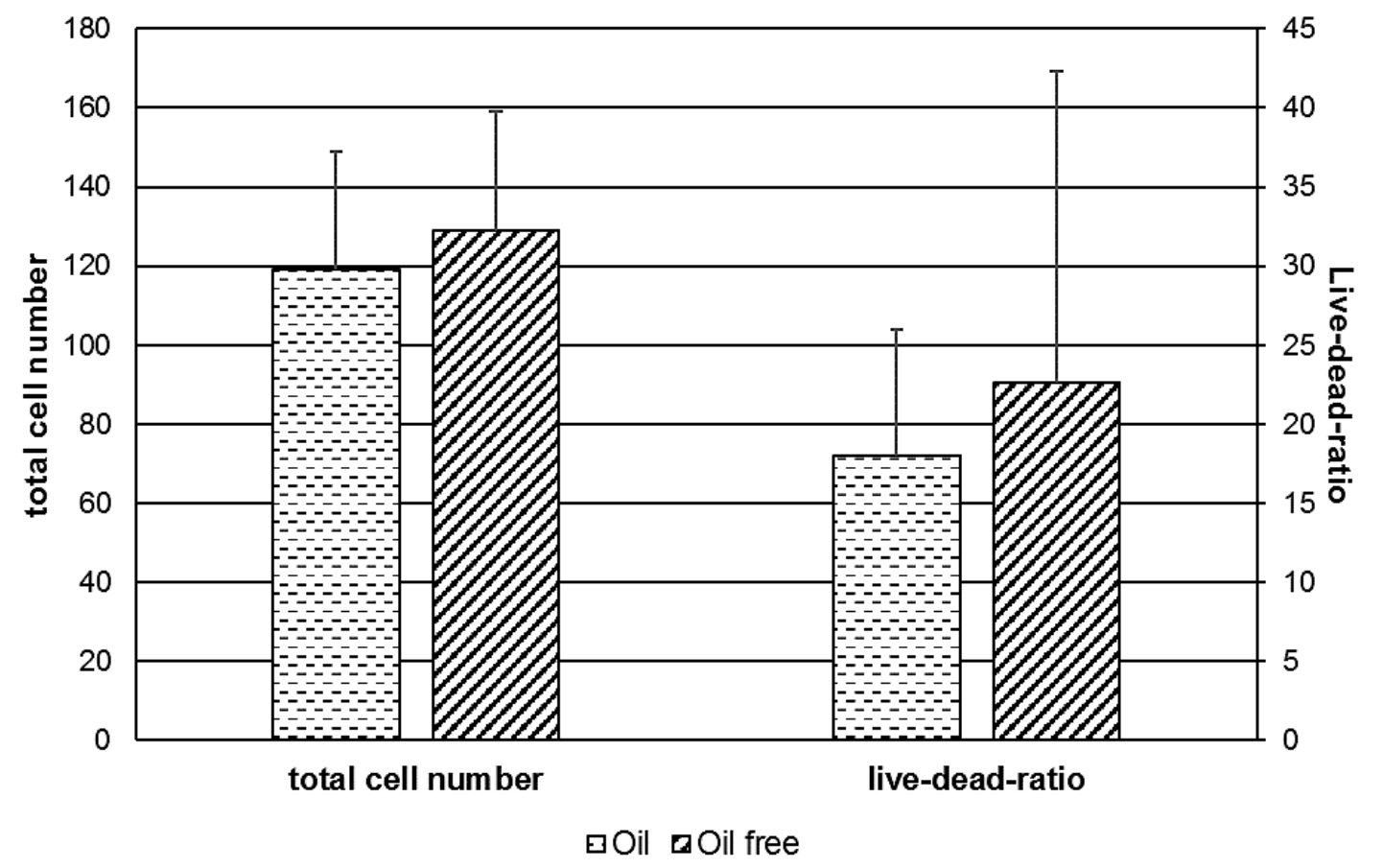

Figure 3: Total cell number and live-dead-ratio of expanded blastocysts (with oil: $\mathrm{n}=25$; without oil: $\mathrm{n}=26$; mean $\pm \mathrm{SD} ; \mathrm{p}>0.05)$.

\subsection{Osmolality}

The osmolality of IVM did not differ between both groups (with and without oil) and the control before maturation. After 8 days of culture, the osmolality was significant lower in medium without an oil overlay $(\mathrm{p} \leq 0.05)$ compared to the medium with overlay and the control $(0 \mathrm{~h})$. The results are shown in table 1.

Table 1: Osmolality of IVP media (without COCs) with and without an oil overlay $($ mean $\pm \mathrm{SD})$

\begin{tabular}{|l|l|l|l|l|l|}
\hline & $\begin{array}{l}\text { Osmolality } \\
(\mathrm{mOsm} / \\
\mathrm{kg} \mathrm{H} \mathrm{O} \mathrm{O}\end{array}$ & $\mathrm{n}$ & & $\begin{array}{l}\text { Osmolality } \\
(\mathrm{mOsm} / \\
\left.\mathrm{kg} \mathrm{H}_{2} \mathrm{O}\right)\end{array}$ & $\mathrm{n}$ \\
\hline $\begin{array}{l}0 \mathrm{~h} \\
\text { (before incubation) }\end{array}$ & $287.8 \pm 3.1$ & 4 & $\begin{array}{l}0 \mathrm{~h} \\
\text { (before incubation) }\end{array}$ & $275.2 \pm 2.6^{\mathrm{a}}$ & 5 \\
\hline $\begin{array}{l}24 \mathrm{~h} \mathrm{IVM} \\
\text { with oil overlay }\end{array}$ & $289.7 \pm 2.8$ & 6 & $\begin{array}{l}8 \text { days IVC } \\
\text { with oil overlay }\end{array}$ & $275.5 \pm 2.7^{\mathrm{a}}$ & 5 \\
\hline $\begin{array}{l}24 \text { h IVM } \\
\text { without oil overlay }\end{array}$ & $288.6 \pm 2.7$ & 6 & $\begin{array}{l}8 \text { days IVC } \\
\text { without oil overlay }\end{array}$ & $270.3 \pm 2.3^{\mathrm{b}}$ & 5 \\
\hline
\end{tabular}

IVM: in vitro maturation; IVC: in vitro culture; a:b $\mathrm{p} \leq 0.05$ 


\section{Discussion}

Currently, the application of oil overlays is common-practice in IVP systems, because it has advantages in terms of work flow and the assessment of gametes and embryos. It can, however, take up lipophilic steroid hormones, which might negatively affect IVP outcome.

Steroids, especially E2 and P4 have a crucial role such as for follicular development in physiological oestrus cycles (Forde et al. 2011). During the final maturation, a switch from E2 to P4 dominance takes place in the follicle (Dieleman et al. 1983). Mingoti et al. (2002) demonstrated that cumulus cells of COCs are able to secret E2 and P4 into the medium when they are matured in a medium enriched with bovine serum albumin (BSA) and gonadotropins. A pattern similar to that observed in vivo has, however, not been demonstrated and the role of these steroids during IVM remains controversially discussed (Blaschka et al. 2019). In the present study, an obvious reduction of E2 and P4 concentration in medium covered with oil was demonstrated, which is likely due to absorption by the oil overlay. This clearly confirms previous results from IVM with pig COC's (Shimada et al. 2002). Clemente et al. (2009) also showed a reduction of P4 in medium used for bovine embryo culture covered with oil, but with no effect of the P4 concentration on the blastocyst development or quality, even if exogenous P4 was supplemented. However, during maturation $\mathrm{Xu}$ et al. (1988) showed a decreased E2-, but not P4-concentration. The kind of oil used for covering has an effect on the steroid concentration as well (Miller and Pursel 1987). It has been shown that silicon oil takes up seven times more E2 than paraffin oil. Reinsberg et al. (2004) also reported a different absorption of E2 versus $\mathrm{P} 4$ and an effect of the oil/medium ratio in a human system. They suggested a lower lipophilicity of E2 compared to P4, which might also explain the higher absorbed concentrations of P4 than of E2 in the current study.

Moreover, a delayed nuclear maturation of oocytes in vitro in a system with oil overlay has been reported for pig (Shimada et al. 2002) and a delayed meiosis progression after in vitro follicle culture in mouse oocytes (Segers et al. 2008). In the present study, a significantly reduced maturation rate has been found in the presence of an oil cover.

One of the core factors during in vitro production of embryos is the osmolality. An increasing osmolality has an adverse effect on oocyte maturation and fertilisation (Lim et al. 1994), high concentration of sodium chloride in IVF medium can increase the occurrence of polyspermy (Roh et al. 2002) as well as affecting embryo development (Liu and Foote 1996). A beneficial effect of the oil overlay is maintaining the osmotic pres- 
sure. However, Swain (2018) determined a significant increased osmolality after six days of culture in medium covered with different types of oil (mineral and paraffin). To beware an oil overlay and avoid evaporation of medium, large volumes of medium will be usually used. Conversely, with large volumes, important compounds for embryo interaction (paracrine and autocrine factors) can be diluted (Canseco et al. 1992, Hoelker et al. 2009, Martinez et al. 2018). Gasperin et al. (2010) showed that an increase of the osmolality in $400 \mu \mathrm{l}$ medium can be avoided by adding water in the central hole of a four well plate. In an IVP system used for pigs, it could be clearly demonstrated that osmolality can be stabilized if the medium is surrounded by water. But in contrast, no differences could be determined for the maturation or development rate in both systems (with or without oil; Martinez et al. 2015). In the present study, the osmolality remained constant during the maturation phase and slightly decreased during culture, even the maturation and development rates were higher in the system without an oil overlay and no negative effect of the morphological quality of the embryos were observed in a small volume system. However, if single parts of the IVP system were covered with oil, the development rate has not been changed. It would suggest that an oil-free maturation is not the key factor. Van Soom et al. (2001) determined a considerable decrease of the development rate (up to $12 \%$ ), if the bovine IVP system was not covered with oil.

The presence or absence of oil per se did not alter the output of an IVP system. If oil is used, however, the type of oil (Van Soom et al. 2001, Martinez et al. 2018) and a potential treatment of the oil used (Tae et al. 2006) has an impact on embryo development and quality. Also, the batch of the oil, especially for silicon oil (Van Soom et al. 2001; own observations) and the storage (light and temperature; Otsuki et al. 2009), affect the results. In the present study, paraffin oil dedicated to IVP was used. In contrast, Labied et al. (2019) could not determine an effect of the tested oils on the rate of pregnancy per fresh transfer, live birth rate per fresh transfer as well as miscarriage rate after IVF in women. However, within oil-covered system, components can be shifted from one medium drop to another, which has to be kept in mind, especially in a research context (Miller et al. 1987). Further, the used oil can contain toxic compounds able to transfer to the medium as reviewed by Martinez et al. (2018). Added chelating agents (EDTA or BSA) as well as hemoglobin (nitric oxide scavenger) and co-culture systems are partially able to resolve toxic effects (Van Soom et al. 2001, Lee et al. 2004, Tae et al. 2006). In comparison, it is reported by Miller et al. (1994) that oil is competent to absorb embryotoxic substances. 


\section{Conclusion}

An oil overlay on medium used for IVP is usually done because of its protective effects. However, oil covering is able to influence the outcome in a significant way. It is still an undefined product with different purity. In the current study, it has been shown that an oil overlay can be avoided during the whole procedure even with a small volume of medium, with a positive effect on maturation and development rate as well as the steroid concentration in maturation medium. A negative effect on the embryo quality could not be determined. Nevertheless, there is need for experiments to assess whether the oil overlay has an impact on gene expression patterns.

\section{Acknowledgements}

We gratefully acknowledge our colleagues S. Feller, H. Hellmold, D. Teuteberg and M. Vopel.

\section{References}

Abele E., Stinshoff H., Hanstedt A., Wilkening S., Meinecke-Tillmann S. and Wrenzycki C. (2014). "Influence of selected (pre-)maturational parameters on in vitro development and sex distribution of bovine embryos." Zygote 22(1): 41-49 DOI: $10.1017 / \mathrm{S} 0967199412000275$.

Anderiesz C., Ferraretti A., Magli C., Fiorentino A., Fortini D., Gianaroli L., Jones G. M. and Trounson A. O. (2000). "Effect of recombinant human gonadotrophins on human, bovine and murine oocyte meiosis, fertilization and embryonic development." Hum Reprod 15 DOI: 10.1093/humrep/15.5.1140.

Blaschka C., Sanchez-Guijo A., Zimmer B., Stohr J., Kotarski F., Grothmann H., Hartmann M. F., Wudy S. A. and Wrenzycki C. (2019). "Temporal expression pattern of steroid-metabolizing enzymes in bovine coc during in vitro maturation employing different gonadotropin concentrations." Theriogenology 131: 182192 DOI: 10.1016/j.theriogenology.2019.03.028.

Canseco R. S., Sparks A. E. T., Pearson R. E. and Gwazdauskas F. C. (1992). "Embryo density and medium volume effects on early murine embryo development." Journal of Assisted Reproduction and Genetics 9(5): 454-457 DOI: 10.1007/BF01204051. 
Clemente M., De La Fuente J., Fair T., Al Naib A., Gutierrez-Adan A., Roche J. F., Rizos D. and Lonergan P. (2009). "Progesterone and conceptus elongation in cattle: A direct effect on the embryo or an indirect effect via the endometrium?" Reproduction 138(3): 507-517 DOI: 10.1530/rep-09-0152.

Dieleman S. J., Kruip T. A., Fontijne P., De Jong W. H. and Van Der Weyden G. C. (1983). "Changes in oestradiol, progesterone and testosterone concentrations in follicular fluid and in the micromorphology of preovulatory bovine follicles relative to the peak of luteinizing hormone." J Endocrinol 97(1): 31-42 DOI: 10.1677/joe.0.0970031.

Forde N., Beltman M. E., Lonergan P., Diskin M., Roche J. F. and Crowe M. A. (2011). "Oestrous cycles in bos taurus cattle." Anim Reprod Sci 124(3-4): 163-169 DOI: 10.1016/j.anireprosci.2010.08.025.

Fukuda Y., Ichikawa M., Naito K. and Toyoda Y. (1990). "Birth of normal calves resulting from bovine oocytes matured, fertilized, and cultured with cumulus cells in vitro up to the blastocyst stage." Biol Reprod 42(1): 114-119 DOI: 10.1095/biolreprod42.1.114.

Gasperin B. G., Barreta M. H., Santos J. T., Ferreira R., Neves J. P., Oliveira J. F. C. and Gonçalves P. B. D. (2010). "Oil-free culture system for in vitro bovine embryo production." Italian Journal of Animal Science 9(2): e32 DOI: 10.4081/ijas.2010.e32.

Hoelker M., Rings F., Lund Q., Ghanem N., Phatsara C., Griese J., Schellander K. and Tesfaye D. (2009). "Effect of the microenvironment and embryo density on developmental characteristics and gene expression profile of bovine preimplantative embryos cultured in vitro." 137(3): 415 DOI: 10.1530/rep-080370.

Hoffmann B., Kyrein H. J. and Ender M. L. (1973). "An efficient procedure for the determination of progesterone by radioimmunoassay applied to bovine peripheral plasma." Horm Res 4(5): 302-310 DOI: 10.1159/000178317.

Klein R., Schams D., Failing K. and Hoffmann B. (2003). "Investigations on the reestablishment of the positive feedback of oestradiol during anoestrus in the bitch." Reprod Domest Anim 38(1): 13-20 DOI: 10.1046/j.14390531.2003.00389.x.

Labied S., Jouan C., Wenders F., Ravet S., Gaspard O., Thonon F., Gridelet V., Henry L., Perrier D'hauterive S. and Nisolle M. (2019). "Comparison between paraffin 
and mineral oil covering on early human embryo culture: A prospective randomized study." Syst Biol Reprod Med 65(1): 81-86 DOI: 10.1080/19396368.2018.1492645.

Lee S., Cho M., Kim E., Kim T., Lee C., Han J. and Lim J. (2004). "Renovation of a drop embryo cultures system by using refined mineral oil and the effect of glucose and/or hemoglobin added to a serum-free medium." Journal of Veterinary Medical Science 66(1): 63-66 DOI: 10.1292/jvms.66.63.

Lim J. M., Kim J. H., Okuda K. and Niwa K. (1994). "The importance of nacl concentration in a chemically defined medium for the development of bovine oocytes matured and fertilized in vitro." Theriogenology 42(3): 421-432 DOI: https://doi.org/10.1016/0093-691X(94)90680-H.

Liu Z. and Foote R. H. (1996). "Sodium chloride, osmolyte, and osmolarity effects on blastocyst formation in bovine embryos produced by in vitro fertilization (ivf) and cultured in simple serum-free media." Journal of Assisted Reproduction and Genetics 13(7): 562-568 DOI: 10.1007/BF02066609.

Lonergan P., Rizos D., Gutierrez-Adan A., Fair T. and Boland M. P. (2003). "Oocyte and embryo quality: Effect of origin, culture conditions and gene expression patterns." Reprod Domest Anim 38(4): 259-267 DOI: 10.1046/j.14390531.2003.00437.x.

Martinez C., Martinez E. and Gil M. (2018). "Importance of oil overlay for production of porcine embryos in vitro." Reproduction in Domestic Animals 53(2): 281-286 DOI: $10.1111 /$ rda.13114.

Martinez C. A., Martinez E. A. and Gil M. A. (2018). "Importance of oil overlay for production of porcine embryos in vitro." Reprod Domest Anim 53(2): 281-286 DOI: $10.1111 /$ rda.13114.

Martinez C. A., Nohalez A., Cuello C., Vazquez J. M., Roca J., Martinez E. A. and Gil M. A. (2015). "The use of mineral oil during in vitro maturation, fertilization, and embryo culture does not impair the developmental competence of pig oocytes." Theriogenology 83(4): 693-702

DOI: 10.1016/j.theriogenology.2014.11.001.

Menezo Y. J. and Herubel F. (2002). "Mouse and bovine models for human ivf." Reprod Biomed Online 4(2): 170-175 DOI: 10.1016/S1472-6483(10)61936-0. 
Miller K. F., Goldberg J. M. and Collins R. L. (1994). "Covering embryo cultures with mineral oil alters embryo growth by acting as a sink for an embryotoxic substance." J Assist Reprod Genet 11(7): 342-345 DOI: 10.1007/bf02214139.

Miller K. F. and Pursel V. G. (1987). "Absorption of compounds in medium by the oil covering microdrop cultures." Gamete Res 17(1): 57-61 DOI: 10.1002/mrd.1120170107.

Mingoti G. Z., Garcia J. M. and Rosa-E-Silva A. A. (2002). "Steroidogenesis in cumulus cells of bovine cumulus-oocyte-complexes matured in vitro with bsa and different concentrations of steroids." Anim Reprod Sci 69(3-4): 175-186 DOI: $10.1016 / \mathrm{s} 0378-4320(01) 00187-7$.

Morbeck D. E. (2012). "Importance of supply integrity for in vitro fertilization and embryo culture." Semin Reprod Med 30(3): 182-190 DOI: 10.1055/s-00321311520.

Navara C. S., Simerly C. and Schatten G. (1995). "Imaging motility during fertilization." Theriogenology 44(8): 1099-1114

DOI: $10.1016 / 0093-691 x(95) 00323-z$.

Neuber E. and Powers R. D. (2000). "Is the mouse a clinically relevant model for human fertilization failures?" Hum Reprod 15(1): 171-174 DOI: 10.1093/humrep/15.1.171.

Otsuki J., Nagai Y. and Chiba K. (2009). "Damage of embryo development caused by peroxidized mineral oil and its association with albumin in culture." Fertil Steril 91(5): 1745-1749 DOI: 10.1016/j.fertnstert.2008.03.001.

Reinsberg J., Ackermann D. and Van Der Ven H. (2004). "Pitfalls in assessment of progesterone production by granulosa cells cultured in contact with silicone rubber or paraffin oil." Arch Gynecol Obstet 270(3): 174-178 DOI: 10.1007/s00404-003-0539-0.

Rizos D., Ward F., Duffy P., Boland M. P. and Lonergan P. (2002). "Consequences of bovine oocyte maturation, fertilization or early embryo development in vitro versus in vivo: Implications for blastocyst yield and blastocyst quality." Mol Reprod Dev 61(2): 234-248 DOI: 10.1002/mrd.1153.

Roh S., Hwang W., Lee B., Lim J. and Lee E. (2002). "Improved monospermic fertilization and subsequent blastocyst formation of bovine oocytes fertilized in vitro in a medium containing nacl of decreased concentration." J Vet Med Sci 64(8): 667-671 DOI: 10.1292/jvms.64.667. 
Segers I., Adriaenssens T., Coucke W., Cortvrindt R. and Smitz J. (2008). "Timing of nuclear maturation and postovulatory aging in oocytes of in vitro-grown mouse follicles with or without oil overlay." Biol Reprod 78(5): 859-868 DOI: 10.1095/biolreprod.107.062539.

Shimada M., Kawano N. and Terada T. (2002). "Delay of nuclear maturation and reduction in developmental competence of pig oocytes after mineral oil overlay of in vitro maturation media." Reproduction 124(4): 557-564 DOI: 10.1530/rep.0.1240557.

Stinshoff H., Wilkening S., Hanstedt A., Bruning K. and Wrenzycki C. (2011). "Cryopreservation affects the quality of in vitro produced bovine embryos at the molecular level." Theriogenology 76(8): 1433-1441

DOI: 10.1016/j.theriogenology.2011.06.013.

Sutton M. L., Gilchrist R. B. and Thompson J. G. (2003). "Effects of in-vivo and invitro environments on the metabolism of the cumulus-oocyte complex and its influence on oocyte developmental capacity." Hum Reprod Update 9(1): 35-48 DOI: $10.1093 /$ humupd/dmg009.

Swain J. E. (2018). "Different mineral oils used for embryo culture microdrop overlay differentially impact media evaporation." Fertility and Sterility 109(3): e53 DOI: 10.1016/j.fertnstert.2018.02.101.

Tae J. C., Kim E. Y., Lee W. D., Park S. P. and Lim J. H. (2006). "Sterile filtered paraffin oil supports in vitro developmental competence in bovine embryos comparable to co-culture." J Assist Reprod Genet 23(3): 121-127 DOI: 10.1007/s10815-006-9024-6.

Van Soom A., Mahmoudzadeh A. R., Christophe A., Ysebaert M. T. and De Kruif A. (2001). "Silicone oil used in microdrop culture can affect bovine embryonic development and freezability." Reprod Domest Anim 36(3-4): 169-176 DOI: 10.1046/j.1439-0531.2001.00281.x.

Wrenzycki C. (2016). "In vitro culture systems: How far are we from optimal conditions?" Anim Reprod Sci 13(3): 279-282 DOI: 10.21451/1984-3143AR869.

Wrenzycki C., Herrmann D., Lucas-Hahn A., Korsawe K., Lemme E. and Niemann H. (2005). "Messenger rna expression patterns in bovine embryos derived from in vitro procedures and their implications for development." Reprod Fertil Dev 17(1-2): 23-35 DOI: $10.1071 / \mathrm{rd} 04109$. 
$\mathrm{Xu} \mathrm{K}$. P., Hoier R. and Greve T. (1988). "Dynamic changes of estradiol and progesterone concentrations during in vitro oocyte maturation in cattle." Theriogenology 30(2): 245-255 DOI: 10.1016/0093-691x(88)90174-4. 


\subsection{Diskussion}

In der vorliegenden Studie wurden die Entwicklungen von Oozyten bzw. Embryonen in zwei Kultursystemen, mit und ohne Ölüberschichtung, verglichen.

Verwendet wurden dafür Wells einer Mikrotiterplatte, jeweils vier Wells wurden in einer Petrischale angeordnet, zwei Wells mit je $100 \mu \mathrm{L}$ Medium befüllt. In die anderen beiden Wells und in die Petrischale wurde destilliertes Wasser zum Schutz vor Evaporation gegeben. Im ölüberschichteten System fand die Überschichtung mit $75 \mu \mathrm{L}$ Paraffinöl, welches für die Nutzung in bovinen IVP-Systemen getestet ist, statt.

In Abbildung 2 sind die verwendeten Well-Systeme, mit und ohne Ölüberschichtung, im Vergleich zum weit verbreiteten Tropfen-System dargestellt.

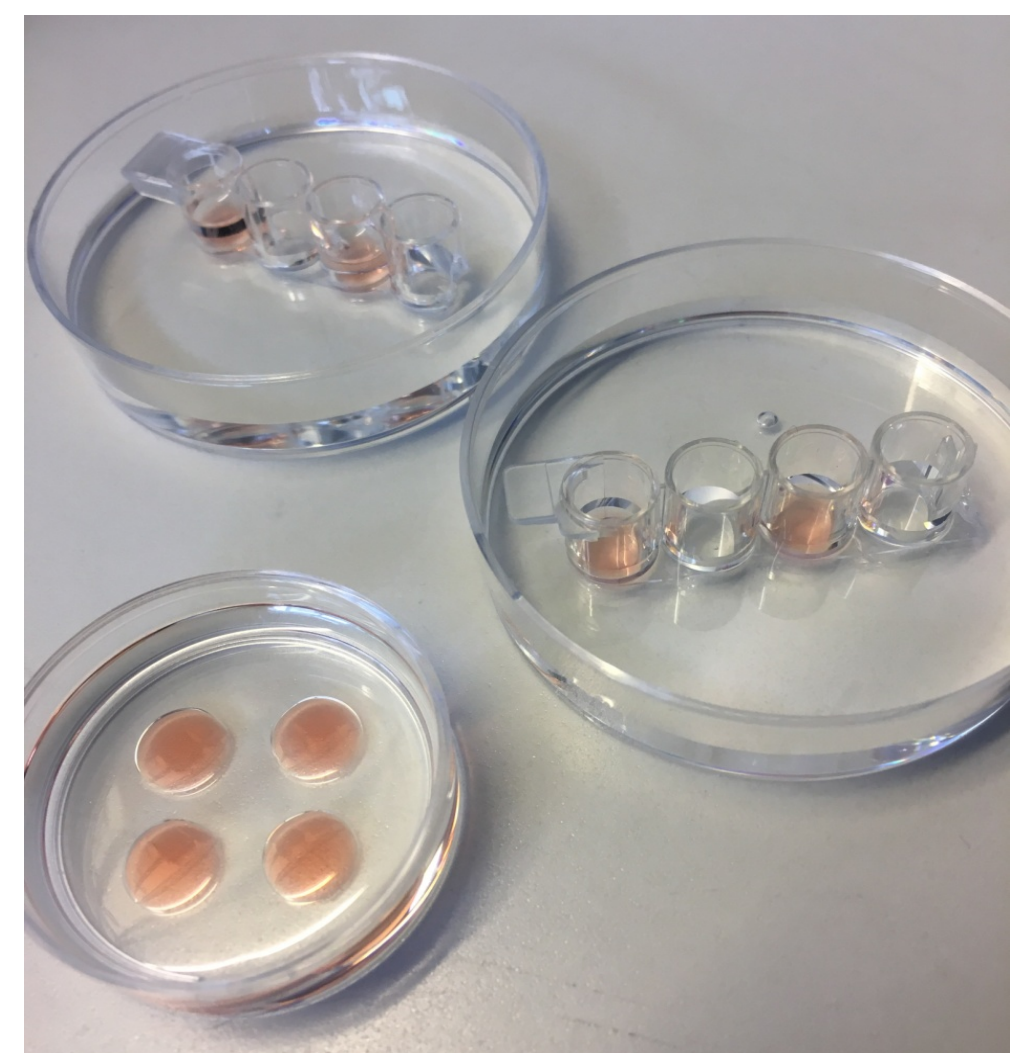

Abbildung 3: Darstellung der Kultursysteme. Von oben nach unten: ölüberschichtetes Well-System, ölfreies Well-System und Tropfen-System.

Sowohl die Maturationsraten der Oozyten als auch die Entwicklungsraten der Embryonen im ölfreien System waren signifikant höher als die Raten der Oozyten, die im ölüberschichteten System maturierten. Dies stimmt mit den Ergebnissen von Shimada et al. (2002) überein, die im ölüberschichteten System ebenfalls geringere Maturationsraten porziner Oozyten feststellten. Die Analyse des Maturationsmediums ergab signifi- 
kant höhere Progesteronkonzentrationen im Medium des ölfreien Systems. Die Östradiolkonzentrationen in den Medien beider Systeme unterschieden sich nicht signifikant voneinander. Im ölfreien System wurde aber auch die Tendenz zu höheren Östradiolkonzentrationen im Medium festgestellt als im ölüberschichteten System. Dass die Steroide in das Öl diffundieren, wurde bereits anhand einer Vielzahl von Studien bestätigt (Miller \& Pursel 1987; Funahashi et al. 1994; Shimada et al. 2002). Da die Steroide, wie oben bereits erwähnt, entscheidende Faktoren für die Entwicklung der Oozyte während der Maturation sind (Moor et al. 1980; Armstrong et al. 1996), sind die schlechteren Maturations- und Entwicklungsraten im überschichteten System vermutlich auf die Absorption der Steroide durch das Öl zurückzuführen. Hier finden sich in der Literatur kontroverse Angaben. Xu et al. (1988) beobachteten eine erhöhte Absorption von Östradiol durch das Öl, aber keinen Einfluss auf die Maturationsraten. Allerdings zeigten sich signifikante Unterschiede zwischen den Teilungsraten in den beiden untersuchten Systemen mit und ohne Ölüberschichtung (Xu et al. 1988). Clemente et al.(2009) stellten ebenfalls geringere Progesteronkonzentrationen im Medium mit Ölüberschichtung fest, aber keinen Einfluss auf die Entwicklung boviner Embryonen. Reinsberg et al. (2004) testeten verschiedene Ölüberschichtungen an humanen Granulosazellen und vermuteten, dass die verminderte Absorption von Östradiol im Vergleich zum Progesteron mit einer geringeren Lipophilie des Östradiols zusammenhängt.

Insgesamt ist hier aber der unterschiedliche Versuchsaufbau der einzelnen Studien zu beachten, denn es wurden unterschiedliche Systeme und verschiedene Medienmengen und Öle eingesetzt. Folglich sind diese Studienergebnisse nur eingeschränkt übertragbar.

Allein die Art des eingesetzten Öls kann die Höhe der Absorption beeinflussen. So wird von Silikonöl beispielsweise mehr Östradiol absorbiert als von Paraffinöl (Miller \& Pursel 1987).

In der vorliegenden Studie muss außerdem berücksichtigt werden, dass zusätzlich zum durchgängig ölfreien bzw. ölüberschichteten System auch verschiedene Kombinationen von ölfreien und ölüberschichteten Teilschritten untersucht wurden. Hier zeigten sich, unabhängig von den Kombinationen, keine signifikanten Unterschiede, weder zwischen den Maturations- noch zwischen den Entwicklungsraten. Das lässt darauf schließen, dass weitere Faktoren für die Entwicklungskompetenz der Oozyten bzw. Embryonen entscheidend sind. In Folgestudien sollte so z.B. die Expression entwicklungsrelevanter 
Gene untersucht werden, um den Einfluss der Ölüberschichtung und die Rolle der Steroide in vitro weiter zu beleuchten.

Die Osmolalität konnte in beiden Systemen insgesamt in einem für die IVP stabilen Rahmen gehalten werden. Die Osmolalität sollte, je nach Teilschritt der IVP, bei 255 295 mOsm/kg liegen (Liu \& Foote 1996; Li et al. 2007; Gasperin et al. 2010). In der vorliegenden Studie zeigten sich nach der Maturation keine signifikanten Unterschiede. An Tag 8 der Kultur wurden die Osmolalitäten erneut bestimmt. Das ölfreie System zeigte nun signifikant niedrigere Osmolalitäten als die Kontrolle und das ölüberschichtete System. In der Literatur werden im ölfreien System ausschließlich höhere Osmolalitäten als Folge der Wasserverdampfung beschrieben, die in unserem Versuch durch destilliertes Wasser in den Zwischenräumen der Wells verhindern wurde. Die niedrigere Osmolalität scheint sich insgesamt nicht negativ auszuwirken, zumal die Veränderung in einem moderaten Bereich liegt. Berücksichtigt werden sollte hier, dass die Messung der Osmolalität nur im Medium ohne Oozyten bzw. Embryonen stattgefunden hat, es wurde also nur das reine Medium als Voraussetzung für die Versuche gemessen. Hier wäre eine Berücksichtigung der Oozyten in Ergänzung wünschenswert. Außerdem ist die Probenanzahl mit vier bis sechs Proben gering.

Das in unserer Studie eingesetzte Medienvolumen von $100 \mu \mathrm{L}$ ist gut geeignet bei begrenzt zur Verfügung stehenden Proben. Allerdings war die Medienmenge für die Untersuchung von Einzelproben über den Radioimmunoassay zu gering, so dass hier lediglich gepoolte Proben eingesetzt werden konnten.

Die Wells der Mikrotiterplatte eignen sich für die IVP, die Handhabung und Beurteilung der Embryonen ist aber gegenüber der mit Öl überschichteten Medientropfen erschwert. Das Medientropfen-System haben wir parallel zur vorliegenden Studie als Laborkontrolle mit aufgenommen. Die verwendeten Well-Systeme zeigten sowohl mit als auch ohne Ölüberschichtung signifikant höhere Entwicklungsraten der Embryonen im Vergleich zur Laborkontrolle.

Damit ist das von uns verwendete Well-System, insbesondere ohne Ölüberschichtung, eine gute Alternative zum etablierten Tropfen-System und kann für den Einsatz in der IVP empfohlen werden. 


\section{Einfluss des Wirkstoffes Glyphosat auf die In-vitro-Maturation und weitere Entwicklung boviner Oozyten}

\subsection{Einleitung}

Glyphosat (N-Phosphonomethyl-Glycin) ist der meistgenutzte Herbizidwirkstoff weltweit (Benbrook 2016). Der Chemiker Dr. Henri Martin synthetisierte Glyphosat erstmals im Jahr 1950. Über Firmenverkäufe gelangte der Wirkstoff schließlich zur USamerikanischen Firma Monsanto. Dort wurde die Verbindung zunächst zur Wasserenthärtung getestet, bevor die herbizide Wirkungsweise durch Dr. John Franz entdeckt wurde. Der Wirkstoff wurde 1974 in den USA patentiert und gleichzeitig für das Pflanzenschutzmittel Roundup zugelassen (Franz et al. 1997).

Pflanzen nehmen das Breitbandherbizid über ihre Oberfläche auf. Das Enzym 5Enolpyruvylshikimat-3-Phosphat-Synthase (EPSP-Synthase), das innerhalb des Shikimat-Weges für die Biosynthese der Aminosäuren Phenylalanin, Tyrosin und Tryptophan essentiell ist, wird gehemmt. Diese Blockade führt zum Absterben der Pflanze (Steinrücken \& Amrhein 1980; Schönbrunn et al. 2001). Der Shikimat-Weg ist ein Stoffwechselweg, der ausschließlich in Pflanzen und Mikroorganismen stattfindet. Säugetiere sind nicht in der Lage, die oben genannten Aminosäuren selbst zu bilden (Kishore \& Shah 1988).

Glyphosathaltige Herbizide werden heute hauptsächlich in Beständen glyphosatresistenter Kulturpflanzen eingesetzt (James 2011). In der EU ist der Einsatz auf gentechnisch unveränderte Pflanzen beschränkt, aber dennoch von großer Bedeutung für die Unkrautbekämpfung in der Landwirtschaft, insbesondere für die Stoppelbearbeitung (BVL 2017).

Im Jahr 2017 verlängerte die Europäische Kommission die Zulassung von Glyphosat für weitere fünf Jahre bis Ende 2022 (EC 2017). Der Abstimmung gingen verschiedene Studien über die mögliche kanzerogene Wirkung des Stoffes voraus. Die Internationale Agentur für Krebsforschung (IARC) führte eine gemeinsame Bewertung des Wirkstoffs, des Hauptmetaboliten Aminomethylphosphonsäure (AMPA) und verschiedener glyphosathaltiger Pflanzenschutzmittel durch und ordnete Glyphosat der gleichen Kategorie wie rotes Fleisch, der Kategorie 2A ,wahrscheinlich krebserregend beim Menschen“, zu (IARC 2015). 
Die Europäische Behörde für Lebensmittelsicherheit (EFSA) widerspricht der Einschätzung der IARC und hält ein kanzerogenes Potenzial von Glyphosat für den Menschen für unwahrscheinlich. Glyphosathaltige Pflanzenschutzmittel wurden bei der Auswertung der EFSA, die in Zusammenarbeit mit dem deutschen Bundesinstitut für Risikobewertung (BfR) entstanden ist, allerdings nicht berücksichtigt, sondern nur der reine Wirkstoff untersucht (EFSA 2015). Die unterschiedlichen Aussagen zum Krebsrisiko durch Glyphosat sind auf die verschiedenen Bewertungsschlüssel der Behörden zurückzuführen (Tarazona et al. 2017). Die Ergebnisse der EFSA wurden allerdings sowohl durch die US-Umweltschutzbehörde (EPA), als auch durch die Welternährungs- und die Weltgesundheitsorganisation bestätigt (EPA 2018; FAO/WHO 2019). Das BfR sah in einer erneuten Stellungnahme im Jahr 2019 ebenfalls keinen Anlass zu einer Änderung der Wirkstoffbewertung (BfR 2019).

Neben Studien zur kanzerogenen Einstufung von Glyphosat, gibt es eine Vielzahl an Untersuchungen zur Auswirkung von Glyphosat und glyphosathaltigen Pflanzenschutzmitteln auf das Reproduktionssystem.

Roundup führte so beispielsweise in Sertoli-Zellen bei präpubertären Ratten zum Zelltod durch oxidativen Stress (De Liz Oliveira Cavalli et al. 2013) und zu mitochondrialer Dysfunktion in einer Sertoli-Zelllinie der Maus (Vanlaeys et al. 2018).

Auch Störungen weiblicher Fortpflanzungsfunktionen verschiedener Wirbeltiere wurden ermittelt. Slaby et al. (2019) beobachteten Auswirkungen von Glyphosat und Roundup auf die Oozytenreifung des Krallenfrosches (Xenopus laevis). Durch eine erhöhte Retinsäureaktivität verursachte Missbildungen in Xenopus laevis und Hühnerembryonen, wurden von Paganelli et al. (2010) ermittelt. Zhang et al. (2019). berichteten von oxidativem Stress und Apoptose bei Mäuseoozyten. Perego et al. (2017) stellten einen negativen Einfluss von Glyphosat und Roundup auf die Steroidogenese und Proliferation boviner Granulosazellen in vitro fest. Dabei hatte Roundup einen stärkeren negativen Effekt auf die Zellfunktion als reines Glyphosat. Eine höhere Toxizität von Pflanzenschutzmitteln im Vergleich zum reinen Wirkstoff wurde auch in anderen Studien beobachtet (Richard et al. 2005; Benachour \& Séralini 2009; Vanlaeys et al. 2018) und den Polyoxyethylenamin (POEA)-Verbindungen zugeschrieben (Benachour \& Séralini 2009; Vanlaeys et al. 2018). Diese Zusätze vermitteln die Aufnahme der Wirkstoffe, indem sie die Zellpermeabilität verändern. Die EFSA bestätigte in Absprache mit dem BfR die erhöhte Toxizität von POE-Tallowaminen (EFSA_POEA 2015). Dies 
führte $2016 \mathrm{zu}$ einem Verbot dieser Verbindungen als Beistoff in glyphosathaltigen Pflanzenschutzmitteln durch die Europäische Kommission (EC 2016).

Zusätzlich wurde Roundup in einigen Studien als endokriner Disruptor eingestuft, nachdem es zur Hemmung der Cytochrom-450-Aromatase-Aktivität in humanen Plazentazellen (Richard et al. 2005) und zur Hemmung von Östrogenrezeptoren in humanen Leberzellen führte (Gasnier et al. 2009). Das von der EPA entwickelte Endocrine Disruptor Screening Program (EDSP) untersuchte ebenfalls den potenziellen Einfluss von Glyphosat auf den Östrogen-, Androgen- und Schilddrüsenstoffwechsel und fand keine Hinweise auf eine Wechselwirkung (EPA 2015). Auch die EFSA stellte keine endokrine Wirkung von Glyphosat fest (EFSA 2017). Von beiden Behörden wurde allerdings auch hier nur der reine Wirkstoff bewertet.

Nutztiere können Glyphosatrückstände über das Futter aufnehmen, über die genaue Aufnahmemenge und die Stoffwechselwege ist jedoch wenig bekannt. Schnabel et al. (2017) untersuchten Futterrationen mit unterschiedlichen Glyphosatkonzentrationen. Keine der Konzentrationen zeigte Auswirkungen auf die Gesundheit, Leistung oder Energiebilanz der laktierenden Kühe. Von Soosten et al. (2016) stellten im Rahmen ihres Fütterungsversuchs mit Milchkühen fest, dass $61 \%$ des aufgenommenen Glyphosats unabhängig von der gefütterten Konzentration über den Kot und $8 \%$ über den Urin ausgeschieden wurden. In der Milch konnte kein Glyphosat nachgewiesen werden (von Soosten et al. 2016).

Eine weitere Studie zeigte Glyphosatrückstände von 15 bis $25 \mathrm{ng} / \mathrm{g}$ in verschiedenen Organen geschlachteter Kühe (Krüger et al. 2014).

Ebenfalls untersucht wurde die Zusammensetzung der Pansenflora nach der Aufnahme von Glyphosat über das Futter. Riede et al. (2016) konnten hier mit Hilfe der Pansensimulationstechnik RUSITEC keinen Effekt auf das ruminale Mikrobiom feststellen.

Insgesamt ist die Wirkung von Glyphosat auf landwirtschaftliche Nutztiere noch nicht hinreichend untersucht. Auch über die Reproduktionsleistung des Rindes unter dem Einfluss von Glyphosat gibt es bisher keinerlei Aussagen.

Ziel dieser Studie war es daher, erstmalig den Einfluss von Glyphosat, in reiner Form und in der Formulierung von Roundup, auf die In-vitro-Maturation und weitere Entwicklung boviner Oozyten zu untersuchen. Da die frühe Embryonalentwicklung des Rindes auch als Model für die Entwicklung des Menschen gilt (Wrenzycki et al. 2005), 
können hieraus möglicherweise ebenfalls neue Erkenntnisse für den Humanbereich abgeleitet werden. 


\title{
4.2 Effect of glyphosate on bovine oocyte development during in vitro maturation
}

\author{
S. Diers ${ }^{1}$, C. Blaschka ${ }^{1}$, A. Silbersdorff ${ }^{2}$, C. Knorr $^{1}$, J. Tetens ${ }^{1}$ \\ ${ }^{1}$ Department of Animal Sciences, Georg-August-University Göttingen, Göttingen, Germany \\ ${ }^{2}$ Department of Economics, Georg-August-University Göttingen, Göttingen, Germany
}

\section{Erschienen in:}

Reproduction in Domestic Animals 2019, 54(S1):3

onlinelibrary.wiley.com/doi/10.1111/rda.13387

DOI: $10.1111 /$ rda. 13387

Glyphosate is the most widely used agent for non-selective herbicides worldwide (Benbrook 2016, Environ Sci Eur, 28:3). The aim of this study is to determine, whether the active ingredient alone or in formulation with Roundup, the global market leader of glyphosate-based herbicides, affects the maturation and further development of bovine oocytes. Ovaries of healthy cows were collected at a slaughterhouse. The selected cumulus-oocyte-complexes matured for 24 hours. Glyphosate (96\%) and Roundup were added to the maturation medium in concentrations of $1 \mu \mathrm{g} / \mathrm{ml}$ and $10 \mu \mathrm{g} / \mathrm{ml}$ each. After 24 hours of incubation $\left(39^{\circ} \mathrm{C}, 5 \% \mathrm{CO} 2\right)$, the oocytes were stained with Hoechst 33342 to detect the metaphase II stage. The maturation rates of the three tested groups Glyphosate, Roundup and Control showed no significant differences irrespective of the used concentrations. On day seven and eight post-fertilization the embryos were evaluated morphologically. The development rates also showed no significant differences between test groups and concentrations. After addition of $1 \mu \mathrm{g} / \mathrm{ml}$, the average rates of development on day eight were 19.2\% $( \pm 10,8 \%)$ for pure Glyphosate $(\mathrm{n}=301), 22.6 \%( \pm$ $12.3 \%)$ for Roundup $(\mathrm{n}=315)$ and $24.1 \%( \pm 9.4 \%)$ for Control $(\mathrm{n}=295)$. After adding $10 \mu \mathrm{g} / \mathrm{ml}$ to the maturation medium, the developmental averages on day eight were $26.9 \%( \pm 14.7 \%)$ for Glyphosate $(n=523), 24.1 \%( \pm 12.6 \%)$ for Roundup $(n=479)$ and $25.6 \%( \pm 11.0 \%)$ for Control $(\mathrm{n}=389)$. In this study, negative effects of glyphosate and Roundup on bovine oocyte development could not be detected so far, further analysis will follow. 


\title{
4.3 Does glyphosate affect the expression of developmental genes in bovine oo- cytes?
}

\author{
S. Diers ${ }^{1}$, C. Blaschka ${ }^{1}$, I. Kilic ${ }^{1}$, A. Silbersdorff ${ }^{2}$, J. Tetens ${ }^{1}$ \\ ${ }^{1}$ Department of Animal Sciences, Georg-August-University Göttingen \\ ${ }^{2}$ Department of Economics, Georg-August-University Göttingen
}

\section{Erschienen in:}

Reproduction in Domestic Animals 2020, 55(S1): 8 .

onlinelibrary.wiley.com/doi/10.1111/rda.13591

DOI: $10.1111 /$ rda.13591

The aim of this study is to determine, whether the active ingredient glyphosate alone or in formulation with Roundup affects the expression of developmentally important genes in bovine oocytes. Ovaries of healthy cows were collected at a slaughterhouse. Glyphosate and Roundup were added to the maturation medium in active agent concentration of $10 \mu \mathrm{g} / \mathrm{ml}$ each. After $24 \mathrm{~h}$ of incubation $\left(39^{\circ} \mathrm{C}, 5 \% \mathrm{CO} 2\right)$, oocytes were denuded individually for separate treatment of cumulus cells and oocytes ( $n=12$ for each group). Total RNA was isolated with TRIzol and cDNA was synthesized. The relative expression of the gene transcripts was determined by qPCR with EvaGreen detection. The samples were quantified according to the method of Pfaffl (Pfaffl, Nucleic Acids Res 2001, 29:e45). The expression levels were analysed via ANOVA and Tukey's HSD test. Bone morphogenetic protein 15 was significantly higher expressed in the oocytes of the Roundup group compared to the control $(\mathrm{p}<0.05)$. Zygote arrest 1 was significantly higher expressed in oocytes of the glyphosate group $(\mathrm{p}<0.01)$ and of the Roundup group $(\mathrm{p}<0.001)$ compared to the control. Estrogen receptor 1 was significantly higher expressed in cumulus cells of the glyphosate group than in the control $(p<0.05)$. No significant differences in expression could be observed for growth differentiation factor 9 , nuclear progesterone receptor and hydroxy-delta-5-steroid dehydrogenase. In this study, negative effects of glyphosate and Roundup on bovine oocyte development could not be detected. 


\subsection{Beeinflusst Glyphosat die In-vitro-Maturation und weitere Entwicklung bo- viner Oozyten?}

Sophie Diers ${ }^{1}$, Carina Blaschka ${ }^{1}$, Isabel Kilic ${ }^{1}$, Anna Rathgeb ${ }^{2}$, A. Silbersdorff ${ }^{3}$, P. Karlovsky $^{2}$, J. Tetens ${ }^{1}$

${ }^{1}$ Department für Nutztierwissenschaften, Georg-August-Universität, Burckhardtweg 2, 37077 Göttingen,

${ }^{2}$ Department für Nutzpflanzenwissenschaften, Georg-August-Universität, Grisebachstraße 6, 37077 Göttingen,

${ }^{3}$ Department für Volkswirtschaftslehre, Georg-August-Universität Göttingen, Humboldtallee 3, 37073 Göttingen,

Korrespondenzautorin: Sophie Diers, Burckhardtweg 2, 37077 Göttingen, 0551 399740, sophie.diers@uni-goettingen.de

\section{Erscheint in:}

Züchtungskunde 2020, 92(4)

ISSN: 0044-5401

\section{Zusammenfassung}

Ziel der Arbeit war es, einen möglichen Einfluss des Wirkstoffes Glyphosat auf die Maturation und weitere Entwicklung boviner Oozyten zu untersuchen.

Dazu wurden dem Maturationsmedium der Herbizidwirkstoff Glyphosat sowie ein glyphosathaltiges Pflanzenschutzpräparat mit Glyphosatkonzentrationen von $1 \mu \mathrm{g} / \mathrm{ml}$ und $10 \mu \mathrm{g} / \mathrm{ml}$ zugesetzt. Sowohl die Maturationsraten der Oozyten, die Teilungs- und Entwicklungsraten der Embryonen als auch das Lebend/Tot-Verhältnis der gefärbten Zellen unterschieden sich nicht zwischen den Versuchsgruppen und den eingesetzten Konzentrationen. Die relativen Expressionslevel ausgesuchter entwicklungsrelevanter Gene wurden nach Zugabe der höheren Wirkstoffkonzentrationen untersucht. Dabei wurden signifikant höhere Expressionen der Gene bone morphogenetic protein 15 (BMP15) und zygote arrest 1 (ZAR1) in Oozyten und von estrogen receptor 1 (ESR1) in Kumuluszellen nach Zugabe des Wirkstoffes Glyphosat im Vergleich zur Kontrolle nachgewiesen.

Es konnte kein negativer Einfluss des Wirkstoffes Glyphosat auf die Maturation und weitere Entwicklung boviner Oozyten bzw. Embryonen festgestellt werden. Eine unterschiedliche Wirkung von Roundup im Vergleich zum reinen Wirkstoff konnte ebenfalls nicht ermittelt werden. 
Schlüsselwörter: bovine Oozyten, Glyphosat, glyphosathaltiges Herbizid, In-vitroMaturation

\section{Summary}

Does glyphosate affect the in vitro maturation and further development of bovine oocytes?

The aim of this study was to determine, whether glyphosate affects the maturation and further development of bovine oocytes in vitro. The pure active ingredient and a glyphosate-based herbicide were compared in the analyses. For this purpose, glyphosate and the glyphosate-based herbicide were added to the maturation medium in active substance concentrations of $1 \mu \mathrm{g} / \mathrm{ml}$ and $10 \mu \mathrm{g} / \mathrm{ml}$. The maturation, cleavage and development rates of the tested groups showed no statistically significant differences irrespective of the concentrations used. The average ratio of live to dead cells of stained blastocysts also showed no significant differences between groups treated with glyphosate and the controls. The relative expression levels of selected genes were only evaluated for the concentration of $10 \mu \mathrm{g} / \mathrm{ml}$. The bone morphogenetic protein 15 (BMP15) and zygote arrest $1(Z A R l)$ were significantly higher expressed in oocytes treated with the active ingredient as compared to the control. In cumulus cells, the relative expression of the estrogen receptor 1 (ESR 1 ) was significantly higher after treatment with the active ingredient than in the control. No differences between the effect of glyphosate formulated as a herbicide and glyphosate in pure form were observed.

Keywords: bovine oocytes, glyphosate, glyphosate-based herbicide, in vitro maturation

\section{Einleitung}

Glyphosat ist der meistgenutzte Herbizidwirkstoff weltweit (BENBROOK, 2016). In der EU ist der Einsatz auf gentechnisch unveränderte Pflanzen beschränkt, aber dennoch von großer Bedeutung für die Unkrautbekämpfung in der Landwirtschaft, insbesondere für die Stoppelbearbeitung (BVL, 2017). SLABY et al. (2019) beobachteten Auswirkungen von Glyphosat und Roundup auf die Eizellreifung des Krallenfrosches (Xenopus laevis). Durch eine erhöhte Retinsäureaktivität verursachte Missbildungen in Xenopus laevis und Hühnerembryonen, wurden von PAGANELLI et al. (2010) ermittelt. PEREGO et al. (2017) stellten einen negativen Einfluss von Glyphosat und Roundup auf die Steroidogenese und Proliferation boviner Granulosazellen in vitro fest. Dabei hatte Roundup 
einen stärkeren negativen Effekt auf die Zellfunktion als reines Glyphosat. Nutztiere können Glyphosatrückstände über das Futter aufnehmen, über die genaue Aufnahmemenge und die Stoffwechselwege ist jedoch wenig bekannt. KRÜGER et al. (2014) zeigten Glyphosatrückstände von 15 bis 25 ng/g in verschiedenen Organen geschlachteter Kühe. Ziel dieser Studie war es daher, erstmalig den Einfluss von Glyphosat, in reiner Form und in der Formulierung von Roundup, auf die In-vitro-Maturation und weitere Entwicklung boviner Oozyten zu untersuchen.

\section{Material und Methoden}

\subsection{Sammlung der bovinen Kumulus-Oozyten-Komplexe}

Die Studie wurde in Übereinstimmung mit den in Deutschland geltenden rechtlichen und ethischen Anforderungen durchgeführt. Es wurden keine Tiere zu Studienzwecken euthanasiert. Die Proben wurden während des konventionellen Schlachtprozesses entnommen. Schlachtpraktiken wurden gemäß der EU-Verordnung (EG) Nr. 1099/2009 zum Schutz von Tieren zum Zeitpunkt der Tötung (EU, 2009) eingehalten.

Die Ovarien von Kühen wurden in einem Schlachthof entnommen. Kumulus-OozytenKomplexe (KOK) wurden durch die Slicing-Methode gewonnen (ECKERT und NIEMANN, 1995) und morphologisch beurteilt. Nach den Kriterien von PAVLOK et al. (1992) wurden die Kategorien 1 bis 3 verwendet. Die ausgewählten KOK (n=30/Gruppe) wurden in $250 \mu 1$ Maturationsmedium ohne Ölüberschichtung übertragen (ABELE et al., 2012). Dem Maturationsmedium wurde Glyphosat (96\%, Sigma-Aldrich, Deutschland) in Wirkstoffkonzentrationen von $1 \mu \mathrm{g} / \mathrm{ml}$ (G1) und $10 \mu \mathrm{g} / \mathrm{ml}$ (G10) zugesetzt. Das glyphosathaltige Herbizid Roundup (Roundup LB Plus, 360 g/l Glyphosat, Monsanto, Deutschland) wurde dem Maturationsmedium ebenfalls in den gleichen Wirkstoffkonzentrationen von $1 \mu \mathrm{g} / \mathrm{ml}$ (GBH1) und $10 \mu \mathrm{g} / \mathrm{ml}$ (GBH10) zugesetzt. Da die beiden Konzentrationen nacheinander getestet wurden, gibt es zwei Kontrollgruppen ohne Zusatz. Eine Kontrollgruppe, die mit der Konzentration von $1 \mu \mathrm{g} / \mathrm{ml}(\mathrm{CON}-1)$ verglichen wurde, und eine Kontrollgruppe, die im Vergleich zur Konzentration von $10 \mu \mathrm{g} / \mathrm{ml}$ (CON-10) untersucht wurde.

Die KOK reiften 24 Stunden bei $39^{\circ} \mathrm{C}$ und $5 \% \mathrm{CO}_{2}$ im Inkubator. 


\subsection{Maturationsraten}

Nach der Maturation wurden die denudierten Oozyten $(\mathrm{n}=30 / \mathrm{Gruppe})$ mit 0,004 \% Hoechst bisbenzimid 33342 (Sigma-Aldrich, Deutschland), wie bereits beschrieben (BlAsCHKA et al., 2019), gefärbt, um die Metaphase II als Indikator für die nukleäre Reifung nachzuweisen. Das Stadium der Metaphase II ist durch die Metaphaseplatte und das ausgeschleuste erste Polkörperchen charakterisiert. Für G1, GBH1 und CON-1 wurden sieben Replikate innerhalb von sechs Wochen analysiert. Für G10, GBH10 und CON-10 wurden acht Replikate innerhalb von sechs Wochen analysiert.

\subsection{Teilungs- und Entwicklungsraten}

Nach der Maturation wurden die KOK ( $\mathrm{n}=30$ /Gruppe) nach STINSHOFF et al. (2011) fertilisiert. Neunzehn Stunden später wurden die denudierten Zygoten für eine Woche im Inkubator mit $5 \% \mathrm{O}_{2}, 5 \% \mathrm{CO}_{2}$ und $39^{\circ} \mathrm{C}$ kultiviert, wie bereits beschrieben (STINSHOFF et al., 2011).

Die Teilungs- und Entwicklungsraten der Embryonen wurden am achten Tag der Kultivierung morphologisch beurteilt und der prozentuale Anteil der Oozyten, die sich bis zum Morula- und Blastozystenstadium entwickelt haben, wurde notiert. Die Raten von G1, GBH1 und CON-1 wurden über einen Zeitraum von 18 Wochen mit 26 bis 33 Replikaten vermerkt. Für G10, GBH10 und CON-10 wurden 23 bis 27 Replikate über einen Zeitraum von 16 Wochen analysiert.

\subsection{Lebend/Tot-Verhältnis}

Die Lebend/Tot-Färbung wurde nach STINSHOFF et al. (2011) am achten Tag der Kultivierung an expandierten Blastozyten durchgeführt. Ethidium homodimer (Invitrogen, USA) und Hoechst bisbenzimid 33342 wurden in Konzentrationen von 0,01 \% bzw. $0,004 \%$ eingesetzt, um zwischen intakten und toten Zellen zu unterscheiden. Die expandierten Blastozyten ( $\mathrm{n}=2-3 /$ Gruppe) wurden wöchentlich über einen Zeitraum von vier bis fünf Wochen gefärbt. Die Beurteilung der gefärbten Blastozysten fand mit Hilfe des Fluoreszenzmikroskops Eclipse Ci (Nikon, Deutschland) statt. Die Zellzählung wurde mit dem Bildbeurteilungsprogramm Fiji (Version 2.0.0-rc-69/1.52p, 2018, ImageJ) durchgeführt. 


\subsection{Expression entwicklungsrelevanter Gene}

Zur Isolierung der Gesamt-RNA wurden Kumuluszellen und Oozyten nach der Maturation separiert und in phosphatgepufferter Kochsalzlösung (Sigma-Aldrich, Deutschland) mit $0,1 \%$ Polyvinylalkohol (Sigma-Aldrich, Deutschland) bei $-80^{\circ} \mathrm{C}$ gelagert. Für jede Versuchsgruppe wurden zwölf einzelne Eizellen und der entsprechende Kumulus untersucht. Die Gesamt-RNA wurde, wie bereits beschrieben, mit TRIzol (Invitrogen, USA) isoliert (MACABELLI et al., 2014). Die extrahierte RNA wurde in $10 \mu$ RNAse-freiem $\mathrm{H}_{2} \mathrm{O}$ aufgelöst und mit dem High Capacity cDNA Reverse Transcription Kit (Applied Biosystems, USA) wurde nach den Anweisungen des Herstellers die reverse Transkription durchgeführt. Die genomische DNA-Kontamination wurde durch Endpunkt-PCR unter Verwendung von intron-übergreifenden Primern getestet, die für bone morphogenetic protein 15 (BMP15), estrogen receptor 1 (ESR1), hydroxy-delta-5-steroid dehydrogenase $(H S D 3 B 1)$, nuclear progesterone receptor $(P G R)$ and zygote arrest 1 (ZARl) spezifisch sind.

Die relative Expression der Gentranskripte wurde mittels qPCR mit EvaGreenDetektion (Biotium, USA) ermittelt.

Growth differentiation factor 9 (GDF9), BMP15 und ZAR1 wurden untersucht, um die Entwicklungskompetenz der Oozyten zu beurteilen. Da die Steroidsynthese für eine vollständige Eizellreifung unerlässlich ist (CARPINTERO et al., 2014), wurden die Expressionen von ESR1, PGR und HSD3B1 in den Kumuluszellen untersucht.

Die für die Normalisierung verwendeten Referenzgene waren tyrosine 3monooxygenase/tryptophan 5-monooxygenase activation protein zeta (YWHAZ) und peptidylprolyl isomerase A (PPIA).

Die Primerpaare für $B M P 15, Z A R 1$ und $H S D 3 B 1$ wurden mit der Software Primer3 Input (Version 0.4.0) entworfen und ihre Spezifität wurde mit NCBI Primer-BLAST überprüft. ESR1 wurde auf der Grundlage von BLASCHKA et al. (2019) entworfen. Die Primer für GDF9 und $P G R$ wurden von BLASCHKA et al. (2019) übernommen. Der Vorwärts-Primer für $Y W H A Z$ wurde von HUGHES et al. (2015) entnommen, der Rückwärts-Primer wurde selbst entworfen. Die Primersequenzen für PPIA wurden aus GANGULY et al. (2012) verwendet. Alle für die qPCR verwendeten Primer sind in Tabelle 1 aufgeführt. 
Tab. 1. In der qPCR eingesetzte Oligonukleotide

Oligonucleotides used for qPCR

\begin{tabular}{|c|c|c|c|c|}
\hline Gen & $\begin{array}{c}\text { Sequenz } \\
\left(5^{\prime}-3^{\prime}\right)\end{array}$ & $\begin{array}{l}\text { Fragment } \\
\text { Größe } \\
\text { (bp) }\end{array}$ & $\begin{array}{l}\text { Primer } \\
\text { Position }\end{array}$ & $\begin{array}{l}\text { GenBank } \\
\text { Nummer }\end{array}$ \\
\hline \multirow[t]{2}{*}{$B M P 15$} & f: AGTGGACACCCTAGGGAAAAC & 202 & 241 & NM_0010 \\
\hline & r: GGTGGGAATGAGTTAGGTGA & & 442 & 31752 \\
\hline \multirow[t]{2}{*}{ GDF9 } & f: TCCTTTGGTTTTGCTGCTTT & 204 & 57 & NM_1746 \\
\hline & r: GTTCCCTGTGCCCATCATAC & & 260 & 81.2 \\
\hline \multirow[t]{2}{*}{ ZARl } & f: GAGTGGAGGATATCACCTGC & 215 & 989 & NM_0010 \\
\hline & r: TTCACAGTGGGACCTCAGTT & & 1203 & 76203.1 \\
\hline \multirow[t]{2}{*}{$H S D 3 B 1$} & f: GCGAGAGACCATCATGAACG & 192 & 383 & NM_1743 \\
\hline & r: TATGGGTATGGAGAGGACCA & & 574 & 43 \\
\hline \multirow[t]{2}{*}{$P G R$} & f: TACCTTAGGCCGGATTCAGA & 197 & 1570 & NM_0012 \\
\hline & r: CAATCGTTTCTTCCAGCACA & & 1766 & 05356 \\
\hline \multirow[t]{2}{*}{ ESR1 } & f: GCCTCAAATCCATCATCTTGCT & 91 & 1495 & NM_0010 \\
\hline & r: CGGTGGATGTGGTCCTTCT & & 1585 & 01443 \\
\hline \multirow[t]{2}{*}{ PPIA } & f: ATGCTGGCCCCAACACAA & 101 & 316 & NM_1783 \\
\hline & r: СССТСТTТСАССТTGCCAAA & & 416 & 20.2 \\
\hline \multirow[t]{2}{*}{$Y W H A Z$} & f:CTACCGCTACTTGGCTGAGG & 121 & 428 & NM_1748 \\
\hline & r:AGGATGTGTTGGTTGCATTTC & & 548 & 14.2 \\
\hline
\end{tabular}

Jedes PCR-Fragment wurde nach Sanger sequenziert und an die entsprechende Referenzsequenz angepasst. Die Spezifität wurde vor den qPCR-Analysen durch NucleotidBLAST (https://blast.ncbi.nlm.nih.gov/Blast.cgiPROGRAM=blastn\&PAGE_TYPE= BlastSearch\&LINK_LOC=blasthome) bewertet, um die Amplifikation des korrekten Gens sicherzustellen.

PCR-Produkte wurden unter Verwendung von $2 \mu$ cDNA (cDNA-Oozyten 1:2 verdünnt), 5 mmol/1 dNTPs (Roche, Schweiz), $10 \mu \mathrm{mol} / 1$ jedes Primers (Sigma-Aldrich, Deutschland), 0,5 $\mu$ l EvaGreen und 1,5 U FastStart Taq-Polymerase in 1x PCR-Puffer mit $\mathrm{MgCl}_{2}$ und 1x GC-Lösung (Roche, Schweiz) in einem Endvolumen von $25 \mu 1$ amplifiziert.

Die qPCR wurde in einem Stratagene Mx3005P Real-Time Cycler (Agilent, USA) mit folgendem thermischen Profil durchgeführt: Denaturierung für $10 \mathrm{~min}$ bei $95^{\circ} \mathrm{C}, 38$ Zyklen von $30 \mathrm{~s}$ bei $95^{\circ} \mathrm{C}, 30 \mathrm{~s}$ bei $58^{\circ} \mathrm{C}$ und $30 \mathrm{~s}$ bei $72^{\circ} \mathrm{C}$. Auf die Amplifikation folgte eine Schmelzkurvenmessung mit 1 min bei $95^{\circ} \mathrm{C}, 30 \mathrm{~s}$ bei $70^{\circ} \mathrm{C}$, Erwärmung der Proben auf $95^{\circ} \mathrm{C}$, wobei die Änderung der Fluoreszenz bei jedem Anstieg um $0,5^{\circ} \mathrm{C}$ gemessen wurde. 
Die Amplifikationseffizienz wurde mit Hilfe von Standardkurven berechnet, die durch acht fünffach serielle Verdünnungen bekannter Konzentrationen der Zielamplifikate erzeugt wurden.

Jede Probe wurde in Dreifachbestimmung analysiert und die Proben wurden nach PFAFFL (2001) quantifiziert.

\subsection{Quantifizierung von Glyphosat und AMPA über HPLC-MS/MS}

Die Maturationsmedien der Versuchsgruppen mit Glyphosat- bzw. Roundup-Zusatz wurden nach 24-stündiger Maturation mittels HPLC-MS/MS auf das Vorhandensein des Wirkstoffs Glyphosat und seines Metaboliten AMPA untersucht.

Zusätzlich wurde von insgesamt 24 Kühen vom Schlachthof über einen Zeitraum von sechs Wochen Follikelflüssigkeit entnommen. Die Flüssigkeit wurde mittels HPLCMS/MS auf Glyphosat-Rückstände untersucht, um eine frühere Exposition auszuschließen.

Alle verwendeten Chemikalien und Reagenzien wurden von Sigma-Aldrich (Deutschland) gekauft, sofern nicht anders angegeben. Die Proben wurden nach ZOUAOUI et al. (2013) mit leichten Modifikationen aufbereitet. Die Methode basiert auf einer Derivatisierung der Analyten mit Para-Toluolsulfonylchlorid (PTSCl), gefolgt von einer Flüssig-Flüssig-Extraktion unter sauren Bedingungen, um die derivatisierten Produkte zu konzentrieren.

Für die Deproteinisierung wurden 0,25 ml Acetonitril zu $1 \mathrm{ml}$ der Probe des Maturationsmediums und 0,5 ml Acetonitril zu $1 \mathrm{ml}$ der Probe der Follikelflüssigkeit zugegeben. Die Derivatisierung wurde durch Inkubation in 0,625 $\mathrm{ml}$ Probe mit 0,5 $\mathrm{ml} \mathrm{0,4} \mathrm{M}$ Phosphatpuffer mit pH 11 und 0,25 ml PTSCl (40 g/l in Acetonitril) für $15 \mathrm{~min}$ in einem Ultraschallbad und weitere $15 \mathrm{~min}$ in einem Wasserbad bei $50^{\circ} \mathrm{C}$ durchgeführt. Nach Zugabe von 0,5 ml 6 M Salzsäure wurden die PTSCl-Derivate von Glyphosat und AMPA in $4 \mathrm{ml}$ Ethylacetat extrahiert. Über Nacht wurden 3,5 $\mathrm{ml}$ des Extrakts mittels Speedvac (Christ, Deutschland) getrocknet. Der Trockenrückstand wurde in 0,15 ml 20 $\mathrm{mM}$ Ammoniumformiatpuffer ( $\mathrm{pH}$ 3) gelöst. Die Proben wurden in ein Infinity-IIHochleistungs-Flüssigkeitschromatographiesystem in Verbindung mit einem Agilent 6460 Triple-Quadrupol-Tandem-Massenspektrometer (Agilent, Deutschland) injiziert. Zur externen Kalibrierung wurden zu Beginn des Extraktionsverfahrens nicht kontami- 
nierte Follikelflüssigkeit bzw. nicht kontaminiertes Maturationsmedium mit Glyphosat und AMPA mit Konzentrationen von 50 bis $1000 \mathrm{ng} / \mathrm{ml}$ gespikt.

Es wurde eine Kinetex C18-Säule (2,5 x 100 mm, 2,5 $\mu \mathrm{m}$ Partikelgröße) von Phenomenex (Deutschland) verwendet und ein linearer Gradient von 5 bis $98 \%$ Methanol in Wasser für 10 Minuten gefahren, wobei sowohl Wasser als auch Methanol mit 0,1 \% HPLC-MS-Ameisensäure angesäuert wurden. Methanol in HPLC-MS-Qualität wurde von Th. Geyer (Deutschland) gekauft und destilliertes Wasser wurde durch ein AriumPro-Wassersystem (Sartorius, Deutschland) nochmals gereinigt. Für die Injektion wurden jeweils $20 \mu 1$ der Proben verwendet und die Flussrate wurde auf $200 \mu 1 /$ min eingestellt.

Die Massenübergänge wurden nach ZOUAOUI et al. (2013) ausgewählt. Der Quantifier für Glyphosat betrug 322,2 $\rightarrow$ 278,2 und der Qualifier 322,2 $\rightarrow$ 155,3. Für AMPA wurde 264,0 $\rightarrow$ 63,0 als Quantifier und 264,0 $\rightarrow$ 81,1 als Qualifier festgelegt.

\subsection{Statistische Analysen}

Statistische Analysen wurden mit $R$ (Version 3.4.4; R Development Core Team, 2018) durchgeführt.

Die Maturationsraten, die Teilungs- und Entwicklungsraten, das Lebend/Tot-Verhältnis, und auch die relativen Expressionslevel der Gentranskripte zwischen den Behandlungen innerhalb einer Konzentration wurden mittels ANOVA und anschließendem Tukey's HSD Test analysiert. Die Ergebnisse für die beiden jeweiligen Konzentrationen wurden mit Hilfe eines linearen Regressionsmodells verglichen. Ein p-Wert $<0,05$ wurde als statistisch signifikant bewertet.

\section{Ergebnisse}

Sowohl die Maturations- als auch die Teilungs- und Entwicklungsraten der Versuchsgruppen zeigten, unabhängig von den eingesetzten Konzentrationen, keine signifikanten Unterschiede (Tab. 2 und Tab. 3). 
Tab. 2. Maturationsraten, Probenumfang (n), Mittelwert (M) und Standardabweichung (SD)

Maturation rates, sample size (n), mean (M) and standard deviation (SD)

\begin{tabular}{llll}
\hline & $n$ & $\mathrm{M}, \%$ & $\mathrm{SD}, \%$ \\
\hline $\mathrm{G}^{\dagger}$ & 186 & 67,17 & 7,81 \\
$\mathrm{GBH}^{\ddagger}$ & 185 & 64,48 & 5,46 \\
$\mathrm{CON}^{\ddagger} 1^{\S}$ & 167 & 63,03 & 5,43 \\
\hline $\mathrm{G}^{\dagger} 0^{\dagger}$ & 223 & 66,57 & 5,83 \\
$\mathrm{GBH} 10^{\ddagger}$ & 212 & 67,28 & 12,01 \\
$\mathrm{CON}-10^{\S}$ & 221 & 62,49 & 7,21 \\
\hline
\end{tabular}

${ }^{\dagger} \mathrm{G} 1$ : Glyphosat-1 $\mu \mathrm{g} / \mathrm{ml}$, G10: Glyphosat-10 $\mu \mathrm{g} / \mathrm{ml}$

${ }^{\ddagger} \mathrm{GBH} 1$ : Glyphosathaltiges Herbizid-1 $\mu \mathrm{g} / \mathrm{ml}$, GBH10: Glyphosathaltiges Herbizid-10 $\mu \mathrm{g} / \mathrm{ml}$ ${ }^{\S} \mathrm{CON}-1$ : Kontrolle-zugehörig zur $1 \mu \mathrm{g} / \mathrm{ml}$ Behandlung, CON-10: Kontrolle-zugehörig zur $10 \mu \mathrm{g} / \mathrm{ml}$ Behandlung

Tab. 3. Teilungs- und Entwicklungsraten an Tag 8 der Kultivierung, Probenumfang (n), Mittelwert (M) und Standardabweichung (SD)

Cleavage and development rates on day 8 of cultivation, sample size (n), mean (M) and standard deviation (SD)

\begin{tabular}{|c|c|c|c|c|c|}
\hline & \multirow[b]{2}{*}{$n$} & \multicolumn{2}{|c|}{ Teilung } & \multicolumn{2}{|c|}{ Entwicklung } \\
\hline & & $\mathrm{M}, \%$ & $\mathrm{SD}, \%$ & $\mathrm{M}, \%$ & $\mathrm{SD}, \%$ \\
\hline $\mathrm{G} 1^{\dagger}$ & 810 & 55,36 & 8,28 & 21,84 & 8,31 \\
\hline GBH1 ${ }^{\ddagger}$ & 883 & 50,88 & 8,06 & 21,56 & 8,42 \\
\hline $\mathrm{CON}-1^{\S}$ & 736 & 56,73 & 10,46 & 23,60 & 8,31 \\
\hline${\mathrm{G} 10^{\dagger}}^{+}$ & 685 & 56,31 & 11,86 & 28,86 & 14,69 \\
\hline GBH10 & 691 & 52,68 & 16,12 & 23,49 & 11,69 \\
\hline $\mathrm{CON}-10^{\S}$ & 604 & 57,43 & 11,42 & 25,21 & 12,61 \\
\hline
\end{tabular}

${ }^{\dagger} \mathrm{G} 1$ : Glyphosat-1 $\mu \mathrm{g} / \mathrm{ml}, \mathrm{G10}$ : Glyphosat-10 $\mu \mathrm{g} / \mathrm{ml}$

${ }^{\ddagger}$ GBH1: Glyphosathaltiges Herbizid-1 $\mu \mathrm{g} / \mathrm{ml}$, GBH10: Glyphosathaltiges Herbizid-10 $\mu \mathrm{g} / \mathrm{ml}$

${ }^{\S} \mathrm{CON}-1$ : Kontrolle-zugehörig zur $1 \mu \mathrm{g} / \mathrm{ml}$ Behandlung, CON-10: Kontrolle-zugehörig zur $10 \mu \mathrm{g} / \mathrm{ml}$ Behandlung 
Auch das durchschnittliche Verhältnis von lebenden zu toten Zellen gefärbter Blastozysten zeigte keine signifikanten Unterschiede zwischen den Versuchsgruppen und den Konzentrationen (Tab. 4).

Tab. 4. Lebend/Tot-Verhältnis, Probenumfang (n), Mittelwert (M) und Standardabweichung (SD)

Live/dead-ratio, sample size (n), mean (M) and standard deviation (SD)

\begin{tabular}{llll}
\hline & $n$ & $\mathrm{M}$ & $\mathrm{SD}$ \\
\hline $\mathrm{G}^{\dagger}$ & 11 & 12,26 & 4,65 \\
$\mathrm{GBH}^{\ddagger}$ & 10 & 12,60 & 6,00 \\
$\mathrm{CON}-1^{\S}$ & 12 & 13,25 & 4,58 \\
\hline $\mathrm{G} 10^{\dagger}$ & 10 & 9,48 & 6,81 \\
$\mathrm{GBH} 10^{\ddagger}$ & 10 & 14,08 & 6,98 \\
$\mathrm{CON}-10^{\S}$ & 9 & 13,25 & 4,58 \\
\hline
\end{tabular}

${ }^{\dagger}$ G1: Glyphosat-1 $\mu \mathrm{g} / \mathrm{ml}$, G10: Glyphosat-10 $\mu \mathrm{g} / \mathrm{ml}$

${ }^{\ddagger} \mathrm{GBH} 1$ : Glyphosathaltiges Herbizid-1 $\mu \mathrm{g} / \mathrm{ml}$, GBH10: Glyphosathaltiges Herbizid-10 $\mu \mathrm{g} / \mathrm{ml}$

${ }^{\S} \mathrm{CON}-1$ : Kontrolle-zugehörig zur $1 \mu \mathrm{g} / \mathrm{ml}$ Behandlung, CON-10: Kontrolle-zugehörig zur $10 \mu \mathrm{g} / \mathrm{ml}$ Behandlung

Die Standardkurven aller Gene wiesen Effizienzen im Bereich von 94,7 \% bis 100,8 \% und Steigungen im Bereich von -3,30 bis -3,46 auf. Alle untersuchten entwicklungsrelevanten Gene waren in Oozyten oder Kumuluszellen nachweisbar und konnten quantifiziert werden.

BMP15 wurde in Eizellen der Gruppe GBH10 im Vergleich zu CON-10 signifikant höher exprimiert $(p<0,05)$. Für die Gruppe G10 wurden im Vergleich zu den beiden anderen Gruppen keine Unterschiede beobachtet (Abb. 1). 


\section{BMP15}

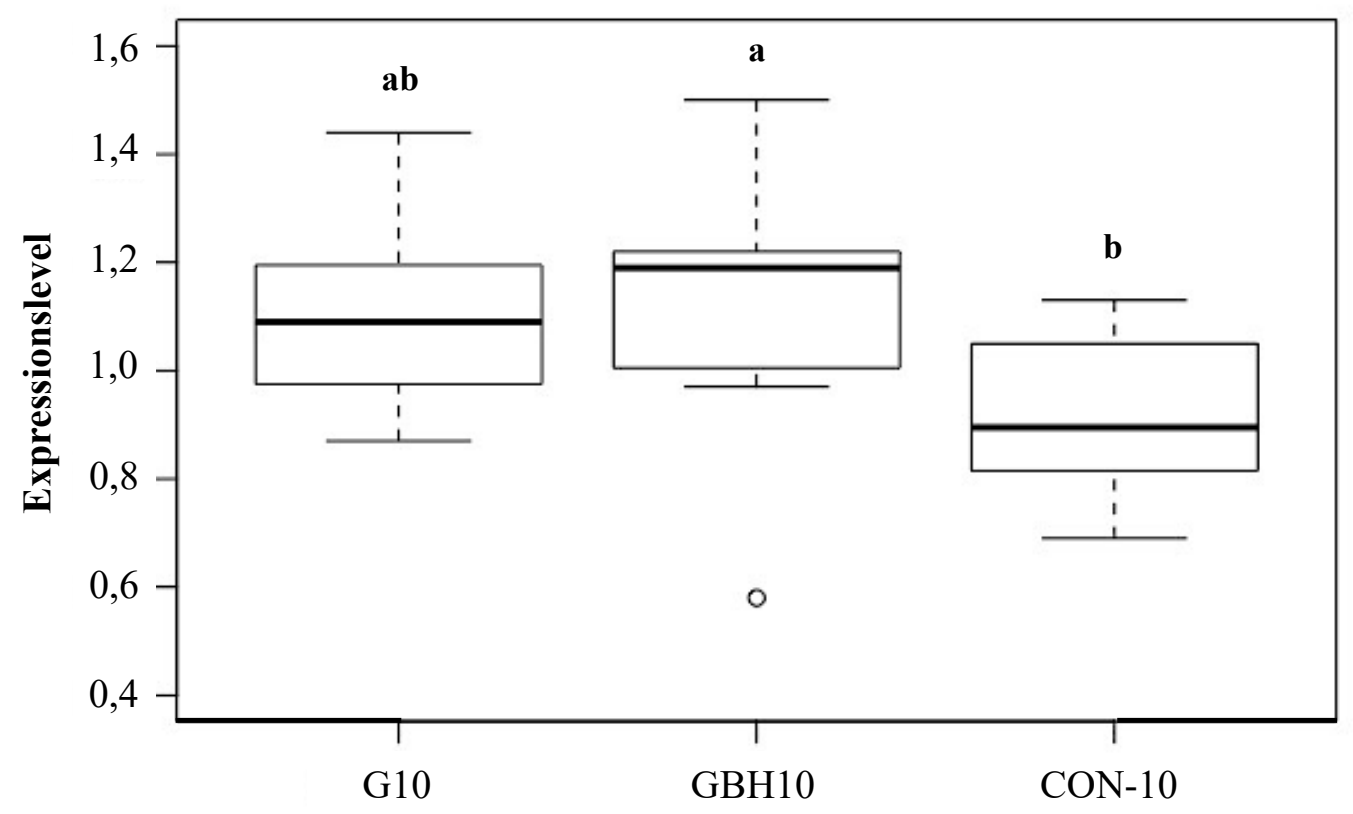

Abb. 1. BMP15-Expressionslevel in bovinen Oozyten.

Die Abbildung zeigt die BMP15-Expressionslevel der Versuchsgruppen mit den Zusätzen von $10 \mu \mathrm{g} / \mathrm{ml}$ reinem Glyphosat (G10), $10 \mu \mathrm{g} / \mathrm{ml}$ glyphosathaltigem Herbizid (GBH10) und der Kontrolle (CON-10). Es wurden jeweils zwölf Oozyten in Dreifachbestimmung analysiert. ${ }^{\mathrm{a}-\mathrm{b}} \mathrm{p}<0.05$.

Expression of BMP15 in bovine oocytes. The figure shows the expression levels of bone morphogenetic protein 15 (BMP15) for the test groups with $10 \mu \mathrm{g} / \mathrm{ml}$ pure glyphosate added (G10), $10 \mu \mathrm{g} / \mathrm{ml}$ glyphosate-based herbicide added (GBH10) and the control (CON-10). Twelve oocytes were analyzed in triple determination. ${ }^{\mathrm{a}-\mathrm{b}} \mathrm{p}<0.05$.

Im Vergleich zur Gruppe CON-10 wurde ZARI in den Eizellen der Gruppen G10 ( $<<0,01)$ und GBH10 ( $<<0,001)$ signifikant höher exprimiert (Abb. 2). 


\section{ZAR1}

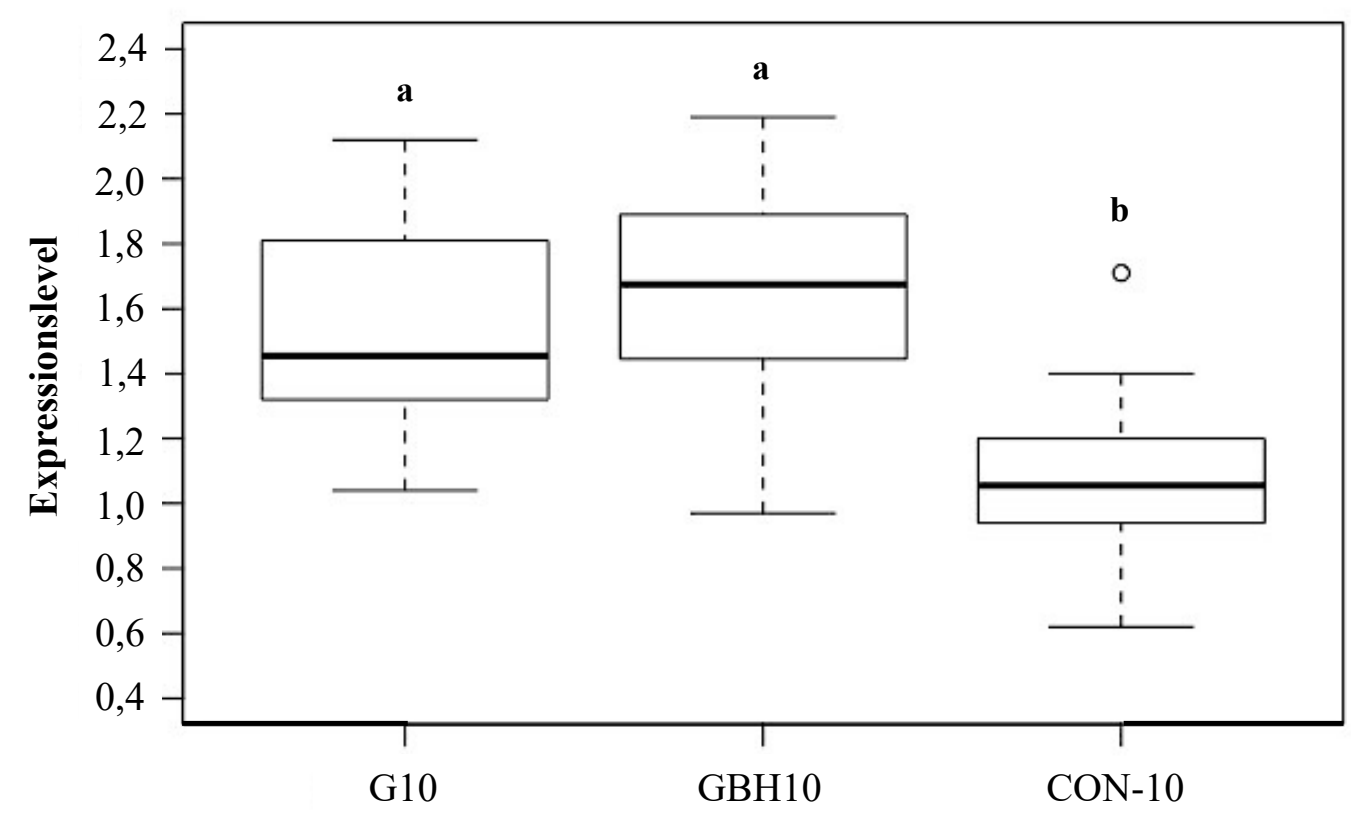

Abb. 2. ZAR1-Expressionslevel in bovinen Oozyten.

Die Abbildung zeigt die ZARl-Expressionslevel der Versuchsgruppen mit den Zusätzen von $10 \mu \mathrm{g} / \mathrm{ml}$ reinem Glyphosat (G10), $10 \mu \mathrm{g} / \mathrm{ml}$ glyphosathaltigem Herbizid (GBH10) und der Kontrolle (CON-10). Es wurden jeweils zwölf Oozyten in Dreifachbestimmung analysiert. ${ }^{\mathrm{a}-\mathrm{b}} \mathrm{p}<0.01$.

Expression of ZAR1 in bovine oocytes. The figure shows the expression levels of zygote arrest 1 (ZARl) for the test groups with $10 \mu \mathrm{g} / \mathrm{ml}$ pure glyphosate added (G10), $10 \mu \mathrm{g} / \mathrm{ml}$ glyphosate-based herbicide added (GBH10) and the control (CON-10). Twelve oocytes were analyzed in triple determination. ${ }^{\mathrm{a}-\mathrm{b}} \mathrm{p}<0.01$.

Auch die relative Expression von ZAR1 zeigte keine Unterschiede zwischen G10 und GBH10. Die Expression von GDF9 wurde durch keine der Behandlungen beeinflusst.

In Kumuluszellen war die relative Expression von ESRI in der Gruppe G10 signifikant höher als in CON-10 (p< 0,05). Die Gruppe GBH10 zeigte keine Unterschiede im Vergleich zu den anderen Gruppen (Abb. 3). 


\section{ESR1}

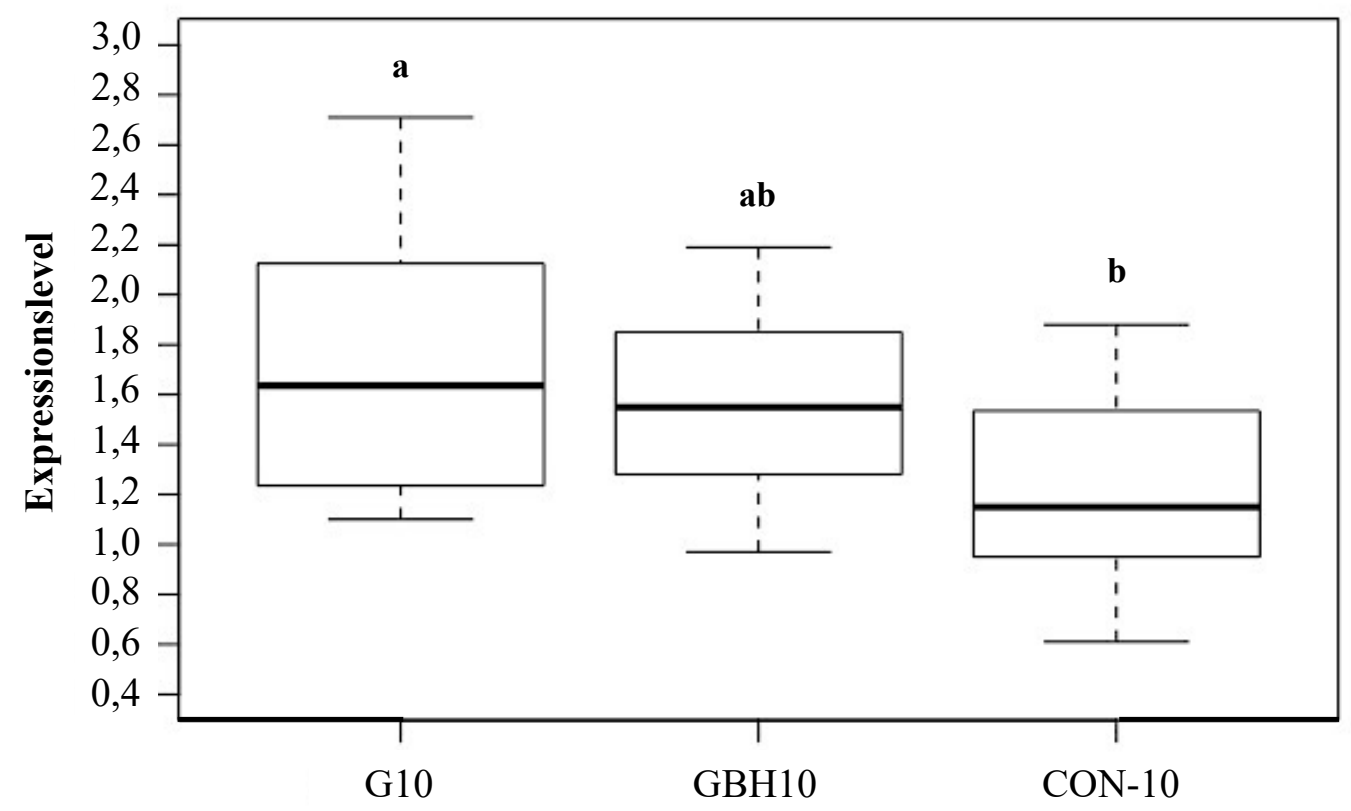

Abb. 3. ESR 1-Expressionslevel in bovinen Oozyten.

Die Abbildung zeigt die ESRl-Expressionslevel der Versuchsgruppen mit den Zusätzen von $10 \mu \mathrm{g} / \mathrm{ml}$ reinem Glyphosat (G10), $10 \mu \mathrm{g} / \mathrm{ml}$ glyphosathaltigem Herbizid (GBH10) und der Kontrolle (CON-10). Es wurden jeweils zwölf Oozyten in Dreifachbestimmung analysiert. ${ }^{\mathrm{a}-\mathrm{b}} \mathrm{p}<0.05$. Expression of ESR1 in bovine cumulus cells.

The figure shows the expression levels of estrogen receptor 1 (ESR1) for the test groups with $10 \mu \mathrm{g} / \mathrm{ml}$ pure glyphosate added (G10), $10 \mu \mathrm{g} / \mathrm{ml}$ glyphosate-based herbicide added (GBH10) and the control (CON-10). The corresponding cumulus cells of twelve oocytes were analyzed in triple determination. ${ }^{\mathrm{a}-\mathrm{b}} \mathrm{p}<0.05$.

Für $P G R$ und $H S D 3 B 1$ wurden keine Expressionsunterschiede in den Kumuluszellen festgestellt.

Glyphosat konnte auch nach 24-stündiger Reifung stabil im Maturationsmedium nachgewiesen werden.

Weder Glyphosat noch der Hauptmetabolit AMPA wurden in den beprobten Follikelflüssigkeiten nachgewiesen.

\section{Diskussion}

Mit der vorliegenden Studie wurde erstmalig der Einfluss von Glyphosat auf die Maturation und weitere Entwicklung boviner Oozyten in vitro untersucht. Beschrieben wur- 
den dabei die für die Entwicklungskompetenz der späteren Embryonen essentielle Maturation, sowie die frühe Embryonalentwicklung bis zum achten Tag der Kultivierung. Der konstante Verbleib des Wirkstoffes im Medium während der 24-stündigen Reifung der Eizellen wurde durch eine Analyse des Mediums mittels HPLC-MS/MS überprüft. Bei der Maturationskontrolle mittels Hoechst-Färbung zeigte der Zusatz von Glyphosat bzw. Roundup zum Medium hierbei keine Auswirkungen auf die Maturationsraten der Oozyten. SlABY et al. (2019) und ZHANG et al. (2019) kamen in ihren Studien zu konträren Ergebnissen. Glyphosat und Roundup führten $\mathrm{zu}$ spontanen Maturationen und Anomalien des Spindelapparats in Oozyten von Xenopus laevis (SLABY et al. 2019) oder zur Apoptose in Mäuseoozyten (ZHANG et al. 2019). Allerdings ist zu beachten, dass in diesen Studien supraphysiologische Wirkstoffkonzentrationen, nämlich $85 \mu \mathrm{g} / \mathrm{ml}$ (ZhANG et al. 2019) und bis zu $250 \mu \mathrm{g} / \mathrm{ml}$ (SLABY et al. 2019), verwendet wurden und somit die Vergleichbarkeit mit unserer Studie sehr einschränkt ist. In unserem Versuch konnten für die Teilungs- und Entwicklungsraten an Tag 8 keine Unterschiede zwischen den Versuchsgruppen und den Konzentrationen festgestellt werden. Die Entwicklungsraten aller Versuchsgruppen waren in einem für die IVP zufriedenstellenden Bereich. Die Lebend/Tot-Färbung der expandierten Blastozysten zeigte ebenfalls keine signifikanten Unterschiede und ließ damit auf einen gleichen Entwicklungsstand aller Versuchsgruppen schließen.

In der vorliegenden Studie waren die höheren Expressionen der Gene BMP15, ZAR1 und ESR1 nach Zugabe von Glyphosat und/oder Roundup im Vergleich zur jeweiligen Kontrollgruppe auffallend.

UREN WEBSTER et al. (2014) zeigten eine höhere Expression von ESRl im ZebrafischOvar nach Zugabe von Roundup im Vergleich zum reinen Glyphosat. In dieser In-vivoStudie nahmen die Autoren an, dass die Formulierungszusätze in Roundup die Genexpression beeinflussen könnten. Sie vermuteten kompensatorische Mechanismen hinter der höheren Expression (UREN WEBSTER et al. 2014). Obwohl wir in vitro die gleiche Konzentration wie UREN WEBSTER et al. (2014) in vivo verwendet haben, konnten wir die Unterschiede in den ESR1-Expressionen zwischen der Glyphosat- und der RoundupGruppe nicht bestätigen. Allerdings lagen die relativen mRNA-Expressionen der Glyphosat- und der Roundup-Gruppe für alle Gene, die signifikante Unterschiede zeigten, über der Kontrollgruppe. Dies könnte auf kompensatorische Effekte innerhalb der Eizellen hinweisen. 
Eine weitere Studie von MESNAGE et al. (2017) zeigte eine Aktivierung von ESR1 nach Zugabe von Wirkstoffkonzentrationen $\geq 10 \mu \mathrm{g} / \mathrm{ml}$. Die Autoren haben keinen Unterschied zwischen reinem Glyphosat und verschiedenen Herbizidformulierungen gefunden (MESNAGE et al. 2017), was mit unseren Ergebnissen übereinstimmt. Sie vermuteten hinter der höheren Expression von ESRl ebenfalls einen Kompensationseffekt und damit einhergehend eine vermehrte Proliferation (MESNAGE et al. 2017).

Im Gegensatz zu den eben angeführten Expressionsstudien, stellten VARAYOUD et al. (2017) eine verminderte Expression von Östrogen- und Progesteronrezeptoren fest, beobachteten aber auch unterschiedliche Tendenzen in Abhängigkeit von der Wirkstoffkonzentration des Herbizids (VARAYOUD et al. 2017). ALARCÓN et al. (2019) konnten ebenfalls keinen Einfluss von Roundup auf die Expression von BMP15, ESR1 und PGR in Lämmerovarien nachweisen, jedoch eine verminderte GDF9-Expression. Im Rattenhoden wurden keine Effekte von Glyphosat und Roundup auf die Expression von HSD3B1 beobachtet (JOHANSSON et al. 2018).

Die signifikanten Expressionsunterschiede, die in der vorliegenden Studie in Eizellen und Kumuluszellen gezeigt wurden, variierten im Durchschnitt zwischen 0,21 und maximal 0,56 und lagen somit in einem relativ engen Bereich. Daher sollten sich weitere Studien auf eine erhöhte Probenzahl konzentrieren und sowohl andere entwicklungsrelevante Gene als auch höhere Konzentrationen in Betracht ziehen, um eine differenziertere Aussage treffen zu können.

In der vorliegenden Studie wurde die Expression entwicklungsrelevanter Gene nach Zugabe von $1 \mu \mathrm{g} / \mathrm{ml}$ nicht bestimmt, da unter Berücksichtigung der weiteren Ergebnisse aus der IVP nach Zugabe von $1 \mu \mathrm{g} / \mathrm{ml}$ von noch geringeren Expressionsunterschieden ausgegangen wurde, wie auch bereits in anderen Studien beschrieben (MESNAGE et al. 2017; VARAYOUD et al. 2017).

Über die Auswirkungen von Glyphosat auf die Aromatase (CYP19A1)-Aktivität und die Expression des steroidogenic acute regulatory (STAR)-Proteins wurde in der Literatur ebenfalls berichtet (WALSH et al. 2000; RICHARD et al. 2005). CYP19A1 und STAR waren in den Proben dieser Untersuchung allerdings nicht nachweisbar.

In unserer Studie wurden keine Rückstände von Glyphosat oder AMPA in der Follikelflüssigkeit der getesteten Kühe nachgewiesen. Die in das Maturationsmedium eingesetzten Eizellen waren also nicht mit Glyphosat vorbelastet, so dass sie nur den hier verwendeten Konzentrationen ausgesetzt waren. Die Proben wurden von geschlachteten, konventionell aufgezogenen Rindern gewonnen. Diese Rinder haben möglicher- 
weise über die Fütterung Glyphosatreste aufgenommen. Es konnten diese Rückstände jedoch nicht in den Eierstöcken der Kühe wiedergefunden werden. Dies steht im Widerspruch zu den Ergebnissen von KRÜGER et al. (2014), die Rückstände in anderen Organen gefunden haben.

Es ist zu berücksichtigen, dass die Nachweisgrenze in der vorliegenden Studie noch relativ hoch und die Anzahl der getesteten Kühe mit 24 Tieren relativ gering ist.

Zur Wirkung von Glyphosat als endokriner Disruptor, wie in anderen Studien angenommen (RICHARD et al. 2005; GASNIER et al. 2009), sind mit den Ergebnissen der vorliegenden Untersuchung keine Aussagen möglich. Die vorhandenen Studien zu dieser Fragestellung lieferten kein einheitliches Ergebnis und sind stark vom Studiendesign, insbesondere von der Art der untersuchten Proben und den verwendeten Konzentrationen abhängig.

Zusammenfassend zeigten sowohl die Maturationsraten, die Teilungs- und Entwicklungsraten als auch das Lebend/Tot-Verhältnis der gefärbten Zellen keine signifikanten Unterschiede zwischen den Versuchsgruppen und den eingesetzten Konzentrationen. Allerdings wurden signifikant höhere Expressionen der Gene BMP15, ZAR1 und ESR1 nach Zugabe des Wirkstoffes Glyphosat nachgewiesen. Weitere Untersuchungen sind hier nötig, um Ursachen und Folgen dieser Aktivierung abschätzen zu können.

Unter Berücksichtigung aller in dieser Studie durchgeführten Analysen, konnte kein negativer Einfluss des Wirkstoffes Glyphosat auf die Maturation und weitere Entwicklung boviner Oozyten bzw. Embryonen festgestellt werden. Eine unterschiedliche Wirkung von Roundup im Vergleich zum reinen Wirkstoff konnte ebenfalls nicht ermittelt werden.

\section{Danksagung}

Wir danken H. Hellmold, D. Teuteberg und M. Vopel für die Probensammlung und die hervorragende Unterstützung im Labor und der H. Wilhelm Schaumann Stiftung für die finanzielle Förderung.

\section{Literatur}

Abele, E., H. Stinshoff, A. Hanstedt, S. Wilkening, S. Meinecke-Tillmann, and C. WRENZYCKI (2012): Influence of selected (pre-)maturational parameters on in 
vitro development and sex distribution of bovine embryos. Zygote 22, 41-49. doi:10.1017/S0967199412000275.

Alarcón, R., P. I. Ingaramo, O. E. Rivera, G. H. Dioguardi, M. R. Repetti, L. D. Demonte, M. M. Milesi, J. Varayoud, M. Muñoz-De-Toro, and E. H. LUQUE (2019): Neonatal exposure to a glyphosate-based herbicide alters the histofunctional differentiation of the ovaries and uterus in lambs. Mol. Cell. Endocrinol 482, 45-56. doi:10.1016/j.mce.2018.12.007.

BENBROOK, C. M. (2016): Trends in glyphosate herbicide use in the United States and globally. Environ. Sci. Eur 28, 1-15. doi:10.1186/s12302-016-0070-0.

Blaschka, C., A. SÁnchez-Guijo, B. Zimmer, J. Stöhr, F. Kotarski, H. Grothmann, M. F. Hartmann, S. A. Wudy, and C. Wrenzycki (2019): Temporal expression pattern of steroid-metabolizing enzymes in bovine COC during in vitro maturation employing different gonadotropin concentrations. Theriogenology 131, 182-192. doi:10.1016/j.theriogenology.2019.03.028.

BVL (2017): Federal Office of Consumer Protection and Food Safety: Sales of plant protection products in the Federal Republic of Germany. Available from: https://www.bvl.bund.de/psmstatistiken

Carpintero, N. L., O. A. SuÁrez, C. C. Mangas, C. G. Varea, and R. G. Rioja (2014): Follicular steroid hormones as markers of oocyte quality and oocyte development potential. J. Hum. Reprod. Sci. 7, 187-193. doi:10.4103/09741208.142479.

ECKERT, J., and H. NIEMANN (1995): In vitro maturation, fertilization and culture to blastocysts of bovine oocytes in protein-free media. Theriogenology 43, 121125. doi:10.1016/0093-691x(95)00093-n.

EU (2009): COUNCIL REGULATION (EC) No 1099/2009 of 24 September 2009 on the protection of animals at the time of killing. Off. J. Eur. Union: 1-30.

Ganguly, I., G. K. Gaur, S. Kumar, D. K. Mandal, M. Kumar, U. Singh, and A. SHARMA (2012): Differential expression of protamine 1 and 2 genes in mature spermatozoa of normal and motility impaired semen producing crossbred Frieswal (HF $\times$ Sahiwal) bulls. Res. Vet. Sci. 94, 256-262. doi:10.1016/j.rvsc.2012.09.001.

Gasnier, C., C. Dumont, N. Benachour, E. Clair, M. C. Chagnon, and G. E. SÉRALINI (2009): Glyphosate-based herbicides are toxic and endocrine disruptors in human cell lines. Toxicology 262, 184-191. 
doi:10.1016/j.tox.2009.06.006.

Hughes, L., R. Carton, S. Minguzzi, G. Mcentee, E. E. Deinum, M. J. O’Connell, and A. PARLE-MCDERMotT (2015): An active second dihydrofolate reductase enzyme is not a feature of rat and mouse, but they do have activity in their mitochondria. FEBS Lett. 589, 1855-1862. doi:10.1016/j.febslet.2015.05.017.

Johansson, H. K. L., C. L. Schwartz, L. N. Nielsen, J. BoberG, A. M. VingGaARD, M. I. BAHL, and T. SVINGEN (2018): Exposure to a glyphosate-based herbicide formulation, but not glyphosate alone, has only minor effects on adult rat testis. Reprod. Toxicol. 82, 25-31. doi:10.1016/j.reprotox.2018.09.008.

KrÜger, M., P. Schledorn, W. Schrödl, H.-W. Hoppe, W. Lutz, and A. A. SHEHATA (2014): Detection of Glyphosate Residues in Animals and Humans. J. Environ. Anal. Toxicol. 04. doi:10.4172/2161-0525.1000210.

Macabelli, C. H., R. M. Ferreira, L. U. Gimenes, N. A. T. De Carvalho, J. G. Soares, H. Ayres, M. L. Ferraz, Y. F. Watanabe, O. Y. Watanabe, J. R. Sangalli, L. C. Smith, P. S. Baruselli, F. V. Meirelles, and M. R.

CHIARATTI (2014): Reference gene selection for gene expression analysis of oocytes collected from dairy cattle and buffaloes during winter and summer. PLoS One 9, 13-21. doi:10.1371/journal.pone.0093287.

Mesnage, R., A. Phedonos, M. Biserni, M. Arno, S. Balu, J. C. Corton, R. UgARTE, and M. N. ANTONIOU (2017): Evaluation of estrogen receptor alpha activation by glyphosate-based herbicide constituents. Food Chem. Toxicol. 108, 30-42. doi:10.1016/j.fct.2017.07.025.

Paganelli, A., V. Gnazzo, H. Acosta, S. L. López, and A. E. Carrasco (2010): Glyphosate-based herbicides produce teratogenic effects on vertebrates by impairing retinoic acid signaling. Chem. Res. Toxicol. 23, 1586-1595. doi:10.1021/tx1001749.

PAVloK, A., A. LuCAS-HAhN, and H. NiemanN (1992): Fertilization and developmental competence of bovine oocytes derived from different categories of antral follicles. Mol. Reprod. Dev. 31, 63-67. doi:10.1002/mrd.1080310111.

Perego, M. C., F. Caloni, C. Cortinovis, L. F. Schutz, M. Albonico, D. TSUZUKIBASHI, and L. J. SPICER (2017): Influence of a Roundup formulation on glyphosate effects on steroidogenesis and proliferation of bovine granulosa cells in vitro. Chemosphere 188, 274-279. doi:10.1016/j.chemosphere.2017.09.007.

PfAFFL, M. W. (2001): A new mathematical model for relative quantification in real- 
time RT-PCR. Nucleic Acids Res. 29, e45. doi:10.1093/nar/29.9.e45.

Richard, S., S. Moslemi, H. Sipahutar, N. Benachour, and G. E. Seralini (2005): Differential effects of glyphosate and roundup on human placental cells and aromatase. Environ. Health Perspect. 113, 716-720. doi:10.1289/ehp.7728.

Slaby, S., P. Titran, G. Marchand, J. Hanotel, A. Lescuyer, A. Leprêtre, J. F. Bodart, M. MARin, and S. Lemiere (2019): Effects of glyphosate and a commercial formulation Roundup ${ }^{\circledR}$ exposures on maturation of Xenopus laevis oocytes. Environ. Sci. Pollut. Res. 27, 3697-3705. doi:10.1007/s11356-01904596-2.

Stinshoff, H., S. Wilkening, A. HAnstedt, K. BrÜning, and C. WrenzyCKi (2011): Cryopreservation affects the quality of in vitro produced bovine embryos at the molecular level. Theriogenology 76, 1433-41.

doi:10.1016/j.theriogenology.2011.06.013.

Uren Webster, T. M., L. V. Laing, H. Florance, and E. M. SAntos (2014): Effects of glyphosate and its formulation, roundup, on reproduction in zebrafish (Danio rerio). Environ. Sci. Technol. 48, 1271-1279. doi:10.1021/es404258h.

Varayoud, J., M. Durando, J. G. Ramos, M. M. Milesi, P. I. Ingaramo, M. MuÑOZ-DE-TORO, and E. H. LuQue (2017): Effects of a glyphosate-based herbicide on the uterus of adult ovariectomized rats. Environ. Toxicol. 32, 11911201. doi:10.1002/tox.22316.

Walsh, L. P., C. McCormick, C. Martin, and D. M. Stocco (2000): Roundup inhibits steroidogenesis by disrupting steroidogenic acute regulatory (StAR) protein expression. Environ. Health Perspect. 108, 769-776.

doi:10.1289/ehp.00108769.

Zhang, J.-W., D.-Q. XU, and X.-Z. Feng (2019): The toxic effects and possible mechanisms of glyphosate on mouse oocytes. Chemosphere 237, 124435. doi:10.1016/j.chemosphere.2019.124435.

Zouaoui, K., S. Dulaurent, J. M. Gaulier, C. Moesch, and G. Lachâtre (2013): Determination of glyphosate and AMPA in blood and urine from humans: About 13 cases of acute intoxication. Forensic Sci. Int. 226, 20-25. doi:10.1016/j.forsciint.2012.12.010. 


\subsection{Diskussion}

Unsere Studie untersuchte erstmalig den Einfluss von Glyphosat auf die Maturation und die weitere Entwicklung boviner Oozyten in vitro.

Glyphosat und Roundup wurden dem Maturationsmedium in zwei unterschiedlichen Konzentrationen zugesetzt. Diese wurden in Anlehnung an andere Studien und unter Berücksichtigung verschiedener Grenzwerte festgelegt:

Perego et al. (2017) untersuchten den Einfluss von Glyphosat und Roundup auf die Steroidogenese und Proliferation boviner Granulosazellen in vitro (Perego et al. 2017). Sie setzten dabei in verschiedenen Teilversuchen Wirkstoffkonzentrationen von 0,1 bis $300 \mu \mathrm{g} / \mathrm{ml}$ ein (Perego et al. 2017). Eine weitere Studie, an der wir uns zur Auswahl der Konzentrationen orientierten, war die Untersuchung von Krüger et al. (2014) zu Glyphosatrückständen in Organen am Schlachthof. Sie fanden Rückstände von 15 bis $25 \mathrm{ng} / \mathrm{g}$ in Leber, Niere, Lunge, Milz und Muskeln geschlachteter Kühe (Krüger et al. 2014). Landwirtschaftliche Nutztiere nehmen Glyphosat wahrscheinlich über das Futter auf, deshalb sollten die Rückstandsgrenzwerte in Futtermitteln berücksichtigt werden. Diese sind durch die EU festgeschrieben und liegen für Soja und die meisten Getreidearten zwischen 10 und $20 \mathrm{mg} / \mathrm{kg}$ (EC 2012). Da, wie oben bereits erwähnt, bisher wenig über die genaue Aufnahme und Metabolisierung von Glyphosat durch das Tier bekannt ist, konnten die verwendeten Konzentrationen nur abgeschätzt werden. Ziel war es dabei, diese in einem physiologisch möglichen Bereich zu halten.

Der konstante Verbleib des Wirkstoffes im Medium während der 24-stündigen Reifung der Eizellen wurde durch eine Analyse des Mediums mittels HPLC-MS/MS überprüft.

Bei der Maturationskontrolle mittels Hoechst-Färbung zeigte der Zusatz von Glyphosat bzw. Roundup zum Medium keine Auswirkungen auf die Maturationsraten der Oozyten. Slaby et al. (2019) und Zhang et al. (2019) kamen in ihren Studien zu konträren Ergebnissen. Glyphosat und Roundup führten zu spontanen Maturationen und Anomalien des Spindelapparats in Oozyten von Xenopus laevis (Slaby et al. 2019) oder zur Apoptose in Mäuseoozyten (Zhang et al. 2019). Allerdings ist zu beachten, dass in diesen Studien supraphysiologische Wirkstoffkonzentrationen, nämlich $500 \mu \mathrm{M}$ (Zhang et al. 2019) und bis zu $1480 \mu \mathrm{M}$ (Slaby et al. 2019), verwendet wurden und somit die Vergleichbarkeit mit unserer Studie sehr einschränkt ist. Eine gute Vergleichbarkeit ist allerdings mit der Studie von Blad-Stahl et al. (2020) gegeben. Hier wurde in einem 
ähnlichen Versuchsaufbau die Entwicklung von Oozyten bzw. Embryonen nach Zugabe von 30 und $300 \mu \mathrm{g} / \mathrm{ml}$ Roundup zum Maturationsmedium untersucht. Die Maturationsraten zeigten in diesem Versuch keine signifikanten Unterschiede zwischen den Gruppen. Nach dem Zusatz von $30 \mu \mathrm{g} / \mathrm{ml}$ Roundup fielen auch die Teilungs- und Entwicklungsraten der Embryonen ohne signifikante Unterschiede im Vergleich zur Kontrolle aus. Allerdings fielen diese Raten nach Zugabe von $300 \mu \mathrm{g} / \mathrm{ml}$ Roundup signifikant niedriger aus, was ebenfalls darauf hindeutet, dass auch diese Konzentration nicht mehr physiologisch ist (Blad-Stahl et al. 2020).

In unserem Versuch konnten für die Teilungs- und Entwicklungsraten an Tag 8 keine Unterschiede zwischen den Versuchsgruppen und den Konzentrationen festgestellt werden. Die Entwicklungsraten aller Versuchsgruppen waren in einem für die IVP zufriedenstellenden Bereich. Nach Zusatz von Roundup lagen die Teilungs- und Entwicklungsraten allerdings etwas unterhalb derer der anderen beiden Versuchsgruppen, zeigten aber keine signifikanten Unterschiede. Die Lebend-Tot-Färbung der expandierten Blastozysten zeigte ebenfalls keine signifikanten Unterschiede und ließ damit auf einen gleichen Entwicklungsstand aller Versuchsgruppen zurückschließen. Zu beachten ist, das Glyphosat und Roundup ausschließlich dem Maturationsmedium zugesetzt wurden. Für Fertilisation und Kultur erfolgte kein erneuter Zusatz.

In der vorliegenden Studie waren die höheren Expressionen der Gene bone morphogenetic protein 15 (BMP15), zygote arrest 1 (ZAR1) und estrogen receptor 1 (ESRl) nach Zugabe von Glyphosat und/oder Roundup im Vergleich zur jeweiligen Kontrollgruppe auffallend.

Alle in der Studie untersuchten Gene sind für die Entwicklung des Kumulus-OozytenKomplexes relevant. Um Rückschlüsse auf die Entwicklungskompetenz der Oozyte ziehen zu können, wurden die relativen Expressionen von BMP15, growth differentiation factor 9 (GDF9) und ZAR1 ermittelt. BMP15 und GDF9 spielen als Wachstumsfaktoren bei der zytoplasmatischen Reifung eine wichtige Rolle (McGrath et al. 1995; Yan et al. 2001), während ZARl an der Regulierung des maternalen Transkriptoms und der translationalen Aktivierung in maturierenden Oozyten mitwirkt (Rong et al. 2019). AuBerdem wurden die Expressionen der an der Steroidsynthese beteiligten Gene ESR1, hydroxy-delta-5-steroid dehydrogenase (HSD3B1) und nuclear progesterone receptor $(P G R)$ in Kumuluszellen untersucht (Ireland et al. 2009; Salhab et al. 2011; Fair \& Lonergan 2012; Liu et al. 2017). 
Uren Webster et al. (2014) zeigten eine höhere Expression von ESR1 im ZebrafischOvar nach Zugabe von Roundup im Vergleich zum reinen Glyphosat. In dieser In-vivoStudie nahmen die Autoren an, dass die Formulierungszusätze in Roundup die Genexpression beeinflussen könnten. Sie vermuteten kompensatorische Mechanismen hinter der höheren Expression (Uren Webster et al. 2014). Obwohl wir in vitro die gleiche Konzentration wie Uren Webster et al. (2014) in vivo verwendet haben, konnten wir die Unterschiede in den ESR1-Expressionen zwischen der Glyphosat- und der RoundupGruppe nicht bestätigen. Zu beachten ist aber die eingeschränkte Vergleichbarkeit von In-vivo- und In-vitro-Studien aufgrund möglicher Unterschiede in physiologischen Prozessen. Allerdings lagen die relativen mRNA-Expressionen der Glyphosat- und der Roundup-Gruppe für alle Gene, die signifikante Unterschiede zeigten, über der Kontrollgruppe. Dies könnte auf kompensatorische Effekte innerhalb der Oozyten hinweisen.

Eine weitere Studie von Mesnage et al. (2017) zeigte eine Aktivierung von ESR1 nach Zugabe von Wirkstoffkonzentrationen $\geq 10.000 \mu \mathrm{g} / \mathrm{l}$. Die Autoren haben keinen Unterschied zwischen reinem Glyphosat und verschiedenen Herbizidformulierungen gefunden (Mesnage et al. 2017), was mit unseren Ergebnissen übereinstimmt. Mesnage et al. (2017) wiesen eine lediglich schwache Interaktion zwischen Glyphosat und dem Östrogenrezeptor nach. Sie zeigten, dass Glyphosat nicht auf die gleiche Weise wirkt wie Östradiol und die Aktivierung von ESRl somit ligandenunabhängig vermittelt sein muss (Mesnage et al. 2017). Sie vermuteten hinter der höheren Expression von ESR1 ebenfalls einen Kompensationseffekt und damit einhergehend eine vermehrte Proliferation (Mesnage et al. 2017). Ob dies wiederum eine erhöhte Kanzerogenität bedingen könnte, muss in Folgestudien abgeschätzt werden. Blad-Stahl et al. (2020) stellten nach Zugabe von $300 \mu \mathrm{g} / \mathrm{ml}$ Roundup zum Maturationsmedium signifikant erhöhte Progesteron- und Östradiolkonzentrationen im Medium fest. Ob es hier einen Zusammenhang zwischen höheren Genexpressionen und erhöhten Steroidkonzentrationen gibt, muss ebenfalls weiterführend untersucht werden. Im vorliegenden Versuch wurde die IVM ohne Ö1überschichtung durchgeführt und das Maturationsmedium gesammelt, so dass dieses unmittelbar zur weiteren Analyse zur Verfügung steht.

Im Gegensatz zu den eben angeführten Expressionsstudien, stellten Varayoud et al. (2017) eine verminderte Expression von Östrogen- und Progesteronrezeptoren fest, beobachteten aber auch unterschiedliche Tendenzen in Abhängigkeit von der Wirkstoffkonzentration des Herbizids (Varayoud et al. 2017). Alarcón et al. (2019) konnten eben- 
falls keinen Einfluss von Roundup auf die Expression von BMP15, ESR1 und PGR in Lämmerovarien nachweisen, jedoch eine verminderte GDF9-Expression. Im Rattenhoden wurden keine Effekte von Glyphosat und Roundup auf die Expression von HSD3B1 beobachtet (Johansson et al. 2018).

Die Expressionsanalysen nach Zugabe des Wirkstoffes Glyphosat fallen in der Literatur also keinesfalls einheitlich aus. Auch die möglichen Folgen einer erhöhten Expression können noch nicht ausreichend abgeschätzt werden. Auf die Entwicklung boviner Oozyten bzw. Embryonen in vitro zeigten sich in unserer Studie keine negativen Auswirkungen. Allerdings stellt die Studie nur die Entwicklung der Embryonen bis Tag 8 der Kultivierung dar. Um Folgeschäden ausschließen zu können, müssten die erzeugten Embryonen transferiert und die Entwicklung bis zur Geburt bzw. darüber hinaus beobachtet werden. Auch sollte der Einfluss von Glyphosat auf Implantation und Plazentation weiterführend untersucht werden. Hier liefern erste Studien bereits Anhaltspunkte für eine mögliche Störung dieser Abläufe (z.B. Ingaramo et al. 2016). In vitro wäre dazu in Ergänzung zu unserem Versuch eine Differentialfärbung zur Bestimmung der inneren Zellmasse und des Trophektoderms möglich. Allgemein ist bei der Durchführung und Interpretation von In-vitro-Studien allerdings die eingeschränkte Vergleichbarkeit zu In-vivo-Studien aufgrund möglicherweise unterschiedlicher physiologischer Prozesse zu berücksichtigen.

Die signifikanten Expressionsunterschiede, die in unserer Studie in Oozyten und Kumuluszellen gezeigt wurden, variierten im Durchschnitt zwischen 0,21 und maximal 0,56 und lagen somit in einem relativ engen Bereich. Daher sollten sich weitere Studien auf eine erhöhte Probenzahl konzentrieren und sowohl andere entwicklungsrelevante Gene als auch höhere Konzentrationen in Betracht ziehen, um eine differenziertere Aussage treffen zu können.

In der vorliegenden Studie haben wir die Expression entwicklungsrelevanter Gene nach Zugabe von $1 \mu \mathrm{g} / \mathrm{ml}$ nicht bestimmt, da wir unter Berücksichtigung der weiteren Ergebnisse aus der IVP nach Zugabe von $1 \mu \mathrm{g} / \mathrm{ml}$ von noch geringeren Expressionsunterschieden ausgegangen sind, wie auch bereits in anderen Studien beschrieben (Mesnage et al. 2017; Varayoud et al. 2017).

Über die Auswirkungen von Glyphosat auf die Aromatase (CYP19A1)-Aktivität und die Expression des steroidogenic acute regulatory (STAR)-Proteins wurde in der Literatur ebenfalls berichtet (Walsh et al. 2000; Richard et al. 2005). CYP19A1 und STAR waren in unseren Proben allerdings nicht nachweisbar. 
In unserer Studie wurden keine Rückstände von Glyphosat oder AMPA in der Follikelflüssigkeit der getesteten Kühe nachgewiesen. Die in das Maturationsmedium eingesetzten Eizellen waren also nicht mit Glyphosat vorbelastet, so dass sie nur den hier verwendeten Konzentrationen ausgesetzt waren. Die Proben wurden von geschlachteten, konventionell aufgezogenen Rindern gewonnen. Diese Rinder haben möglicherweise über die Fütterung Glyphosatreste aufgenommen. Wir konnten diese Rückstände jedoch nicht in den Eierstöcken der Kühe wiederfinden. Dies steht im Widerspruch zu den Ergebnissen von Krüger et al. (2014), die Rückstände in anderen Organen gefunden haben.

Es ist zu berücksichtigen, dass die Nachweisgrenze in der vorliegenden Studie noch relativ hoch und die Anzahl der getesteten Kühe mit 24 Tieren relativ gering ist. Weitere Untersuchungen, z.B. mit einer höheren Anzahl getesteter Kühe und einem Vergleich zwischen Monogastriden und Wiederkäuern und verschiedenen Organen sind erforderlich, um eine fundierte Aussage zu Rückständen im Tier treffen zu können.

Darüber hinaus wären weitere Fütterungsversuche wünschenswert, um die Metabolisierung von Glyphosat genauer zu untersuchen. Aus dem Mangel an In-vivo-Studien bei Wiederkäuern ist bisher wenig über Aufnahme und Stoffwechselwege bekannt.

Zur Wirkung von Glyphosat als endokriner Disruptor, wie in anderen Studien angenommen (Richard et al. 2005; Gasnier et al. 2009), sind mit den Ergebnissen unserer Studie keine Aussagen möglich. Die vorhandenen Studien zu dieser Fragestellung lieferten kein einheitliches Ergebnis und sind stark vom Studiendesign, insbesondere von der Art der untersuchten Proben und den verwendeten Konzentrationen abhängig. Ebenso ist die jeweilige Formulierung des Herbizids zu beachten, vor allem der Einsatz von POE-Tallowaminen. Diese sind seit 2016 aufgrund ihrer erhöhten Toxizität als Beistoff in glyphosathaltigen Herbiziden in der EU verboten (EC 2016). Bei der Bewertung von Studienergebnissen muss also auch unter diesem Gesichtspunkt ein besonderes Augenmerk auf die verwendeten Formulierungen und somit auf die Vergleichbarkeit der Untersuchungen gelegt werden.

Zusammenfassend zeigten sowohl die Maturationsraten, die Teilungs- und Entwicklungsraten als auch das Lebend/Tot-Verhältnis der gefärbten Zellen keine signifikanten Unterschiede zwischen den Versuchsgruppen und den eingesetzten Konzentrationen. Allerdings wurden signifikant höhere Expressionen der Gene BMP15, ZAR1 und ESR1 
nach Zugabe des Wirkstoffes Glyphosat nachgewiesen. Weitere Untersuchungen sind hier nötig, um Ursachen und Folgen dieser Aktivierung abschätzen zu können.

Unter Berücksichtigung aller in dieser Studie durchgeführten Analysen, konnte kein negativer Einfluss des Wirkstoffes Glyphosat auf die Maturation und weitere Entwicklung boviner Oozyten bzw. Embryonen festgestellt werden. Eine unterschiedliche Wirkung von Roundup im Vergleich zum reinen Wirkstoff konnte ebenfalls nicht ermittelt werden. 


\section{$5 \quad$ Allgemeine Diskussion}

Die vorliegende Dissertation geht auf drei verschiedene Zielstellungen ein.

Der erste Teil der Arbeit befasst sich mit dem Einsatz von gesextem Sperma. Die funktionalen Merkmale und Produktionsmerkmale von Färsen wurden nach Besamung mit konventionellem und mit gesextem Sperma ausgewertet. Auffällig war hier besonders der Einfluss von gesextem Sperma auf die Totgeburtenraten männlicher Kälber. Ursächlich hierfür sind wahrscheinlich aneuploide Y-Chromosom-tragende Spermien, die während der Durchflusszytometrie falsch sortiert wurden. Interessant ist, dass diese Chromosomenaberration nicht schon im Embryonal- oder Fetalstadium letal ist, sondern es hier zu einer Entwicklung bis zur Geburt kommt, was auf autosomale Trisomien hindeuten könnte. Da der Anteil der männlichen Kälber aus gesextem Sperma sehr gering ist, besitzen die Totgeburten der männlichen Kälber aus weiblich gesextem Sperma insgesamt keinen hohen ökonomischen Stellenwert. Deutlich höhere Totgeburtenraten dieser männlichen Kälber wurden inzwischen aber in mehreren Studien beschrieben, ohne sie bisher eindeutig begründen zu können. Die Fragestellung ist also sehr wohl von wissenschaftlicher Relevanz und bedarf somit weiterer Forschung, um die Ursache für dieses Phänomen herauszufinden.

Ein methodischer Ansatz zur möglichen Verbesserung der IVP-Bedingungen wurde im zweiten Abschnitt der Arbeit vorgestellt. Ein ölfreies und ein ölüberschichtetes WellSystem, in denen eine geringe Medienmenge eingesetzt wurde, wurde hinsichtlich der Entwicklungskompetenz der Embryonen vergleichend dargestellt. Hier zeigte sich, dass das ölüberschichtete Kultursystem zu einer Absorption von Steroiden in das Öl führte bei gleichzeitig schlechteren Maturations- und Entwicklungsraten. Folglich bietet sich das ölfreie System, besonders in Verbindung mit der Konzentrationsbestimmung von Steroiden, als geeignetes System für die IVP an und kann zu einer Verbesserung des Reproduktionserfolgs beitragen.

Die Wirkung von Glyphosat und Roundup auf die Entwicklung boviner Oozyten bzw. Embryonen wurde im letzten Abschnitt der Arbeit dargestellt. Hier blieb der Reproduktionserfolg auch unter Einfluss des Wirkstoffes stabil, was sich in den Maturations- und Entwicklungsraten widerspiegelte. Hinsichtlich der Expression entwicklungsrelevanter Gene besteht aber weiterer Forschungsbedarf, um hier Auswirkungen auf den langfristi- 
gen Reproduktionserfolg bis hin zur Geburt und Aufzucht gesunder Nachkommen ausschließen zu können. Inwieweit diese Erkenntnisse auf den Humanbereich zu übertragen sind, muss ebenfalls in Folgestudien abgeschätzt werden. Insgesamt ist die Beurteilung der Wirkung von Glyphosat bei landwirtschaftlichen Nutztieren durch verschiedene Faktoren erschwert. So sind die über die Ration aufgenommene Menge, die Metabolisierung und eventuell damit verbundene Unterschiede zwischen Wiederkäuern und Monogastriern noch weitgehend unklar. Dies erschwert die Abschätzung von physiologisch realistischen Glyphosatkonzentrationen, die im Ovar wirken könnten. Hier besteht also noch weiterer Forschungsbedarf.

Nichtsdestotrotz liefert die vorliegende Studie erste Anhaltspunkte zur Wirkung von Glyphosat auf die Entwicklungskompetenz boviner Oozyten und Embryonen.

Der Reproduktionserfolg des Rindes kann unter dem Einsatz von Biotechnologien also verschiedenen methodischen oder umweltbedingten Einflüssen unterliegen.

Die Biotechnologien können dabei sowohl in einem gewissen Maße zu einer Lenkung des Reproduktionserfolgs beitragen, als auch selbst ein wichtiges Instrument im Hinblick auf die Untersuchung aktueller Forschungsfragen sein. 


\section{Zusammenfassung}

Die vorliegende Dissertationsschrift befasst sich mit der Untersuchung verschiedener exogener Einflüsse auf den Reproduktionserfolg des Rindes unter Anwendung von Invitro-Verfahren.

Mögliche Auswirkungen der Spermaart (konventionell vs. weiblich gesext) und des Kalbgeschlechts auf funktionale Merkmale und Produktionsmerkmale von HolsteinFärsen in Niedersachsen werden im ersten Teil der Arbeit untersucht.

Insgesamt sind Felddaten von 55554 Färsen in die Studie eingegangen, 87 \% weibliche Kälber wurden aus gesextem Sperma geboren. Der Anteil männlicher Kälber aus weiblich gesextem Sperma lag bei 5,3 \%. Diese zeigten mit 30,6 \% eine 2,86-fach höhere Totgeburtenrate als männliche Kälber aus konventionellem Sperma. Ursächlich hierfür sind wahrscheinlich aneuploide Y-Chromosom-tragende Spermien, die während des Sortierprozesses aufgrund von Trisomien fehlerhaft selektiert werden. Dies bedarf aber der Bestätigung durch weitere Studien. Die Geburt männlicher Kälber war mit schwierigeren Kalbeverläufen und höheren Schwergeburtenraten verbunden. Die eingesetzte Spermaart war für die meisten anderen Merkmale nicht von Bedeutung.

Im zweiten Teil der Arbeit werden ein ölfreies und ein ölüberschichtetes Kultursystem im Hinblick auf die Entwicklungskompetenz boviner Oozyten verglichen.

In der dazugehörigen Studie waren die Progesteronkonzentrationen im Medium nach Maturation der Oozyten im ölfreien System deutlich höher als im überschichteten System, in dem Progesteron während der Maturation vom Öl absorbiert wurde. Im ölfreien Kultursystem konnten außerdem höhere Maturationsraten der Oozyten beobachtet werden, weshalb das ölfreie System als Alternative zur Ölüberschichtung betrachtet werden kann.

Die Arbeit stellt abschließend den Einfluss des Wirkstoffes Glyphosat auf die Maturation und weitere Entwicklung boviner Oozyten dar.

Dazu wurden dem Maturationsmedium der Herbizidwirkstoff Glyphosat sowie das Pflanzenschutzpräparat Roundup mit Glyphosatkonzentrationen von $1 \mu \mathrm{g} / \mathrm{ml}$ und $10 \mu \mathrm{g} / \mathrm{ml}$ zugesetzt. Sowohl die Maturationsraten der Oozyten, die Teilungs- und Entwicklungsraten der Embryonen als auch das Lebend/Tot-Verhältnis der gefärbten Zellen 
unterschieden sich nicht zwischen den Versuchsgruppen und den eingesetzten Konzentrationen. Die relativen Expressionslevel ausgesuchter entwicklungsrelevanter Gene wurden nach Zugabe der höheren Wirkstoffkonzentrationen untersucht. Dabei wurden signifikant höhere Expressionen der Gene BMP15 (bone morphogenetic protein 15) und ZARl (zygote arrest 1) in Oozyten und von ESR1 (estrogen receptor 1) in Kumuluszellen nach Zugabe des Wirkstoffes Glyphosat im Vergleich zur Kontrolle nachgewiesen. Dies könnte auf kompensatorische Effekte im Kumulus-Oozyten-Komplex während der Maturation hinweisen. Unter Berücksichtigung aller in dieser Studie durchgeführten Analysen, konnte kein negativer Einfluss des Wirkstoffes Glyphosat auf die Maturation und weitere Entwicklung boviner Oozyten bzw. Embryonen festgestellt werden. Eine unterschiedliche Wirkung von Roundup im Vergleich zum reinen Wirkstoff konnte ebenfalls nicht ermittelt werden. 


\section{Summary}

This thesis deals with the analysis of various exogenous factors on the reproductive success of cattle by application of in vitro methods.

Possible effects of semen type (conventional vs. female sexed) and calf sex on production and functional traits of German Holstein heifers in Lower Saxony were evaluated in the first part of the thesis.

The field data of 55554 heifers were included in the study, $87.0 \%$ female calves were born from sexed semen. The proportion of male calves from female sexed semen was $5.3 \%$. The stillbirth rate for these male calves from female sexed semen was $30.6 \%$, which was 2.86 times the stillbirth rate of male calves from conventional semen, possibly due to trisomies. Aneuploid Y-chromosome-bearing sperm may be selected incorrectly during sorting process. Further research is required to disclose the reasons for this finding. Calf sex had an influence on the average calving ease and the dystocia rates. Male calves showed higher calving ease scores and caused a higher risk for dystocia than female calves. For all other traits analyzed, we showed that the type of semen plays a minor role for performances in first lactation.

The second part of the thesis compares the effects of an oil free and an oil covered culture system on bovine oocyte development. After maturation of oocytes, the study showed a higher progesterone concentration in the medium of the oil free system. In the oil covered system, progesterone was absorbed by the oil during maturation. The oil free culture system led to higher maturation rates of the oocytes. Therefore, it can be regarded as an alternative system for in vitro production.

The aim of the last part of the thesis was to determine, whether the active ingredient glyphosate affects the maturation and further development of bovine oocytes in vitro. For this purpose, the active ingredient glyphosate and the formulation Roundup were added to the maturation medium in active substance concentrations of $1 \mu \mathrm{g} / \mathrm{ml}$ and $10 \mu \mathrm{g} / \mathrm{ml}$. The maturation rates of oocytes and the cleavage and development rates of embryos showed no statistically significant differences irrespective of the concentrations used. The average ratio of live to dead cells of stained blastocysts also showed no differences between groups treated with glyphosate and the controls. The relative ex- 
pression levels of selected genes were only analyzed for the concentration of $10 \mu \mathrm{g} / \mathrm{ml}$. An upregulation of the developmental genes BMP15 (bone morphogenetic protein 15), ZARI (Zygote arrest 1) and ESRI was detected after addition of the active ingredient glyphosate to the maturation medium. Compensatory mechanisms within the cumulusoocyte-complex during maturation might be a possible explanation for this finding. Considering all analyses performed here, negative influences of glyphosate and Roundup on bovine oocyte development were not detected. No differences between the effect of glyphosate formulated as a herbicide and glyphosate in pure form were observed. 


\section{$8 \quad$ Literatur}

Abele E, Stinshoff H, Hanstedt A, Wilkening S, Meinecke-Tillmann S \& Wrenzycki C 2012 Influence of selected (pre-)maturational parameters on in vitro development and sex distribution of bovine embryos. Zygote 22 41-49. (doi:10.1017/S0967199412000275)

ADR 2017 ADR - Empfehlung 3.1; Leistungsprüfung für funktionale Merkmale bei Bullen und Kühen. 1-10.

Alarcón R, Ingaramo PI, Rivera OE, Dioguardi GH, Repetti MR, Demonte LD, Milesi MM, Varayoud J, Muñoz-de-Toro M \& Luque EH 2019 Neonatal exposure to a glyphosate-based herbicide alters the histofunctional differentiation of the ovaries and uterus in lambs. Molecular and Cellular Endocrinology 482 45-56. (doi:10.1016/j.mce.2018.12.007)

Alberman ED \& Creasy MR 1977 Frequency of chromosomal abnormalities in miscarriages and perinatal deaths. Journal of Medical Genetics 14 313-315. (doi:10.1136/jmg.14.5.313)

Anderiesz C, Ferraretti A, Magli C, Fiorentino A, Fortini D, Gianaroli L, Jones GM \& Trounson AO 2000 Effect of recombinant human gonadotrophins on human, bovine and murine oocyte meiosis, fertilization and embryonic development in vitro. Human Reproduction (Oxford, England) 15 1140-1148.

(doi:10.1093/humrep/15.5.1140)

Anderson E \& Albertini DF 1976 Gap junctions between the oocyte and companion follicle cells in the mammalian ovary. The Journal of Cell Biology 71 680-686. (doi:10.1083/jcb.71.2.680)

Armstrong DT, Xia P, de Gannes G, Tekpetey FR \& Khamsi F 1996 Differential effects of insulin-like growth factor-I and follicle-stimulating hormone on proliferation and differentiation of bovine cumulus cells and granulosa cells. Biology of Reproduction 54 331-338. (doi:10.1095/biolreprod54.2.331)

Asma-ul-Husna, Awan MA, Mehmood A, Sultana T, Shahzad Q, Ansari MS, Rakha BA, Saqlan Naqvi SM \& Akhter S 2017 Sperm sexing in Nili-Ravi buffalo through modified swim up: Validation using SYBR ${ }^{\circledR}$ green real-time PCR. Animal Reproduction Science 182 69-76. (doi:10.1016/j.anireprosci.2017.04.011)

Austin CR 1951 Observations on the penetration of the sperm in the mammalian egg. Australian Journal of Scientific Research. Ser. B: Biological Sciences 4 581-596. 
(doi:10.1071/bi9510581)

Bavister BD 1995 Culture of preimplantation embryos: facts and artifacts. Human Reproduction Update 191-148. (doi:10.1093/humupd/1.2.91)

Benachour N \& Séralini GE 2009 Glyphosate formulations induce apoptosis and necrosis in human umbilical, embryonic, and placental cells. Chemical Research in Toxicology 22 97-105. (doi:10.1021/tx800218n)

Benbrook CM 2016 Trends in glyphosate herbicide use in the United States and globally. Environmental Sciences Europe 28 1-15. (doi:10.1186/s12302-016-0070$0)$

BfR 2019 Neue Meta-Analyse zu glyphosathaltigen Pflanzenschutzmitteln ändert die Bewertung des Wirkstoffs nicht. Stellungnahme Nr. 008/2019 Des BfR 2015-2018. (doi:10.17590/20190402-104828)

Blad-Stahl N, Beranek J, Mazurek S \& Wrenzycki C 2020 Glyphosate affects in vitro maturation of bovine cumulus-oocyte-complexes. Reproduction in Domestic Animals 55 6-7. (doi:10.1111/rda.13591)

Blaschka C, Sánchez-Guijo A, Zimmer B, Stöhr J, Kotarski F, Grothmann H, Hartmann MF, Wudy SA \& Wrenzycki C 2019 Temporal expression pattern of steroidmetabolizing enzymes in bovine COC during in vitro maturation employing different gonadotropin concentrations. Theriogenology 131 182-192. (doi:10.1016/j.theriogenology.2019.03.028)

Borchersen S \& Peacock M 2009 Danish A.I. field data with sexed semen. Theriogenology 71 59-63. (doi:10.1016/j.theriogenology.2008.09.026)

Brackett BG \& Oliphant G 1975 Capacitation of rabbit spermatozoa in vitro. Biology of Reproduction 12 260-274. (doi:10.1095/biolreprod12.2.260)

Brackett BG \& Zuelke KA 1993 Analysis of factors involved in the in vitro production of bovine embryos. Theriogenology 39 43-64. (doi:10.1016/0093-691X(93)90023$\mathrm{X})$

Brackett BG, Bousquet D, Boice ML, Donawick WJ, Evans JF \& Dressel MA 1982 Normal development following in vitro fertilization in the cow. Biology of Reproduction 27 147-158. (doi:10.1095/biolreprod27.1.147)

Burg MB, Ferraris JD \& Dmitrieva NI 2007 Cellular response to hyperosmotic stresses. Physiological Reviews 87 1441-1474. (doi:10.1152/physrev.00056.2006)

BVL 2017 Federal Office of Consumer Protection and Food Safety: Sales of plant protection products in the Federal Republic of Germany. 
Canseco RS, Sparks AET, Pearson RE \& Gwazdauskas FC 1992 Embryo density and medium volume effects on early murine embryo development. Journal of Assisted Reproduction and Genetics 9 454-457. (doi:10.1007/BF01204051)

Cereda A \& Carey JC 2012 The trisomy 18 syndrome. Orphanet Journal of Rare Diseases 7 81. (doi:10.1186/1750-1172-7-81)

Chang M 1951 Fertilizing capacity of spermatozoa deposited into the fallopian tubes. Nature 168 697-698. (doi:10.1038/168697b0)

Chang M 1959 Fertilization of rabbit ova in vitro. Nature 184 Suppl 7 466-467. (doi:10.1038/184466a0)

Chang MC 1984 The meaning of sperm capacitation. A historical perspective. Journal of Andrology 5 45-50. (doi:10.1002/j.1939-4640.1984.tb00775.x)

Clark JH, Schrader WT \& O'Malley BW 1992 Mechanism of action of steroid hormones. In Williams' Textbook of Endocrinology, 8th editio, pp 35-90. Williams, R. H. Wilson, J. D. Foster, D. W; W. B. Saunders Co Philadelphia.

Clemente M, de La Fuente J, Fair T, Al Naib A, Gutierrez-Adan A, Roche JF, Rizos D \& Lonergan P 2009 Progesterone and conceptus elongation in cattle: a direct effect on the embryo or an indirect effect via the endometrium? Reproduction (Cambridge, England) 138 507-517. (doi:10.1530/REP-09-0152)

Corrêa GA, Rumpf R, Mundim TCD, Franco MM \& Dode MAN 2008 Oxygen tension during in vitro culture of bovine embryos: effect in production and expression of genes related to oxidative stress. Animal Reproduction Science 104 132-142. (doi:10.1016/j.anireprosci.2007.02.002)

DeJarnette JM, Nebel RL, Marshall CE, Moreno JF, McCleary CR \& Lenz RW 2008 Effect of sex-sorted sperm dosage on conception rates in holstein heifers and lactating cows. Journal of Dairy Science 91 1778-1785. (doi:10.3168/jds.20070964)

DeJarnette JM, Nebel RL \& Marshall CE 2009 Evaluating the success of sex-sorted semen in US dairy herds from on farm records. Theriogenology 71 49-58. (doi:10.1016/j.theriogenology.2008.09.042)

Dieleman SJ, Kruip TA, Fontijne P, de Jong WH \& van der Weyden GC 1983 Changes in oestradiol, progesterone and testosterone concentrations in follicular fluid and in the micromorphology of preovulatory bovine follicles relative to the peak of luteinizing hormone. The Journal of Endocrinology 97 31-42. (doi:10.1677/joe.0.0970031) 
EC 2012 VERORDNUNG (EU) Nr. 441/2012 DER KOMMISSION vom 24. Mai 2012. Amtsblatt Der Europäischen Union.

EC 2016 Commission Implementing Regulation (EU) 2016/1313 of 1 August 2016 amending Implementation Regulation (EU) No 540/2011 as regards the conditions of approval of the active substance glyphosate. Official Journal of the European Union L 208/1.

EC 2017 Current status of glyphosate in the EU.

Eckert J \& Niemann H 1995 In vitro maturation, fertilization and culture to blastocysts of bovine oocytes in protein-free media. Theriogenology 43 1211-1225. (doi:10.1016/0093-691x(95)00093-n)

Edwards RG 1965 Maturation in vitro of mouse, sheep, cow, pig, rhesus monkey and human ovarian oocytes. Nature 208 349-351. (doi:10.1038/208349a0)

EFSA_POEA 2015 Request for the evaluation of the toxicological assessment of the coformulant POE-tallowamine. EFSA Journal 13. (doi:10.2903/j.efsa.2015.4303)

EFSA 2015 Conclusion on the peer review of the pesticide risk assessment of the active substance glyphosate. EFSA Journal 13 4302,107 pp.

(doi:10.2903/j.efsa.2015.4302)

EFSA 2017 Peer review of the pesticide risk assessment of the potential endocrine disrupting properties of glyphosate. EFSA Journal 15.

(doi:10.2903/j.efsa.2017.4979)

EPA 2015 Endocrine Disruptor Screening Program: Weight of Evidence Analysis of Potential Interaction with the Estrogen, Androgen or Thyroid Pathways. Glyphosate.

EPA 2018 Draft Human Health and/or Ecological Risk Assessments for Several Pesticides. EPA-HQ-OPP-2009-0361.

Erbach GT, Bhatnagar P, Baltz JM \& Biggers JD 1995 Zinc is a possible toxic contaminant of silicone oil in microdrop cultures of preimplantation mouse embryos. Human Reproduction (Oxford, England) 10 3248-3254. (doi:10.1093/oxfordjournals.humrep.a135897)

Erickson GF, Wang C \& Hsueh AJ 1979 FSH induction of functional LH receptors in granulosa cells cultured in a chemically defined medium. Nature 279 336-338. (doi:10.1038/279336a0)

Faber DC, Molina JA, Ohlrichs CL, Vander Zwaag DF \& Ferré LB 2003 Commercialization of animal biotechnology. Theriogenology 59 125-138. 
(doi:10.1016/S0093-691X(02)01264-5)

Fair T \& Lonergan P 2012 The role of progesterone in oocyte acquisition of developmental competence. Reproduction in Domestic Animals 47 142-147. (doi:10.1111/j.1439-0531.2012.02068.x)

FAO/WHO 20192019 REPORT Pesticide Residues in Food.

Franz JE, Mao MK \& Sikorski JA 1997 Glyphosate: A Unique Global Herbicide. Washington, DC, USA: American Chemical Society.

Funahashi H, Cantley T \& Day BN 1994 Different hormonal requirements of pig oocyte-cumulus complexes during maturation in vitro. Journal of Reproduction and Fertility 101 159-165. (doi:10.1530/jrf.0.1010159)

Garner DL \& Seidel GE 2003 Past, present and future perspectives on sexing sperm. Canadian Journal of Animal Science 83 375-384. (doi:10.4141/A03-022)

Garner DL, Gledhill BL, Pinkel D, Lake S, Stephenson D, Van Dilla MA \& Johnson LA 1983 Quantification of the X- and Y-Chromosome-Bearing Spermatozoa of Domestic Animals by Flow Cytometry. Biology of Reproduction 28 312-321. (doi:10.1095/biolreprod28.2.312)

Gasnier C, Dumont C, Benachour N, Clair E, Chagnon MC \& Séralini GE 2009 Glyphosate-based herbicides are toxic and endocrine disruptors in human cell lines. Toxicology 262 184-191. (doi:10.1016/j.tox.2009.06.006)

Gasperin BG, Barreta MH, Santos JT, Ferreira R, Neves JP, Oliveira JFC \& Gonçalves PBD 2010 Oil-free culture system for in vitro bovine embryo production. Italian Journal of Animal Science 9 169-172. (doi:10.4081/ijas.2010.e32)

Geldermann H 2005 Tier-Biotechnologie, 1. Auflage, pp 361-366. Eugen Ulmer GmbH\&Co., Stuttgart.

Gil MA, Abeydeera LR, Day BN, Vazquez JM, Roca J \& Martinez EA 2003 Effect of the volume of medium and number of oocytes during in vitro fertilization on embryo development in pigs. Theriogenology 60 767-776. (doi:10.1016/s0093$691 \times(03) 00051-7)$

Gilula NB, Epstein ML \& Beers WH 1978 Cell-to-cell communication and ovulation. A study of the cumulus-oocyte complex. The Journal of Cell Biology 78 58-75. (doi:10.1083/jcb.78.1.58)

Gledhill BL, Pinkel D, Garner DL \& Van Della MA 1982 Identifying X- and Ychromosome-bearing sperm by DNA content: retrospective perspectives and prospective opinions. In Prospects for Sexing Mammalian Sperm. Colorado 
Associated University Press 177-191.

Gonzalez-Marin C, Lenz RW, Gilligan TB, Evans KM, Gongora CE, Moreno JF \& Vishwanath R 2016 SexedULTRA $^{\mathrm{TM}}$, a new method of processing sex-sorted bovine sperm improves post-thaw sperm quality and in vitro fertility. Reproduction, Fertility and Development 29 204-205.

(doi:10.1071/rdv29n1ab191)

Gosden R \& Lee B 2010 Portrait of an oocyte: our obscure origin. Journal of Clinical Investigation 120 973-983. (doi:10.1172/JCI41294)

Gregory KE, Cundiff L V. \& Koch RM 1991 Breed effects and heterosis in advanced generations of composite populations for birth weight, birth date, dystocia, and survival as traits of dam in beef cattle. Journal of Animal Science 69 3574-3589. (doi:10.2527/1991.6993574x)

Gröhn YT \& Rajala-Schultz PJ 2000 Epidemiology of reproductive performance in dairy cows. Animal Reproduction Science 60-61 605-614. (doi:10.1016/S03784320(00)00085-3)

Gwatkin RB 1963 Effect of viruses on early mammalian development, I. action of mengo encephalitis virus on mouse ova cultivated in vitro. Proceedings of the National Academy of Sciences of the United States of America 50 576-581. (doi:10.1073/pnas.50.3.576)

Hasler JF 1998 The Current Status of Oocyte Recovery, In Vitro Embryo Production, and Embryo Transfer in Domestic Animals, with an Emphasis on the Bovine. Journal of Animal Science 76 52. (doi:10.2527/1998.76suppl_352x)

Hassold TJ 1986 Chromosome abnormalities in human reproductive wastage. Trends in Genetics 2 105-110. (doi:10.1016/0168-9525(86)90194-0)

Hassold T \& Hunt P 2001 To err (meiotically) is human: the genesis of human aneuploidy. Nature Reviews. Genetics 2 280-291. (doi:10.1038/35066065)

Healy AA, House JK \& Thomson PC 2013 Artificial insemination field data on the use of sexed and conventional semen in nulliparous Holstein heifers. Journal of Dairy Science 96 1905-1914. (doi:10.3168/jds.2012-5465)

Hohenboken WD 1999 Applications of sexed semen in cattle production. Theriogenology 52 1421-1433. (doi:10.1016/s0093-691x(99)00227-7)

IARC 2015 Evaluation of five organophosphate insecticides and herbicides. IARC Monographs 112 1-92.

Ingaramo PI, Varayoud J, Milesi MM, Schimpf MG, Muñoz-De-toro M \& Luque EH 
2016 Effects of neonatal exposure to a glyphosate-based herbicide on female rat reproduction. Reproduction 152 403-415. (doi:10.1530/REP-16-0171)

Ireland JJ, Zielak-Steciwko AE, Jimenez-Krassel F, Folger J, Bettegowda A, Scheetz D, Walsh S, Mossa F, Knight PG, Smith GW et al. 2009 Variation in the Ovarian Reserve Is Linked to Alterations in Intrafollicular Estradiol Production and Ovarian Biomarkers of Follicular Differentiation and Oocyte Quality in Cattle1. Biology of Reproduction 80 954-964. (doi:10.1095/biolreprod.108.073791)

Iritani A \& Niwa K 1977 Capacitation of bull spermatozoa and fertilization in vitro of cattle follicular oocytes matured in culture. Journal of Reproduction and Fertility 50 119-121. (doi:10.1530/jrf.0.0500119)

Jacobs PA \& Strong JA 1959 A case of human intersexuality having a possible XXY sex-determining mechanism. Nature 183 302-303. (doi:10.1038/183302a0)

James C 2011 Global Status of Commercialized Biotech/GM Crops: 2011. ISAAA Brief No. 43.

Johansson HKL, Schwartz CL, Nielsen LN, Boberg J, Vinggaard AM, Bahl MI \& Svingen T 2018 Exposure to a glyphosate-based herbicide formulation, but not glyphosate alone, has only minor effects on adult rat testis. Reproductive Toxicology 82 25-31. (doi:10.1016/j.reprotox.2018.09.008)

Johnson LA, Flook JP \& Look M V. 1987 Flow cytometry of X and Y chromosomebearing sperm for DNA using an improved preparation method and staining with Hoechst 33342. Gamete Research 17 203-212. (doi:10.1002/mrd.1120170303)

Johnson LA, Flook JP \& Hawk HW 1989 Biology of reproduction 41, 199-203 (1989). Biology of Reproduction 41 199-203.

Johnson LA, Welch GR \& Rens W 1999 The Beltsville sperm sexing technology: highspeed sperm sorting gives improved sperm output for in vitro fertilization and AI. Journal of Animal Science 77 Suppl 2 213-220.

Kawarasaki T, Welch G., Long C., Yoshida M \& Johnson L. 1998 Verification of flow cytometorically-sorted $\mathrm{X}$ - and $\mathrm{Y}$-bearing porcine spermatozoa and reanalysis of spermatozoa for DNA content using the fluorescence in situ hybridization (FISH) technique. Theriogenology 50 625-635. (doi:10.1016/S0093-691X(98)00167-8)

Kishore GM \& Shah DM 1988 Amino acid biosynthesis inhibitors as herbicides. Annual Review of Biochemistry 57 627-663.

(doi:10.1146/annurev.bi.57.070188.003211)

Kleine B \& Rossmanith W 2010 Organe des Hormonsystems. In Hormone Und 
Hormonsystem, 2. Auflage, pp 198-202. Springer-Verlag Berlin, Heidelberg.

Krüger M, Schledorn P, Schrödl W, Hoppe H-W, Lutz W \& Shehata AA 2014 Detection of Glyphosate Residues in Animals and Humans. Journal of Environmental \& Analytical Toxicology 04. (doi:10.4172/2161-0525.1000210)

Lane M \& Gardner DK 1992 Effect of incubation volume and embryo density on the development and viability of mouse embryos in vitro. Human Reproduction 7558 562. (doi:10.1093/oxfordjournals.humrep.a137690)

Larsen WJ, Wert SE \& Brunner GD 1986 A dramatic loss of cumulus cell gap junctions is correlated with germinal vesicle breakdown in rat oocytes. Developmental Biology 113 517-521. (doi:10.1016/0012-1606(86)90187-9)

Lee S, Cho M, Kim E, Kim T, Lee C, Han J \& Lim J 2004 Renovation of a drop embryo cultures system by using refined mineral oil and the effect of glucose and/or hemoglobin added to a serum-free medium. Journal of Veterinary Medical Science 66 63-66. (doi:10.1292/jvms.66.63)

Lenz RW, Gonzalez-Marin C, Gilligan TB, DeJarnette JM, Utt MD, Helser LA, Hasenpusch E, Evans KM, Moreno JF \& Vishwanath R 2016 SexedULTRA $^{\mathrm{TM}}$, a new method of processing sex-sorted bovine sperm improves conception rates. Reproduction, Fertility and Development 29 203-204.

(doi:10.1071/RDv29n1Ab190)

Li R, Whitworth K, Lai L, Wax D, Spate L, Murphy CN, Rieke A, Isom C, Hao Y, Zhong $\mathrm{Z}$ et al. 2007 Concentration and composition of free amino acids and osmolalities of porcine oviductal and uterine fluid and their effects on development of porcine IVF embryos. Molecular Reproduction and Development 74 12281235. (doi:10.1002/mrd.20682)

Liu Z \& Foote RH 1996 Sodium chloride, osmolyte, and osmolarity effects on blastocyst formation in bovine embryos produced by in vitro fertilization (IVF) and cultured in simple serum-free media. Journal of Assisted Reproduction and Genetics 13 562-568. (doi:10.1007/bf02066609)

Liu W, Xin Q, Wang X, Wang S, Wang H, Zhang W, Yang Y, Zhang Y, Zhang Z, Wang C et al. 2017 Estrogen receptors in granulosa cells govern meiotic resumption of pre-ovulatory oocytes in mammals. Cell Death and Disease 8 1-11. (doi:10.1038/cddis.2017.82)

De Liz Oliveira Cavalli VL, Cattani D, Heinz Rieg CE, Pierozan P, Zanatta L, Benedetti Parisotto E, Wilhelm Filho D, Mena Barreto Silva FR, Pessoa-Pureur R \& 
Zamoner A 2013 Roundup disrupts male reproductive functions by triggering calcium-mediated cell death in rat testis and Sertoli cells. Free Radical Biology and Medicine 65 335-346. (doi:10.1016/j.freeradbiomed.2013.06.043)

Mallory DA, Lock SL, Woods DC, Poock SE \& Patterson DJ 2013 Hot topic: Comparison of sex-sorted and conventional semen within a fixed-time artificial insemination protocol designed for dairy heifers. Journal of Dairy Science 96854 856. (doi:10.3168/jds.2012-5850)

Martinez CA, Nohalez A, Parrilla I, Motas M, Roca J, Romero I, García-González DL, Cuello C, Rodriguez-Martinez H, Martinez EA et al. 2017 The overlaying oil type influences in vitro embryo production: differences in composition and compound transfer into incubation medium between oils. Scientific Reports 710505. (doi:10.1038/s41598-017-10989-5)

Martinez CA, Martinez EA \& Gil MA 2018 Importance of oil overlay for production of porcine embryos in vitro. Reproduction in Domestic Animals 53 281-286. (doi:10.1111/rda.13114)

McGaughey RW 1977 The maturation of porcine oocytes in minimal, defined culture media with varied macromolecular supplements and varied osmolarity. Experimental Cell Research 109 25-30. (doi:10.1016/0014-4827(77)90040-4)

McGrath SA, Esquela AF \& Lee SJ 1995 Oocyte-specific expression of growth/differentiation factor-9. Molecular Endocrinology (Baltimore, Md.) 9 131136. (doi:10.1210/mend.9.1.7760846)

Meinecke B \& Meinecke-Tillmann S 1979 Effects of gonadotropins on oocyte maturation and progesterone production by porcine ovarian follicles cultured in vitro. Theriogenology 11 351-365. (doi:10.1016/0093-691x(79)90059-1)

Mesnage R, Phedonos A, Biserni M, Arno M, Balu S, Corton JC, Ugarte R \& Antoniou MN 2017 Evaluation of estrogen receptor alpha activation by glyphosate-based herbicide constituents. Food and Chemical Toxicology 108 30-42. (doi:10.1016/j.fct.2017.07.025)

Miller KF \& Pursel VG 1987 Absorption of compounds in medium by the oil covering microdrop cultures. Gamete Research 17 57-61. (doi:10.1002/mrd.1120170107)

Moenter SM, Caraty A \& Karsch FJ 1990 The estradiol-induced surge of gonadotropinreleasing hormone in the ewe. Endocrinology 127 1375-1384. (doi:10.1210/endo127-3-1375)

Moon YS, Tsang BK, Simpson C \& Armstrong DT 197817 beta-Estradiol biosynthesis 
in cultured granulosa and thecal cells of human ovarian follicles: stimulation by follicle-stimulating hormone. The Journal of Clinical Endocrinology and Metabolism 47 263-267. (doi:10.1210/jcem-47-2-263)

Moor RM, Polge C \& Willadsen SM 1980 Effect of follicular steroids on the maturation and fertilization of mammalian oocytes. Journal of Embryology and Experimental Morphology 56 319-335.

Moruzzi JF 1979 Selecting a mammalian species for the separation of X- and Ychromosome-bearing spermatozoa. Journal of Reproduction and Fertility 57 319323. (doi:10.1530/jrf.0.0570319)

Nagai T, Takahashi T, Masuda H, Shioya Y, Kuwayama M, Fukushima M, Iwasaki S \& Hanada A 1988 In-vitro fertilization of pig oocytes by frozen boar spermatozoa. Journal of Reproduction and Fertility 84 585-591. (doi:10.1530/jrf.0.0840585)

Norman HD, Hutchison JL \& Miller RH 2010 Use of sexed semen and its effect on conception rate, calf sex, dystocia, and stillbirth of Holsteins in the United States. Journal of Dairy Science 93 3880-3890. (doi:10.3168/jds.2009-2781)

Otsuki J, Nagai Y \& Chiba K 2009 Damage of embryo development caused by peroxidized mineral oil and its association with albumin in culture. Fertility and Sterility 91 1745-1749. (doi:10.1016/j.fertnstert.2008.03.001)

Paganelli A, Gnazzo V, Acosta H, López SL \& Carrasco AE 2010 Glyphosate-based herbicides produce teratogenic effects on vertebrates by impairing retinoic acid signaling. Chemical Research in Toxicology 23 1586-1595. (doi:10.1021/tx1001749)

Parrish JJ, Susko-Parrish J, Winer MA \& First NL 1988 Capacitation of bovine sperm by heparin. Biology of Reproduction 38 1171-1180. (doi:10.1095/biolreprod38.5.1171)

Parrish JJ, Krogenaes A \& Susko-Parrish JL 1995 Effect of bovine sperm separation by either swim-up or Percoll method on success of in vitro fertilization and early embryonic development. Theriogenology 44 859-869. (doi:10.1016/0093$691 \times(95) 00271-9)$

Pavlok A, Lucas-Hahn A \& Niemann H 1992 Fertilization and developmental competence of bovine oocytes derived from different categories of antral follicles. Molecular Reproduction and Development 31 63-67. (doi:10.1002/mrd.1080310111)

Perego MC, Caloni F, Cortinovis C, Schutz LF, Albonico M, Tsuzukibashi D \& Spicer 
LJ 2017 Influence of a Roundup formulation on glyphosate effects on steroidogenesis and proliferation of bovine granulosa cells in vitro. Chemosphere 188 274-279. (doi:10.1016/j.chemosphere.2017.09.007)

Pincus G 1930 Observations on the living eggs of the rabbit. Proceedings of the Royal Society of London. Series B, Containing Papers of a Biological Character 107 132-167. (doi:10.1098/rspb.1930.0058)

Pincus G \& Enzmann E V. 1932 Fertilisation in the Rabbit. Journal of Experimental Biology 9 403-408.

Pincus G \& Enzmann E V. 1935 The comparative behavior of mammalian eggs in vivo and in vitro: I. The activation of ovarian eggs. The Journal of Experimental Medicine 62 665-675. (doi:10.1084/jem.62.5.665)

Pincus G \& Shapiro H 1940 The Comparative Behavior of Mammalian Eggs in Vivo and in Vitro . VII . Further Studies on the Activation of Rabbit Eggs. Proceedings of the American Philosophical Society 83 631-647.

Pinkel D, Lake S, Gledhill BL, Van Dilla MA, Stephenson D \& Watchmaker G 1982 High resolution DNA content measurements of mammalian sperm. Cytometry 3 19. (doi:10.1002/cyto.990030103)

Rath D Repro-GamTec 2020

Rath D, Barcikowski S, Graaf S De, Garrels W, Grossfeld R, Klein S, Knabe W, Knorr C, Kues W, Meyer H et al. 2013 Sex selection of sperm in farm animals: Status report and developmental prospects. Reproduction 145 15-30. (doi:10.1530/REP12-0151)

Reinsberg J, Ackermann D \& van der Ven H 2004 Pitfalls in assessment of progesterone production by granulosa cells cultured in contact with silicone rubber or paraffin oil. Archives of Gynecology and Obstetrics 270 174-178. (doi:10.1007/s00404-003-0539-0)

Richard S, Moslemi S, Sipahutar H, Benachour N \& Seralini GE 2005 Differential effects of glyphosate and roundup on human placental cells and aromatase. Environmental Health Perspectives 113 716-720. (doi:10.1289/ehp.7728)

Riede S, Toboldt A, Breves G, Metzner M, Köhler B, Bräunig J, Schafft H, LahrssenWiederholt M \& Niemann L 2016 Investigations on the possible impact of a glyphosate-containing herbicide on ruminal metabolism and bacteria in vitro by means of the 'Rumen Simulation Technique'. Journal of Applied Microbiology 121 644-656. (doi:10.1111/jam.13190) 
Rong Y, Ji SY, Zhu YZ, Wu YW, Shen L \& Fan HY 2019 ZAR1 and ZAR2 are required for oocyte meiotic maturation by regulating the maternal transcriptome and mRNA translational activation. Nucleic Acids Research 47 11387-11402. (doi:10.1093/nar/gkz863)

Ross JL, Roeltgen DP, Kushner H, Zinn AR, Reiss A, Bardsley MZ, McCauley E \& Tartaglia N 2012 Behavioral and Social Phenotypes in Boys With 47,XYY Syndrome or 47,XXY Klinefelter Syndrome. Pediatrics 129 769-778. (doi:10.1542/peds.2011-0719)

Salhab M, Tosca L, Cabau C, Papillier P, Perreau C, Dupont J, Mermillod P \& Uzbekova S 2011 Kinetics of gene expression and signaling in bovine cumulus cells throughout IVM in different mediums in relation to oocyte developmental competence, cumulus apoptosis and progesterone secretion. Theriogenology $\mathbf{7 5}$ 90-104. (doi:10.1016/j.theriogenology.2010.07.014)

Salustri A, Yanagishita M \& Hascall VC 1989 Synthesis and accumulation of hyaluronic acid and proteoglycans in the mouse cumulus cell-oocyte complex during follicle-stimulating hormone-induced mucification. Journal of Biological Chemistry 264 13840-13847.

Schenk S 1878 Das Säugetierei künstlich befruchtet außerhalb des Mutterleibes. Mitteilung Des Embryologischen Institutes Der K.K. Universität Wien 1107.

Schenk JL, Suh TK, Cran DG \& Seidel GE 1999 Cryopreservation of flow-sorted bovine spermatozoa. Theriogenology 52 1375-1391. (doi:10.1016/S0093691X(99)00224-1)

Schenk JL, Cran DG, Everett RW \& Seidel GE 2009 Pregnancy rates in heifers and cows with cryopreserved sexed sperm: Effects of sperm numbers per inseminate, sorting pressure and sperm storage before sorting. Theriogenology 71 717-728. (doi:10.1016/j.theriogenology.2008.08.016)

Schnabel K, Schmitz R, von Soosten D, Frahm J, Kersten S, Meyer U, Breves G, Hackenberg R, Spitzke M \& Dänicke S 2017 Effects of glyphosate residues and different concentrate feed proportions on performance, energy metabolism and health characteristics in lactating dairy cows. Archives of Animal Nutrition 71 413427. (doi:10.1080/1745039X.2017.1391487)

Schnorr B \& Kressin M 2001 Entwicklung und Bau der Eizellen. In Embryologie Der Haustiere, 4. Auflage, pp 14-17. Enke Verlag Stuttgart.

Schönbrunn E, Eschenburg S, Shuttleworth WA, Schloss J V., Amrhein N, Evans JNS 
\& Kabsch W 2001 Interaction of the herbicide glyphosate with its target enzyme 5enolpyruvylshikimate 3-phosphate synthase in atomic detail. Proceedings of the National Academy of Sciences of the United States of America 98 1376-1380. (doi:10.1073/pnas.98.4.1376)

Seidel GE 2002 Sexing sperm for beef and dairy cattle breeding. Factors Affecting Calf Crop: Biotechnology of Reproduction. CRC Press Inc. Boca Raton, FL 281-287.

Seidel GE 2007 Overview of sexing sperm. Theriogenology 68 443-446. (doi:10.1016/j.theriogenology.2007.04.005)

Seidel GE 2014 Update on sexed semen technology in cattle. Animal 8 160-164. (doi:10.1017/S1751731114000202)

Seidel GE \& Schenk JL 2008 Pregnancy rates in cattle with cryopreserved sexed sperm: Effects of sperm numbers per inseminate and site of sperm deposition. Animal Reproduction Science 105 129-138. (doi:10.1016/j.anireprosci.2007.11.015)

Seidel GE, Schenk JL, Herickhoff LA, Doyle SP, Brink Z, Green RD \& Cran DG 1999 Insemination of heifers with sexed sperm. Theriogenology 52 1407-1420. (doi:10.1016/s0093-691x(99)00226-5)

Shimada M, Kawano N \& Terada T 2002 Delay of nuclear maturation and reduction in developmental competence of pig oocytes after mineral oil overlay of in vitro maturation media. Reproduction (Cambridge, England) 124 557-564.

(doi:10.1530/rep.0.1240557)

Simon AM, Goodenough DA, Li E \& Paul DL 1997 Female infertility in mice lacking connexin 37. Nature 385 525-529. (doi:10.1038/385525a0)

Slaby S, Titran P, Marchand G, Hanotel J, Lescuyer A, Leprêtre A, Bodart JF, Marin M \& Lemiere S 2019 Effects of glyphosate and a commercial formulation Roundup ${ }^{\circledR}$ exposures on maturation of Xenopus laevis oocytes. Environmental Science and Pollution Research. (doi:10.1007/s11356-019-04596-2)

Van Soom A, Mahmoudzadeh AR, Christophe A, Ysebaert MT \& De Kruif A 2001 Silicone oil used in microdrop culture can affect bovine embryonic development and freezability. Reproduction in Domestic Animals 36 169-176.

(doi:10.1046/j.1439-0531.2001.d01-32.x)

von Soosten D, Meyer U, Hüther L, Dänicke S, Lahrssen-Wiederholt M, Schafft H, Spolders M \& Breves G 2016 Excretion pathways and ruminal disappearance of glyphosate and its degradation product aminomethylphosphonic acid in dairy cows. Journal of Dairy Science 99 5318-5324. (doi:10.3168/jds.2015-10585) 
Steinrücken HC \& Amrhein N 1980 The herbicide glyphosate is a potent inhibitor of 5enolpyruvylshikimic acid-3-phosphate synthase. Biochemical and Biophysical Research Communications 94 1207-1212. (doi:10.1016/0006-291X(80)90547-1)

Steptoe PC \& Edwards RG 1978 Birth after the reimplantation of a human embryo. Lancet (London, England) 2 366. (doi:10.1016/s0140-6736(78)92957-4)

Stinshoff H, Wilkening S, Hanstedt A, Brüning K \& Wrenzycki C 2011 Cryopreservation affects the quality of in vitro produced bovine embryos at the molecular level. Theriogenology 76 1433-1441.

(doi:10.1016/j.theriogenology.2011.06.013)

Suthar VS \& Shah RG 2009 Bovine In vitro embryo production: An overview. Veterinary World 2 478-479.

Sutton ML, Gilchrist RB \& Thompson JG 2003 Effects of in-vivo and in-vitro environments on the metabolism of the cumulus-oocyte complex and its influence on oocyte developmental capacity. Human Reproduction Update 9 35-48. (doi:10.1093/humupd/dmg009)

Tarazona J V., Court-Marques D, Tiramani M, Reich H, Pfeil R, Istace F \& Crivellente F 2017 Glyphosate toxicity and carcinogenicity: a review of the scientific basis of the European Union assessment and its differences with IARC. Archives of Toxicology 91 2723-2743. (doi:10.1007/s00204-017-1962-5)

Tervit HR, Whittingham DG \& Rowson LE 1972 Successful culture in vitro of sheep and cattle ova. Journal of Reproduction and Fertility 30 493-497. (doi:10.1530/jrf.0.0300493)

Thibier M 2005 The zootechnical applications of biotechnology in animal reproduction: current methods and perspectives. Reproduction, Nutrition, Development 45 235242. (doi:10.1051/rnd:2005016)

Thomas JM, Locke JWC, Vishwanath R, Hall JB, Ellersieck MR, Smith MF \& Patterson DJ 2017 Effective use of SexedULTRA ${ }^{\text {TM }}$ sex-sorted semen for timed artificial insemination of beef heifers. Theriogenology 98 88-93. (doi:10.1016/j.theriogenology.2017.03.018)

Tubman LM, Brink Z, Suh TK \& Seidel GE 2004 Characteristics of calves produced with sperm sexed by flow cytometry/cell sorting. Journal of Animal Science $\mathbf{8 2}$ 1029-1036.

Uren Webster TM, Laing L V., Florance H \& Santos EM 2014 Effects of glyphosate and its formulation, roundup, on reproduction in zebrafish (Danio rerio). 
Environmental Science and Technology 48 1271-1279. (doi:10.1021/es404258h)

Vanlaeys A, Dubuisson F, Seralini GE \& Travert C 2018 Formulants of glyphosatebased herbicides have more deleterious impact than glyphosate on TM4 Sertoli cells. Toxicology in Vitro 52 14-22. (doi:10.1016/j.tiv.2018.01.002)

Varayoud J, Durando M, Ramos JG, Milesi MM, Ingaramo PI, Muñoz-de-Toro M \& Luque EH 2017 Effects of a glyphosate-based herbicide on the uterus of adult ovariectomized rats. Environmental Toxicology 32 1191-1201.

(doi:10.1002/tox.22316)

Vishwanath R \& Moreno JF 2018 Review: Semen sexing - Current state of the art with emphasis on bovine species. Animal 12 s85-s96.

(doi:10.1017/S1751731118000496)

Walsh LP, McCormick C, Martin C \& Stocco DM 2000 Roundup inhibits steroidogenesis by disrupting steroidogenic acute regulatory (StAR) protein expression. Environmental Health Perspectives 108 769-776.

(doi:10.1289/ehp.00108769)

Wang WH, Uchida M \& Niwa K 1992 Effects of Follicle Cells on in vitro Penetration of Pig Oocytes by Cryopreserved, Ejaculated Spermatozoa. Journal of Reproduction and Development 38 125-131. (doi:10.1262/jrd.38.125)

Wickramasinghe D \& Albertini DF 1993 Cell cycle control during mammalian oogenesis. Current Topics in Developmental Biology 28 125-153.

(doi:10.1016/s0070-2153(08)60211-2)

Wrenzycki C \& Stinshoff H 2013 Maturation Environment and Impact on Subsequent Developmental Competence of Bovine Oocytes. Reproduction in Domestic Animals 48 38-43. (doi:10.1111/rda.12204)

Wrenzycki C, Herrmann D, Lucas-Hahn A, Korsawe K, Lemme E \& Niemann H 2005 Messenger RNA expression patterns in bovine embryos derived from in vitro procedures and their implications for development. Reproduction, Fertility, and Development 17 23-35. (doi:10.1071/rd04109)

Xu KP, Høier R \& Greve T 1988 Dynamic changes of estradiol and progesterone concentrations during in vitro oocyte maturation in cattle. Theriogenology 30245 255. (doi:10.1016/0093-691X(88)90174-4)

Yan C, Wang P, Demayo J, Demayo FJ, Elvin JA, Carino C, Prasad S V., Skinner SS, Dunbar BS, Dube JL et al. 2001 Synergistic roles of bone morphogenetic protein 15 and growth differentiation factor 9 in ovarian function. Molecular 
Endocrinology 15 854-866. (doi:10.1210/mend.15.6.0662)

Yoshida M, Bamba K \& Kojima Y 1989 Effects of gonadotropins and estradiol17.BETA. on the timing of nuclear maturation and cumulus mass expansion in pig oocytes cultured in vitro. The Japanese Journal of Animal Reproduction 35 86-91. (doi:10.1262/jrd1977.35.86)

Zhang J-W, Xu D-Q \& Feng X-Z 2019 The toxic effects and possible mechanisms of glyphosate on mouse oocytes. Chemosphere 237124435.

(doi:10.1016/j.chemosphere.2019.124435) 


\section{Erklärung über den geleisteten Eigenanteil an der Arbeit}

Hiermit erkläre ich den geleisteten Anteil an den in die Dissertationsschrift aufgenommenen Beiträgen.

Im ersten Beitrag mit dem Titel „Effect of sexed semen on different production and functional traits in German Holsteins", sind folgende Bereiche von mir übernommen worden: Durchführung von Berechnungen und Interpretation der Ergebnisse in Zusammenarbeit mit Herrn Dr. Johannes Heise und Herrn Tony Krebs, Verfassen und Überarbeiten des Beitrags in Abstimmung mit Herrn Dr. Johannes Heise und Herrn Prof. Dr. Jens Tetens.

Im zweiten Teil der Arbeit mit den Beiträgen „The effect of an oil covered culture system on bovine in vitro produced embryos” und „Evaluation of a small volume oil-free in vitro production system for bovine embryos“, sind folgende Bereiche von mir übernommen worden: vorbereitende Untersuchungen für das Experiment, Probensammlung, Unterstützung von Frau Mariya Aravina bei der Versuchsdurchführung, Überarbeitung der Beiträge.

Im dritten Teil der Arbeit mit den Beiträgen „Effect of glyphosate on bovine oocyte development during in vitro maturation”, „Does glyphosate affect the expression of developmental genes in bovine oocytes?“ und „Beeinflusst Glyphosat die In-vitroMaturation und weitere Entwicklung boviner Oozyten?“, sind folgende Bereiche von mir übernommen worden: Die Versuchsplanung fand in Abstimmung mit Frau Dr. Carina Blaschka und Herrn Prof. Dr. Jens Tetens statt. Die Probensammlung wurde von mir mit der Unterstützung von Frau Hannah Hellmold, Herrn Dirk Teuteberg und Herrn Manfred Vopel durchgeführt. Die morphologischen Analysen der Embryonen und die Fluoreszenzfärbungen von Oozyten und Embryonen erfolgten in Zusammenarbeit mit Frau Dr. Carina Blaschka, Frau Hannah Hellmold und Herrn Dirk Teuteberg. Die molekulargenetischen Analysen wurden in Zusammenarbeit mit Frau Dr. Isabel Kilic durchgeführt. Die Follikelflüssigkeit und das Medium wurden in Zusammenarbeit mit Frau Dr. Anna Rathgeb und Herrn Prof. Dr. Petr Karlovsky untersucht. Die Daten wurden zusammen mit Herrn Dr. Alexander Silbersdorff ausgewertet. Das Verfassen und Überarbeiten der Beiträge erfolgte in Abstimmung mit den hier aufgeführten Personen. 


\section{Danksagung}

Zu allererst möchte ich Herrn Prof. Dr. Jens Tetens für die Übernahme der Betreuung meiner Doktorarbeit und die hervorragende Unterstützung in den letzten beiden Jahren danken!

Herrn Prof. Dr. Christoph Knorr danke ich dafür, dass er mir zur Promotion geraten und sie mir ermöglicht hat. Danke, für Ihre Unterstützung und Ihr Vertrauen. Ich hätte Sie gerne bei diesem Abschluss dabei gehabt!

Herrn Prof. Dr. Detlef Rath und Herrn Prof. Dr. Jürgen Hummel danke ich für die Übernahme des Korreferats und des Prüfungsbeisitzes.

Bei der H. Wilhelm Schaumann Stiftung bedanke ich mich für die finanzielle Förderung meiner Arbeit.

Ein großer Dank gilt Hannah, Manni und Dirk für die Fahrten zum Schlachthof und die Unterstützung im Labor.

Vielen Dank außerdem an alle Mitarbeiter im Institut bzw. auf unserer Etage für die kollegiale Gemeinschaft und die schöne Arbeitsatmosphäre.

Isabel und Tony, Euch danke ich für unsere super Bürogemeinschaft und darüber hinaus für Eure Unterstützung, den Zuspruch und unseren Zusammenhalt. Ich werde Euch vermissen!

Anne, Dir danke ich für unsere Doktoranden-WG und dafür, dass Du jeden Frust und jede Freude bei dieser Arbeit mit mir geteilt hast.

Allen meinen Göttinger Freunden danke ich für die unvergesslich schöne Zeit hier. Ihr macht mir den Abschied echt schwer! Danke an die Mittwochsrunde! Danke an Dr. Meyer und Dr. Möllie für die abendlichen Besprechungen. Und ein großer Dank an Judith und Luisa für Eure Freundschaft!

Der größte Dank aber gilt meiner Familie, insbesondere meinen Eltern. Euch widme ich diese Arbeit. Danke für Eure unermessliche Unterstützung, Euren Rückhalt und Euren Zuspruch. Danke, dass Ihr mich so weit gebracht habt und auch Ihr mir somit diese Promotion ermöglicht habt. 


\section{Eidesstattliche Erklärung}

Hiermit erkläre ich eidesstattlich, dass:

1. diese Arbeit weder in gleicher noch in ähnlicher Form bereits anderen Prüfungsbehörden vorgelegen hat.

2. ich mich an keiner anderen Hochschule um einen Doktorgrad beworben habe.

Göttingen, den

(Unterschrift)

Hiermit erkläre ich eidesstattlich, dass diese Dissertation selbständig und ohne unerlaubte Hilfe angefertigt wurde.

Göttingen, den

(Unterschrift) 